\title{
WestVirginiaUniversity
}

THE RESEARCH REPOSITORY @ WVU

Graduate Theses, Dissertations, and Problem Reports

1998

\section{Development of a heavy-duty vehicle chassis dynamometer test route}

James Joseph Daley

West Virginia University

Follow this and additional works at: https://researchrepository.wvu.edu/etd

\section{Recommended Citation}

Daley, James Joseph, "Development of a heavy-duty vehicle chassis dynamometer test route" (1998). Graduate Theses, Dissertations, and Problem Reports. 911.

https://researchrepository.wvu.edu/etd/911

This Thesis is protected by copyright and/or related rights. It has been brought to you by the The Research Repository @ WVU with permission from the rights-holder(s). You are free to use this Thesis in any way that is permitted by the copyright and related rights legislation that applies to your use. For other uses you must obtain permission from the rights-holder(s) directly, unless additional rights are indicated by a Creative Commons license in the record and/ or on the work itself. This Thesis has been accepted for inclusion in WVU Graduate Theses, Dissertations, and Problem Reports collection by an authorized administrator of The Research Repository @ WVU. For more information, please contact researchrepository@mail.wvu.edu. 


\title{
DEVELOPMENT OF A HEAVY DUTY VEHICLE CHASSIS DYNAMOMETER TEST ROUTE
}

\author{
By \\ James Joseph Daley
}

\author{
A THESIS \\ Submitted to \\ The College of Engineering and Mineral Resources \\ at \\ West Virginia University \\ in partial fulfillment of the requirements \\ for the degree of \\ Master of Science \\ in \\ Mechanical Engineering
}

Department of Mechanical and Aerospace Engineering

Morgantown, West Virginia

1998 


\section{Abstract \\ DEVELOPMENT OF A HEAVY DUTY VEHICLE CHASSIS DYNAMOMETER TEST ROUTE}

\section{By James Joseph Daley}

As environmental concerns increase, more emphasis is being placed on heavy duty emissions research and heavy duty emissions inventory prediction. A heavy duty vehicle chassis dynamometer driving route, titled "CitySuburban Heavy Vehicle Route" (CSHVR) was developed. Data for designing the CSHVR were collected using a Campbell Scientific 21x micrologger and various analog tachograph recorders. These data consisted of speed, time and distance information used to develop a series of speed vs. time cycles for interstate, suburban, city, yard and combined city-suburban modes of driving. Procedures were developed to reduce statistically the speed, time and distance data into representative speed vs. time cycles. Criteria for producing the speed vs. time cycles included average vehicle speed, standard deviation of vehicle speed and total cruise time. On completion of the speed vs. time cycle creation, the speed vs. time City-Suburban Cycle was converted into a speed vs. distance route with free acceleration ramps. In order to convert the speed vs. time cycle into a speed vs. distance route a scheme for showing idle times was employed. Idle periods were displayed by creating an adjusted distance axis during periods of zero vehicle speed. Using this method, the CSHVR was developed. Testing of the CSHVR was completed using the West Virginia University transportable heavy duty vehicle emissions testing laboratory. CSHVR results showed that all regulated emissions were significantly greater than those of the WVU 5-Peak Cycle, and WVU 5-Mile Route. Average emissions values in grams/mile were at levels of $23.3\left(\mathrm{NO}_{\mathrm{X}}\right), 2563\left(\mathrm{CO}_{2}\right), 1.98(\mathrm{HC}), 0.78(\mathrm{PM})$ and $6.03(\mathrm{CO})$ while driving the CSHVR. Repeatable emissions results between tests were also conserved when the City-Suburban Cycle was converted to a route. 


\section{Acknowledgments}

I would like to start by thanking, most of all, my parents Mark and Kathy Daley for all the support, persuasion, confidence and trust that they have shown me ever since the first day I was born. All of the sacrifices you both made to educate this "rock" never went unnoticed or forgotten. Thank you Mom and Dad!!! To my talented and taller brothers Jason and Jeff, and to my favorite sister Tricia thank you for all of the support and being true friends.

Dr. Nigel N. Clark there is no way I could ever express how much you have taught me as a student and a friend. Thank you for the trust and honesty you have shown me and for all of the great times camping at the cabin. To my mentor, office mate and friend Ralph Nine thank you for all your help involved with this project and all of the help with problems unrelated to our work environment. Richard Atkinson and Tom Spencer thank you for all the help installing and using my data acquisition system. I would still be working on that system without your help. Thank you, Scott Richmond for all of the help, in all of the engineering classes and projects we worked on together. Getting this far would have been much more difficult without your help. Marcus Gilbert thanks for all the laughs and fun times working on your Fiero and out torturing your Zuk. To my roommate Sorin Petreanu thanks for letting me stay at your apartment and for putting up with my escapades for so long. Thanks to everyone at the ERC Tom McDaniel, Wayne Hildebrand, Matt Hawkins, Mike Traver and Talus Park for all of the laughs and "noon lunches."

To the rest of my family that has supported me, put faith in me and guided me through the rough times I thank you all for everything you have done for me. Once again, to everyone, thank you for all the guidance and good luck in this journey called life. 


\section{Table of Contents}

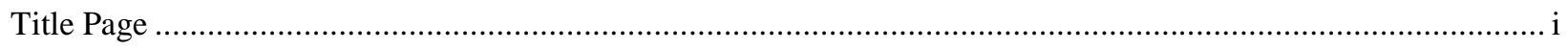

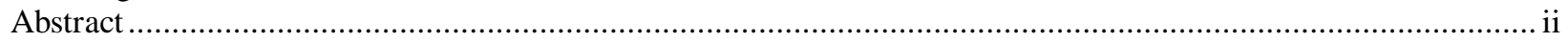

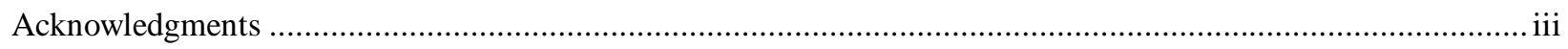

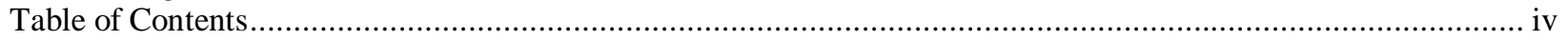

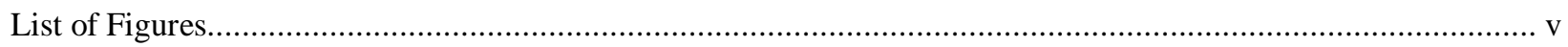

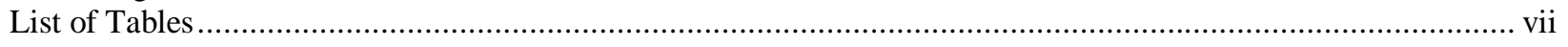

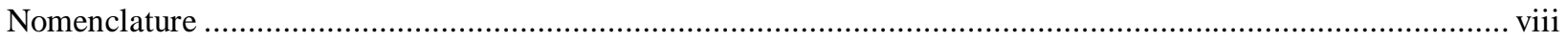

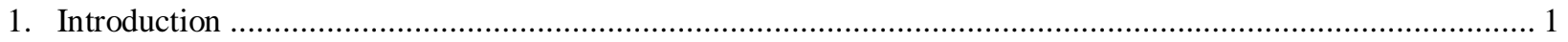

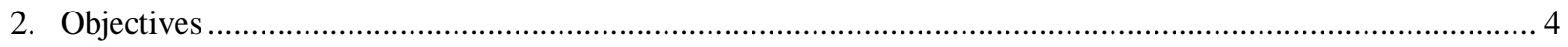

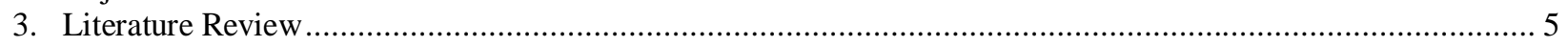

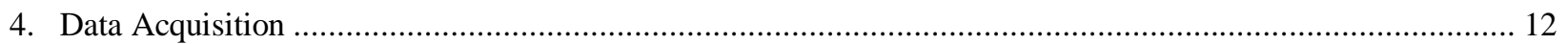

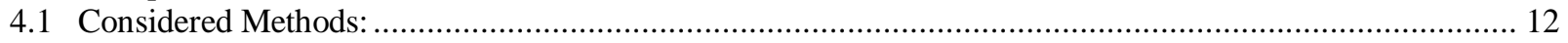

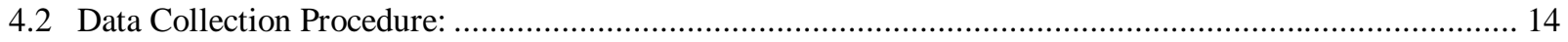

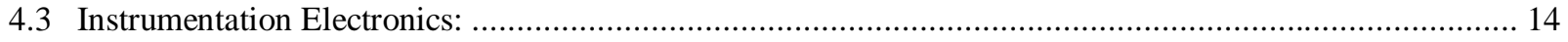

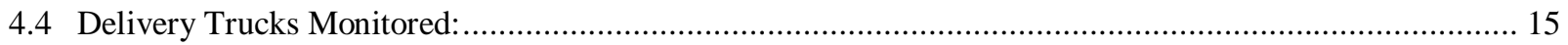

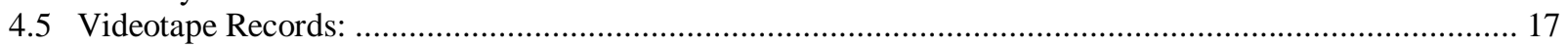

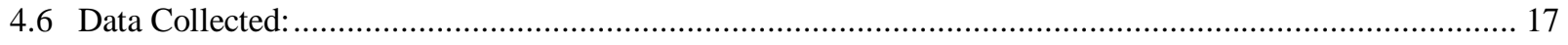

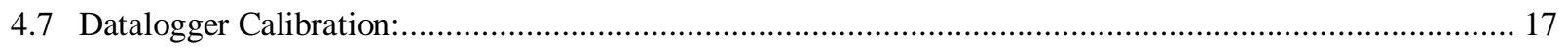

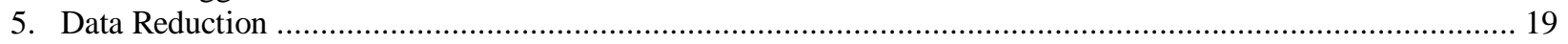

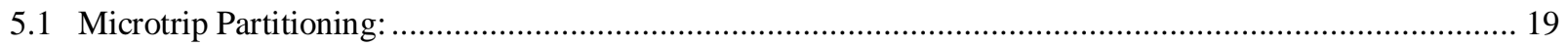

5.2 Instantaneous Speed and Instantaneous Acceleration: .................................................................... 20

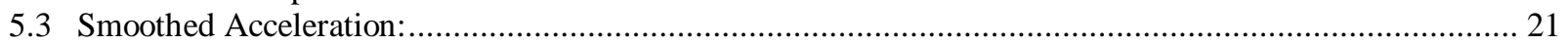

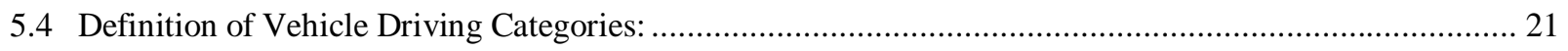

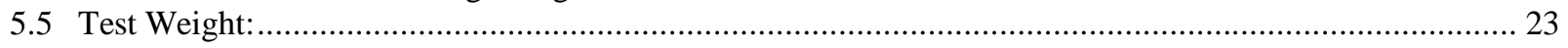

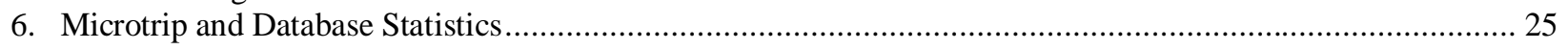

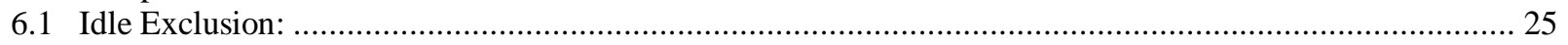

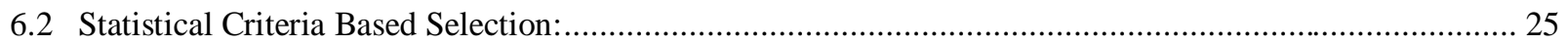

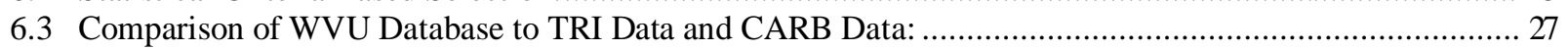

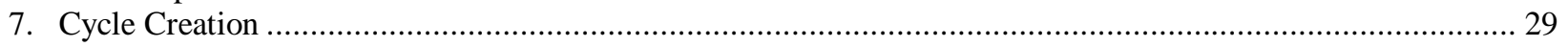

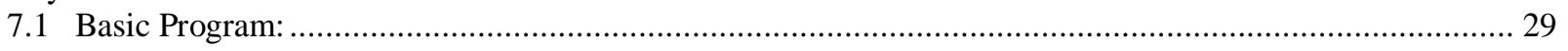

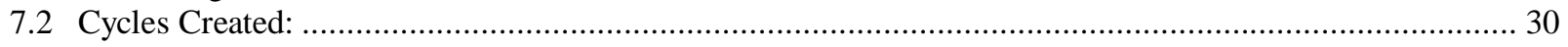

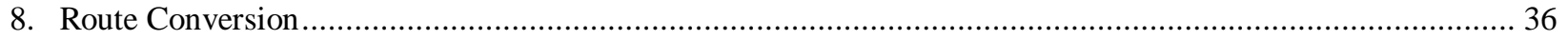

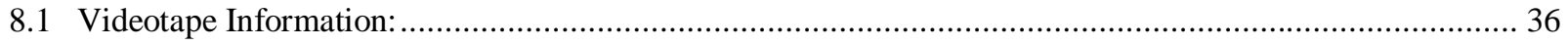

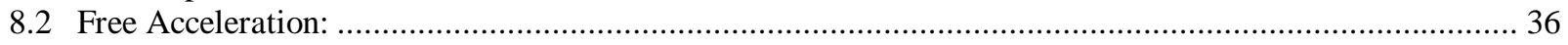

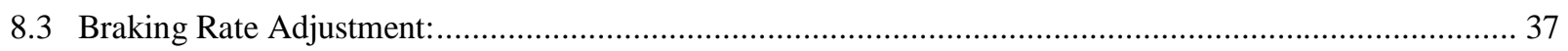

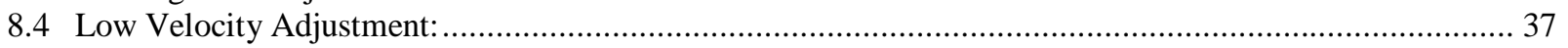

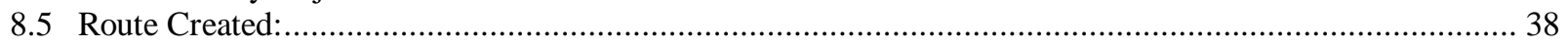

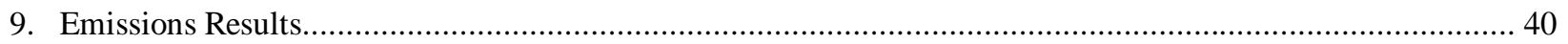

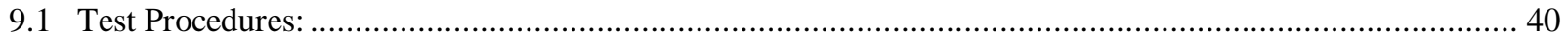

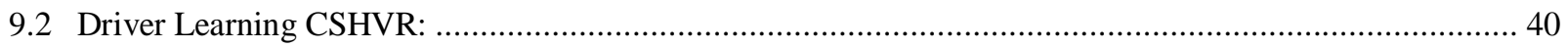

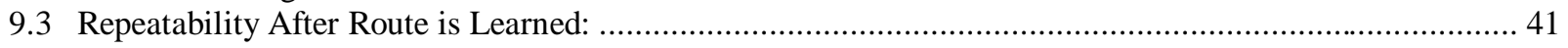

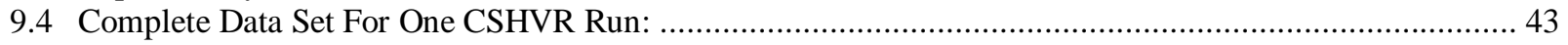

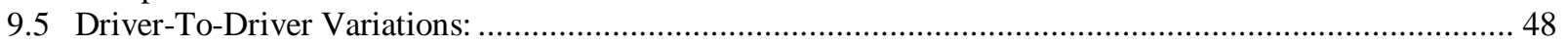

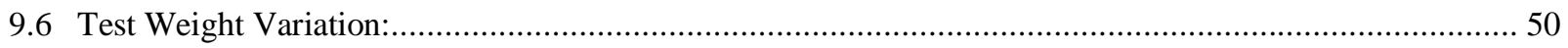

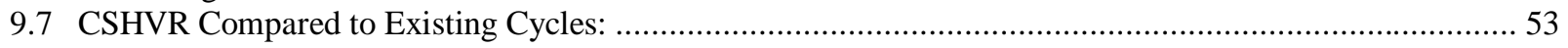

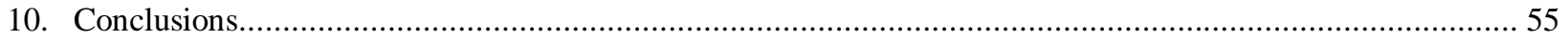

Appendix A Conversion used to convert gaseous emissions results from $\mathrm{ppm} / \mathrm{sec}$. to $\mathrm{g} / \mathrm{mile}$.............................56

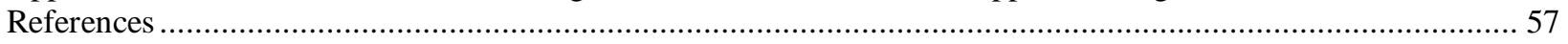

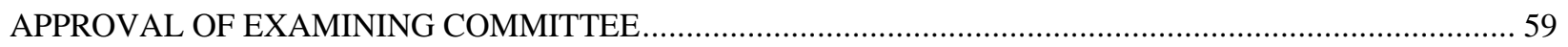




\section{List of Figures}

FIGURE 1.1.1 OVER-POWERED AND UNDER-POWERED VEHICLES FOLLOWING A CHASSIS DYNAMOMETER CYCLE. THE UNDER-POWERED VEHICLE CANNOT FOLLOW THE SCHEDULED

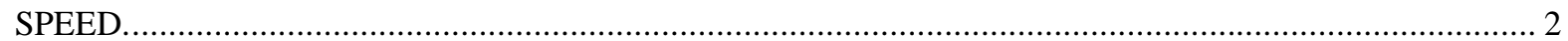

FIGURE 3.1.1 THE CBD CYCLE WAS DEVELOPED FOR USE WITH HEAVY DUTY BUSES AND IS USED TO MIMIC DOWNTOWN CITY TYPE DRIVING .

FIGURE 3.1.2 THE MODIFIED CBD CYCLE WAS DEVELOPED FOR HEAVY DUTY VEHICLES WITH UNSYNCHRONIZED TRANSMISSIONS. THIS CYCLE IS USED IN ORDER TO MIMIC DOWNTOWN CITY STYLE DRIVING.

FIGURE 3.1.3 THE WVU 5-PEAK TRUCK CYCLE WAS DEVELOPED FOR HEAVY DUTY VEHICLES WITH UNSYNCHRONIZED TRANSMISSIONS. IT IS USED TO COMPARE DIESEL FUELED VEHICLE EMISSIONS TO ALTERNATIVELY FUELED VEHICLE EMISSIONS.

FIGURE 3.1.4 THE URBAN DYNAMOMETER DRIVING SCHEDULE DEVELOPED FOR HEAVY DUTY VEHICLES BY THE EPA.

FIGURE 3.1.5 SCHEDULED SPEED TRACE OF WVU 5-MILE ROUTE FOR HEAVY DUTY VEHICLES, WITH UNSYNCHRONIZED TRANSMISSIONS...

FIGURE 4.1.1 CAMPBELL SCIENTIFIC 21X MICROLOGGER, USED TO COLLECT SPEED AND DISTANCE DATA FROM HEAVY DUTY VEHICLES.

FIGURE 4.4.1 TEST VEHICLE AT ROADWAY EXPRESS, INC. IN AKRON, OHIO. THIS VEHICLE PULLED BOTH DOUBLE AND SINGLE TRAILERS.

FIGURE 4.4.2 TEST VEHICLE AT OVERNITE TRANSPORTATION CO. RICHMOND, VIRGINIA. THE AUTHOR IS HOLDING A CAMPBELL SCIENTIFIC 21X MICROLOGGER NEXT TO THE TRUCK. ... 16

FIGURE 5.1.1 EXAMPLE OF A SUBURBAN MICROTRIP RECORDED IN AKRON, OHIO USING THE ROADWAY EXPRESS INC. VEHICLE PULLING A 48 FOOT VAN TRAILER.

FIGURE 5.3.1 INSTANTANEOUS VEHICLE SPEED AND ACCELERATION BEFORE AND AFTER SMOOTHING.

FIGURE 5.4.1 VA, VD, AND CR SEGMENTS DURING A MICROTRIP.

FIGURE 7.1.1 FLOWCHART USED IN THE BASIC PROGRAM TO DEVELOP RANDOMLY A CYCLE FOR EACH DRIVING MODE.

FIGURE 7.2.1 FINAL YARD CYCLE WITH SUITABLE IDLE TIMES ADDED. ........................................... 31

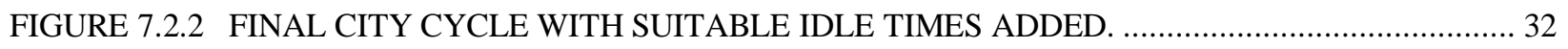

FIGURE 7.2.3 FINAL SUBURBAN CYCLE WITH SUITABLE IDLE TIMES ADDED................................. 32

FIGURE 7.2.4 FINAL CITY-SUBURBAN CYCLE WITH SUITABLE IDLE TIMES ADDED. ....................... 33

FIGURE 7.2.5 FINAL INTERSTATE CYCLE WITH SUITABLE IDLE TIMES ADDED.............................. 34

FIGURE 8.2.1 EXAMPLE OF FREE ACCELERATIONS AND STEADY STATE SPEEDS AS COMPARED TO

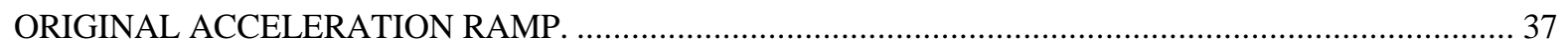

FIGURE 8.5.1 CITY-SUBURBAN HEAVY VEHICLE ROUTE: SPEED VS. DISTANCE. ............................ 38

FIGURE 8.5.2 SCHEDULED SPEED VS. TIME TRACE OF CSHVR USED ONLY TO SHOW THE LENGTHS OF THE IDLE PERIODS DURING THE CSHVR. .

FIGURE 9.2.1 COMPARING TWO RUNS WHILE THE DRIVER IS LEARNING THE CSHVR. TESTS PERFORMED DRIVING A FORD ROAD TRACTOR AT A 46,400 LB. TEST WEIGHT.

FIGURE 9.3.1 COMPARING TWO RUNS AFTER THE DRIVER HAS LEARNED THE CSHVR. TESTS PERFORMED DRIVING AN INTERNATIONAL ROAD TRACTOR AT A 46,400 LB. TEST WEIGHT... 43 
FIGURE 9.4.1 ACTUAL VEHICLE SPEED FROM THE CSHVR USING AN INTERNATIONAL ROAD TRACTOR AT A 46,400 LB. TEST WEIGHT.

FIGURE 9.4.2 ENGINE SPEED FROM THE CSHVR USING AN INTERNATIONAL ROAD TRACTOR AT A 46,400 LB. TEST WEIGHT.

FIGURE 9.4.3 AXLE TORQUE FROM THE CSHVR USING AN INTERNATIONAL ROAD TRACTOR AT A 46,400 LB. TEST WEIGHT.

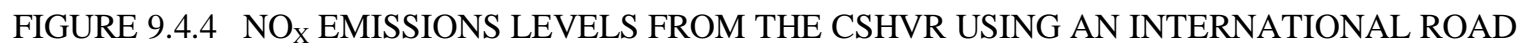
TRACTOR AT A 46,400 LB. TEST WEIGHT. 46

FIGURE 9.4.5 CO EMISSIONS LEVELS FROM THE CSHVR USING AN INTERNATIONAL ROAD TRACTOR AT A 46,400 LB. TEST WEIGHT... 46

FIGURE 9.4.6 $\mathrm{CO}_{2}$ EMISSIONS LEVELS FROM THE CSHVR USING AN INTERNATIONAL ROAD TRACTOR AT A 46,400 LB. TEST WEIGHT. 47

FIGURE 9.4.7 HC EMISSIONS LEVELS FROM THE CSHVR USING AN INTERNATIONAL ROAD TRACTOR AT A 46,400 LB. TEST WEIGHT.

FIGURE 9.4.8 DRIVER 1 SHIFTING PATTERNS DURING TWO RUNS OF THE CSHVR USING AN INTERNATIONAL ROAD TRACTOR AT A 46,400 LB. TEST WEIGHT. 48

FIGURE 9.5.2 SHIFTING PATTERNS BETWEEN THREE DIFFERENT DRIVERS, DRIVING THE CSHVR USING AN INTERNATIONAL ROAD TRACTOR AT A 46,400 LB. TEST WEIGHT. 50

FIGURE 9.6.1 AN INTERNATIONAL ROAD TRACTOR FOLLOWING THE CSHVR AT TWO DIFFERENT TEST WEIGHTS. RESULTS SHOWN ON A SPEED VS. DISTANCE PLOT, SHOWING FASTER ACCELERATION WITH LOWER GVW. 52

FIGURE 9.6.2 AN INTERNATIONAL ROAD TRACTOR FOLLOWING THE CSHVR AT 2 DIFFERENT TEST WEIGHTS. RESULTS SHOWN ON A SPEED VS. TIME PLOT SHOWING FASTER ACCELERATION WITH LOWER GVW. 


\section{List of Tables}

TABLE 4.7.1 CALIBRATION CONSTANTS USED TO CALIBRATE THE CAMPBELL SCIENTIFIC 21X MICROLOGGER.

TABLE 5.4.1 VEHICLE ACCELERATION AND VEHICLE DECELERATION CUTOFF VALUES............... 22

TABLE 6.2.1 AVERAGE VALUES FOR EACH DRIVING MODE IN THE WVU DATABASE. ................... 26

TABLE 6.3.1 COMPARISON BETWEEN CARB AND ENTIRE WVU DATABASES WITH IDLE TIMES

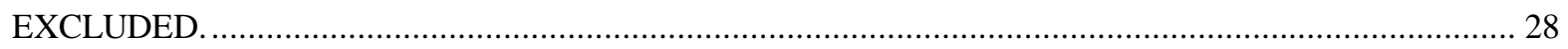

TABLE 7.2.1 CYCLE STATISTICS FOR YARD, CITY, SUBURBAN, CITY-SUBURBAN AND INTERSTATE CYCLES

TABLE 9.2.1 DATA COLLECTED FROM THE FIRST FOUR RUNS OF THE CSHVR. DRIVER WAS LEARNING HOW TO DRIVE THE CSHVR USING A FORD TRACTOR AT A 46,400 LB. TEST WEIGHT. 41

TABLE 9.3.1 DAY ONE CSHVR REPEATABILITY: INTERNATIONAL TRACTOR 46,400 LB. TEST WEIGHT.

TABLE 9.3.2 DAY ONE AND DAY TWO CSHVR REPEATABILITY: INTERNATIONAL TRACTOR 46,400 LB. TEST WEIGHT.

TABLE 9.5.1 COMPARISONS BETWEEN THREE DRIVERS, DRIVING THE CSHVR USING AN INTERNATIONAL ROAD TRACTOR AT A 46,400 LB. TEST WEIGHT. 49

TABLE 9.6.1 EMISSIONS RESULTS FROM THE CSHVR USING A 26,000 LB. TEST WEIGHT WITH DRIVER 1 OPERATING AN INTERNATIONAL ROAD TRACTOR.

TABLE 9.6.2 EMISSIONS RESULTS FROM THE CSHVR USING A 36,000 LB. TEST WEIGHT WITH DRIVER 1 OPERATING AN INTERNATIONAL ROAD TRACTOR.

TABLE 9.6.3 EMISSIONS RESULTS FROM THE CSHVR USING A 46,400 LB. TEST WEIGHT WITH DRIVER 1 OPERATING AN INTERNATIONAL ROAD TRACTOR. 51

TABLE 9.6.4 AVERAGE AXLE HORSEPOWER HOUR FOR THREE DIFFERENT SIMULATED TEST WEIGHTS.

TABLE 9.7.1 EMISSIONS RESULTS FROM THE WVU 5-PEAK CYCLE USING A FORD ROAD TRACTOR AT A 46,400 LB. TEST WEIGHT..

TABLE9.7.2 EMISSIONS RESULTS FROM THE WVU 5-MILE ROUTE USING A FORD ROAD TRACTOR AT A 46,400 LB. TEST WEIGHT.

TABLE 9.7.3 EMISSIONS RESULTS FROM THE CSHVR USING A FORD ROAD TRACTOR AT A 46,400 LB. TEST WEIGHT. 54

TABLE 10.1.1 AVERAGE EMISSIONS LEVEL DIFFERENCE CORRESPONDING TO A 43.48\% TEST WEIGHT DIFFERENCE. 55 


\section{Nomenclature}

ATA

Ahp

ahp-hr

CARB

CBD

CC

CDL

CFR

$\mathrm{CO}$

$\mathrm{CO}_{2}$

$\mathrm{COV}$

CR

CSHVR

GVW

GVWR

ECM

EPA

Es

$\mathrm{HC}$

IA

ID

IV

LNG

$\mathrm{NO}_{\mathrm{X}}$

NREL

PM

RMS

Stdev.

TRI

USDOT

VA

VD

Vs

WVU 5-Peak

WVU 5-Mile
American Trucking Association

axle horsepower

axle horsepower hour

California Air Resources Board

Central Business District Cycle

calibration constant

Commercial Drivers License

Code of Federal Regulations

carbon monoxide

carbon dioxide

coefficient of variance

vehicle cruise

City-Suburban Heavy Vehicle Route

gross vehicle weight

gross vehicle weight rating

electronic control module

Environmental Protection Agency

engine speed

hydrocarbon

instantaneous acceleration

instantaneous distance

instantaneous velocity

liquid natural gas

oxides of nitrogen

National Renewable Energy Laboratory

particulate matter

root mean square

standard deviation

Trucking Research Institute

United States Department of Transportation

vehicle acceleration

vehicle deceleration

vehicle speed

West Virginia University 5-Peak Truck Cycle

West Virginia University 5-Mile Truck Route 


\section{Introduction}

There is presently a lack of realistic driving cycles and routes for the chassis dynamometer emissions testing of heavy duty vehicles. Currently used heavy duty testing cycles are based on speed versus time schedules. There are several such cycles, for instance the West Virginia University 5-Peak (WVU 5-Peak) Truck Cycle (Clark et al., 1995), the Central Business District Cycle (CBD) (SAE recommended practice J1376), and the Central Business District Cycle modified for line haul tractors (Modified CBD) (Clark et al., 1994). These cycles were developed to allow the estimation of the amount of gaseous exhaust emissions and particulate matter that heavy duty trucks and buses emit into our atmosphere.

Some of these cycles, such as the CBD, have been used extensively in the USA and Canada, to give an accurate estimation of the amounts and types of emissions from heavy duty vehicles (Clark et al., 1994). However, all of these cycles have inherently eliminated one very important aspect of a heavy duty vehicle, the power-toweight ratio. In all of the above-listed cycles, a class 8 tractor trailer having an actual gross vehicle weight (GVW) of 50,000 lb. would finish (or attempt to finish) the cycle in the same amount of time as a tractor trailer with an actual GVW of 10,000 lb. A chassis dynamometer driving cycle is only a function of time and not the power of the class 8 tractor driving the cycle. At the end of the chassis dynamometer driving cycle, the amount of time spent driving the cycle would be the same and only the distance traveled would be different between the two vehicles because the under-powered tractor would not be able to keep up with the scheduled trace. Changing the distance traveled changes the validity of the cycle. This does not accurately mimic real world driving. Another problem with speed versus time cycles is acceleration ramps. Some heavier vehicles (having lower power-to-weight ratios) struggle to keep up with the scheduled speed (as depicted in Figure 1.1.1), while lighter vehicles (with higher powerto-weight ratios) can easily follow the acceleration ramps and bias the emissions results. In real world driving, different weight vehicles that travel the same route, covering the same distance, would arrive at the destination at different times (Clark, 1998). Because routes are based on distance traveled and not time spent traveling, the powerto-weight ratio of a heavy duty truck is accounted for.

Both of these cases deviate from the intended purpose of accurately estimating heavy duty truck and bus emissions. This research completed at West Virginia University has developed a route called the City-Suburban Heavy Vehicle Route (CSHVR) that takes into account the vehicle's power-to-weight ratio. This new route is based 
on a speed versus distance schedule which allows the tractor to finish the route as fast as possible and to cover the same amount of distance. The main idea behind this new driving route is that a heavier tractor (lower power-toweight ratio) will complete the route in more time than a lighter tractor (higher power-to-weight ratio). The CSHVR does not fix the major accelerations. It allows the truck to accelerate as naturally as possible. Free accelerations will allow any heavy duty vehicle to operate on a chassis dynamometer at full power, the same way it would on a city street, suburban road, or interstate highway.

Figure 1.1.1 Over-powered and under-powered vehicles following a chassis dynamometer cycle. The underpowered vehicle cannot follow the scheduled speed.

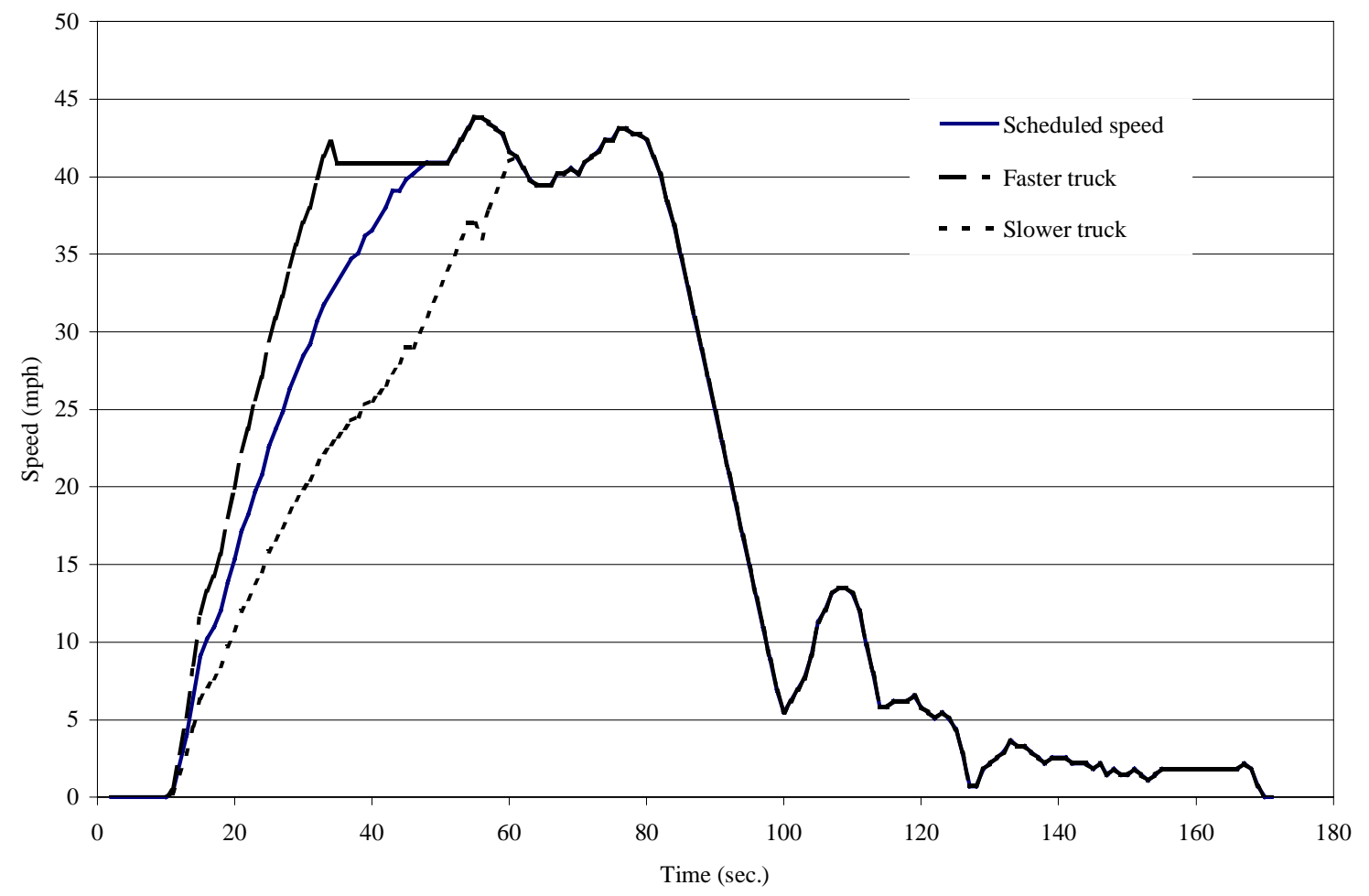

In a typical chassis dynamometer test, the vehicle being tested is driven onto the chassis dynamometer.

Power is absorbed from the vehicles through use of its drive wheels. Power is taken either from the tires rotating on large rollers or directly from the vehicle drive axle. Next, the vehicle is driven through a cycle and data is collected. Accurately following the cycle is accomplished by installing a computer monitor in the vehicle's cab. This monitor is used to display the scheduled speed of the cycle or route and the instantaneous speed of the vehicle being tested. The driver's objective is to match as, closely as possible, the vehicle speed to the scheduled speed. Most heavy duty trucks are equipped with unsynchronized transmissions which allows the driver a significant level of freedom when following the scheduled speed. As a result of this driving freedom, different drivers can follow the scheduled speed 
within a given range, while producing different emissions results. Variations in emissions results could be caused by different shifting behaviors or different levels of aggressiveness of each driver. 


\section{Objectives}

The main objective of this thesis is to detail the process behind developing a heavy duty vehicle chassis dynamometer driving route. The first goal is to (1) evaluate existing cycles being used to evaluate today's heavy duty vehicle fleet. (2) Show data collection and reduction procedures, including the use of videotape data, which are used for reducing the database into driving modes. (3) Show data reduction by calculating different parameters in order to convert the speed time data into a chassis dynamometer driving cycle. (4) Following the completion of the cycle show how changes are made to make the cycle driveable on a heavy duty chassis dynamometer. (5) Once the cycle is created show the conversion of the speed vs. time cycle into a speed vs. distance route allowing for variable power-to-weight ratio. (6) Finally show emissions results using the derived route for repeatability and with varying drivers and test weights. 


\section{Literature Review}

In recent years, environmental concerns have led to increased interest in the regulation and testing of heavy duty vehicles. Unlike light duty vehicle cycles and emissions standards there are more inherent problems with the development and regulation of heavy duty vehicle cycles and emissions levels. Some problems like not being able to shift unsynchronized transmissions rapidly, engine removal cost, engine brakes and differences between drivers are inherent to heavy duty vehicles. However, problems also exist with the testing methods used on heavy duty vehicles which also affect emissions regulations. One of these problems is the power-to-weight ratio of heavy duty vehicles (Nine et al., 1997). Emissions results can be biased by a heavy duty vehicle by not using the full potential of the engine during acceleration ramps. Many heavy duty vehicle cycles have been developed which do not consider the power-to-weight ratio. This literature review was assembled in order to show how modern heavy duty cycles for vehicles with unsynchronized transmissions were developed and how each cycle was derived.

One of the earliest and a well documented heavy duty vehicle cycle is for city buses. The "Central Business District" (CBD) Cycle (SAE recommended practice J1376) was developed to simulate heavy duty buses during inner-city operation. This test is well established and, arguably, accurately accounts for the exhaust emissions from heavy duty inner-city buses (Clark et al., 1994). The CBD Cycle consists of 14 accelerations and 14 steady state operation periods at $20 \mathrm{mph}$ each followed by a deceleration and an idle period, as depicted in Figure 3.1.1. Total traveled distance for the CBD is 2 miles. There are a few disadvantages of the CBD that tend to limit its use beyond inner-city buses. One of these disadvantages is its high acceleration rates. A typical class 8 road tractor with an unsynchronized transmission could not follow the CBD acceleration ramps successfully (Clark et al., 1994). 
Figure 3.1.1 The CBD Cycle was developed for use with heavy duty buses and is used to mimic downtown city type driving .

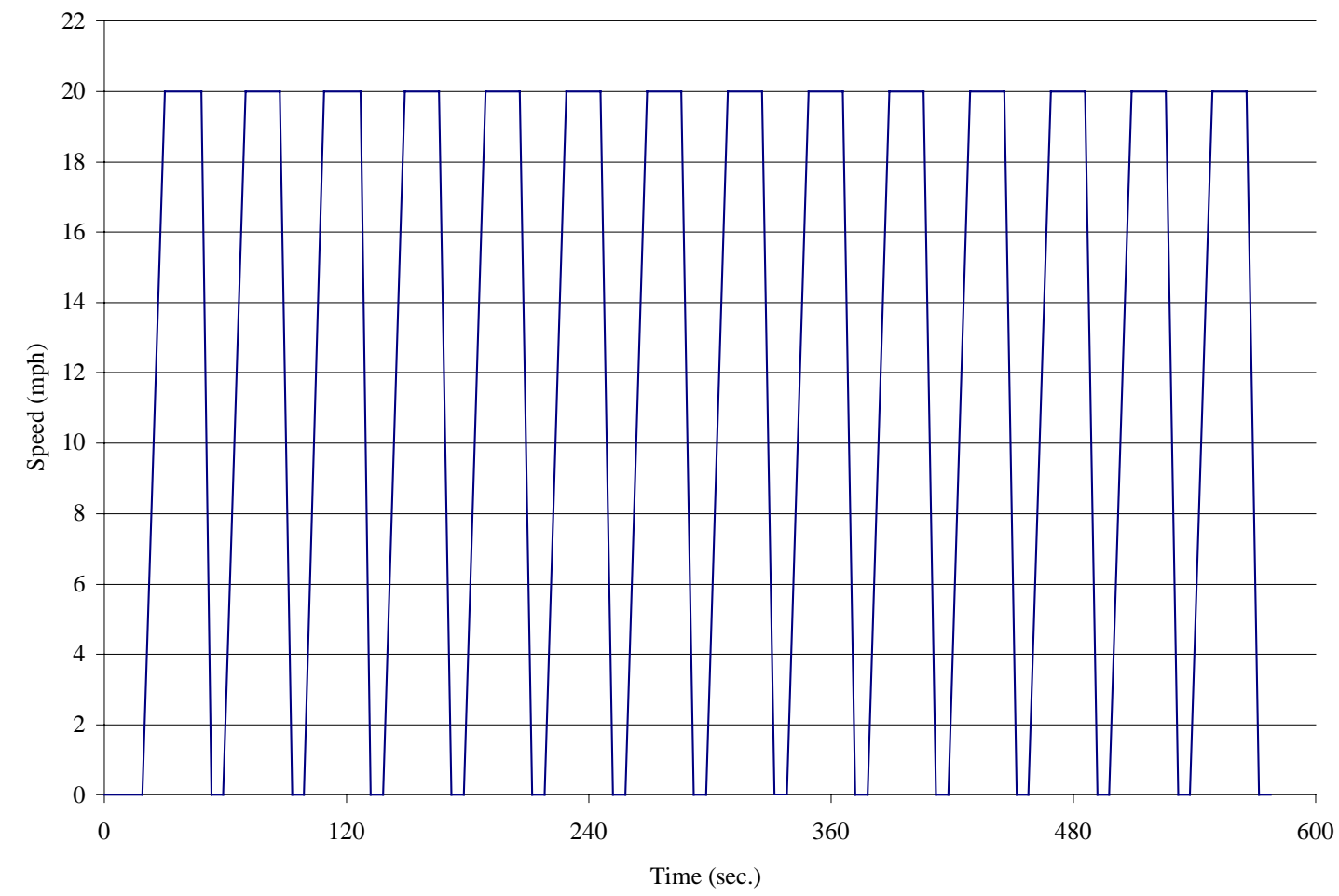

Different schemes have been attempted in order to make the CBD Cycle driveable for heavy duty vehicles. One modification to the CBD Cycle was created by WVU and titled the Modified CBD Cycle. The Modified CBD Cycle has the same sawtooth shape as the CBD. However the fixed acceleration and deceleration rates were reduced so that the cycle could be driven by a heavy duty tractor with an unsynchronized transmission; this cycle is shown in Figure 3.1.2. The total distance traveled during the cycle is 2 miles while the number of acceleration ramps is the same at 14 (Clark et al., 1994). Since the acceleration rates were reduced it was necessary to also shorten the length of the steady state speed portions of the cycle in order to keep the total length the same. This cycle does not allow for a variable power-to-weight ratio. Since the steady state periods are at a constant speed of $20 \mathrm{mph}$ they favor one particular engine speed (Clark et al., 1994).

Another cycle, created by WVU and titled the WVU 5-Peak Cycle was developed in the same sawtooth fashion, with a total of 5 acceleration ramps. Each ramp is followed by different steady state speeds of 20, 25, 30, 35 and $40 \mathrm{mph}$. A speed vs. time trace for the WVU 5 -Peak Cycle is shown in Figure 3.1.3. The WVU 5-Peak Cycle with its 5 different steady state modes eliminates biasing associated with favoring one particular engine condition repeatedly (Clark et al., 1995). However, this cycle does not eliminate the power-to-weight ratio 
problems either. It simply allows a heavy duty vehicle to follow the speed vs. time trace more accurately. Since the WVU 5-Peak Cycle has slow accelerations to accommodate all trucks, the CO and PM emissions are lower for this cycle than some other cycles (Graboski, 1998).

Figure 3.1.2 The Modified CBD Cycle was developed for heavy duty vehicles with unsynchronized transmissions. This cycle is used in order to mimic downtown city style driving.

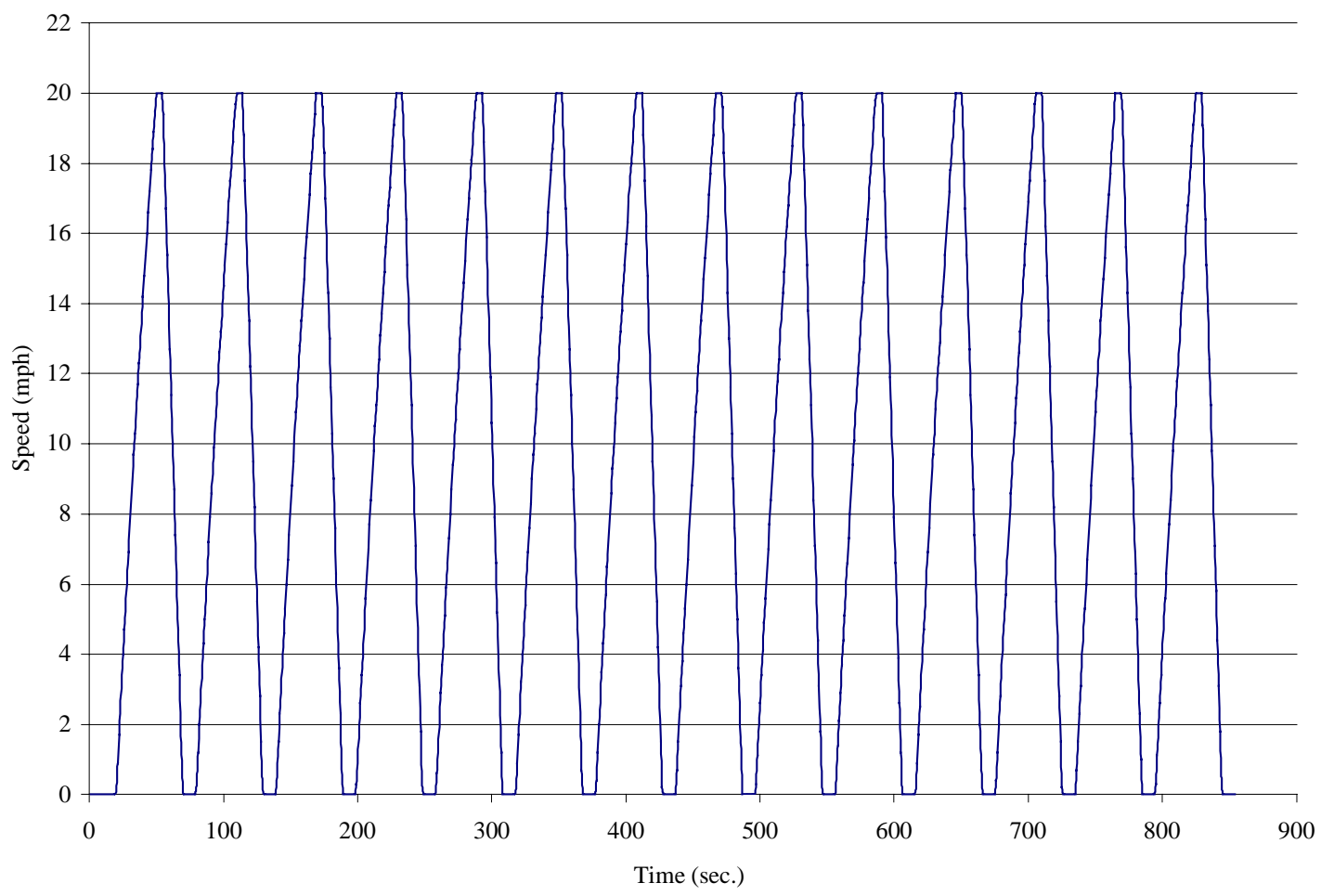


Figure 3.1.3 The WVU 5-Peak Truck cycle was developed for heavy duty vehicles with unsynchronized transmissions. It is used to compare diesel fueled vehicle emissions to alternatively fueled vehicle emissions.

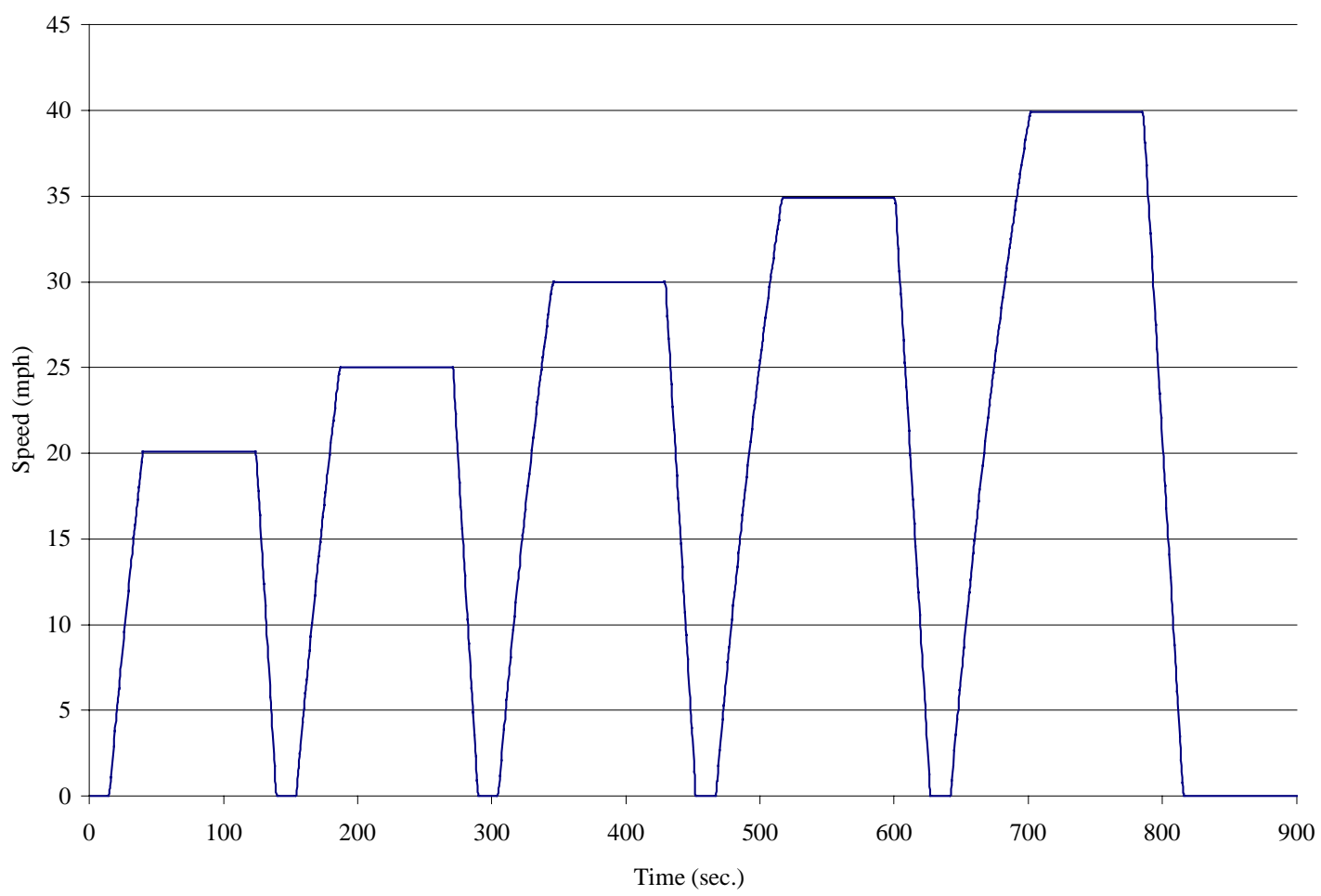

A heavy duty vehicle cycle developed for heavy duty gasoline fueled vehicles was developed by the Environmental Protection Agency (EPA) (Code of Federal Regulations Title 40, 1996). This heavy duty cycle, titled Urban Dynamometer Driving Schedule, was developed to simulate "real world" activities of heavy duty gasoline and diesel fueled vehicles in an urban environment. This cycle is shown in Figure 3.1.4. The Urban Dynamometer Driving Schedule has an average speed of $18.9 \mathrm{mph}$ and 33 percent of the cycle is idle time (Code of Federal Regulations Title 40, 1996). This cycle is speed and time based and does not take into account differences in the power-to-weight ratio between vehicles. However, this cycle is derived from actual data using Monte Carlo simulation and is representative of urban vehicle operation. Applying this cycle for use on modern heavy duty vehicles is questionable, because most modern heavy duty vehicles are powered by only diesel engines, which are operated differently while introduced to the same driving condition as gasoline engines (Clark and Lyons, 1998). 
Figure 3.1.4 The Urban Dynamometer Driving Schedule developed for heavy duty vehicles by the EPA.

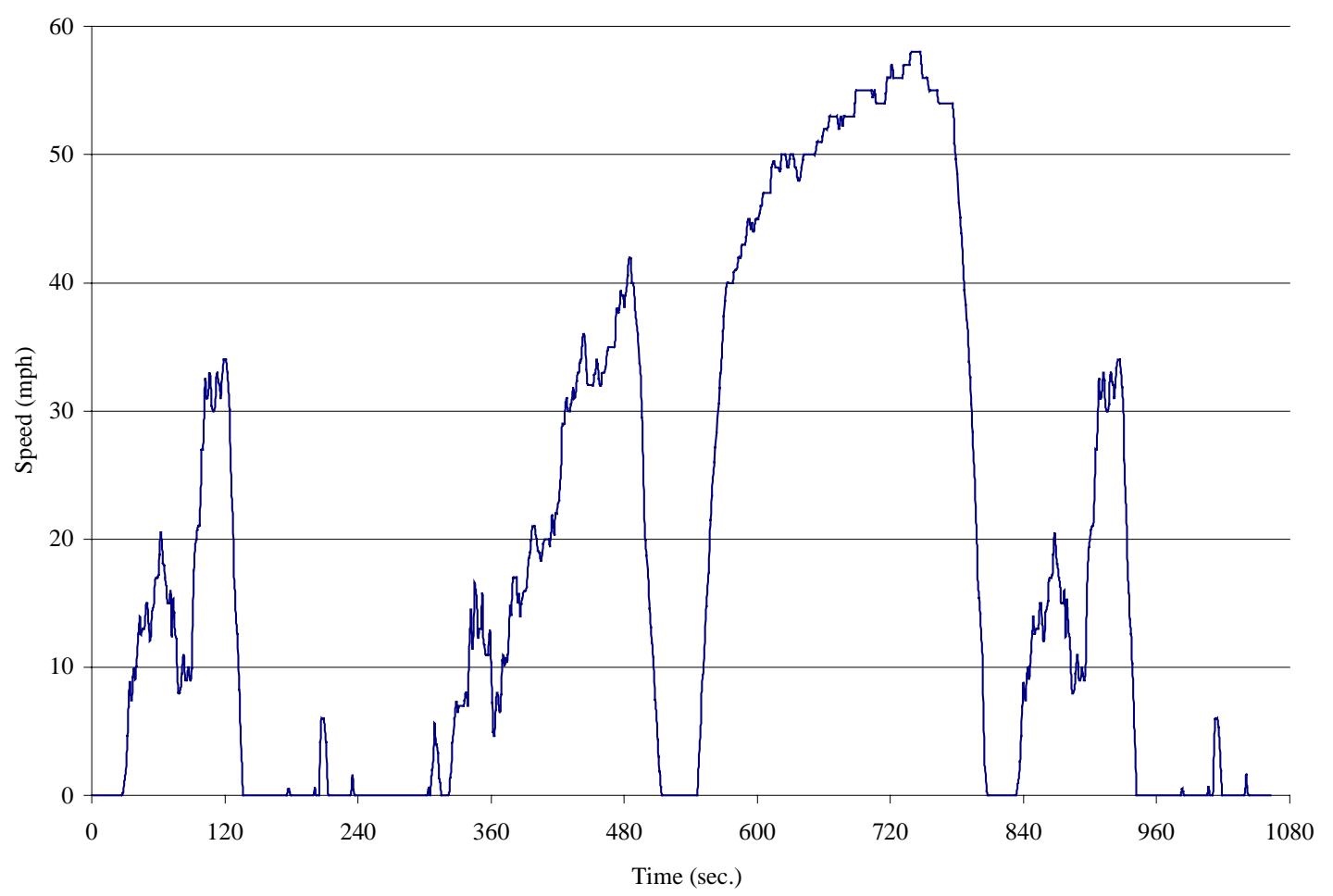

One of the first chassis dynamometer schedules to include the power-to-weight ratio is the WVU 5-Mile Route, shown in Figure 3.1.5. This route takes into account variable power-to-weight ratios by making the acceleration ramps instantaneous speed jumps which no heavy duty vehicle can follow. Physically, other than with respect to acceleration ramps the WVU 5-Mile Route is identical to the WVU 5-Peak Cycle. Because the acceleration ramps are unrestricted the distance is continuously calculated during a test so that the driven distance of each peak is kept the same. At the end of the WVU 5-Mile Route the cumulative distance is fixed at 5 miles while the total time of the route may vary. Allowing the acceleration ramps to be controlled by the engine power of the vehicle and not the speed vs. time trace of the driving cycle affects the carbon monoxide $(\mathrm{CO})$ and particulate matter (PM) results when comparing the WVU 5-Mile Route to the WVU 5-Peak Cycle for diesel compression ignition engines (Clark and Lyons, 1998). The WVU 5-Mile Route takes into account the power-to-weight ratio of the vehicle, however, it is not based on real life data and may not accurately represent real life driving. 
Figure 3.1.5 Scheduled speed trace of WVU 5-Mile Route for heavy duty vehicles, with unsynchronized transmissions.

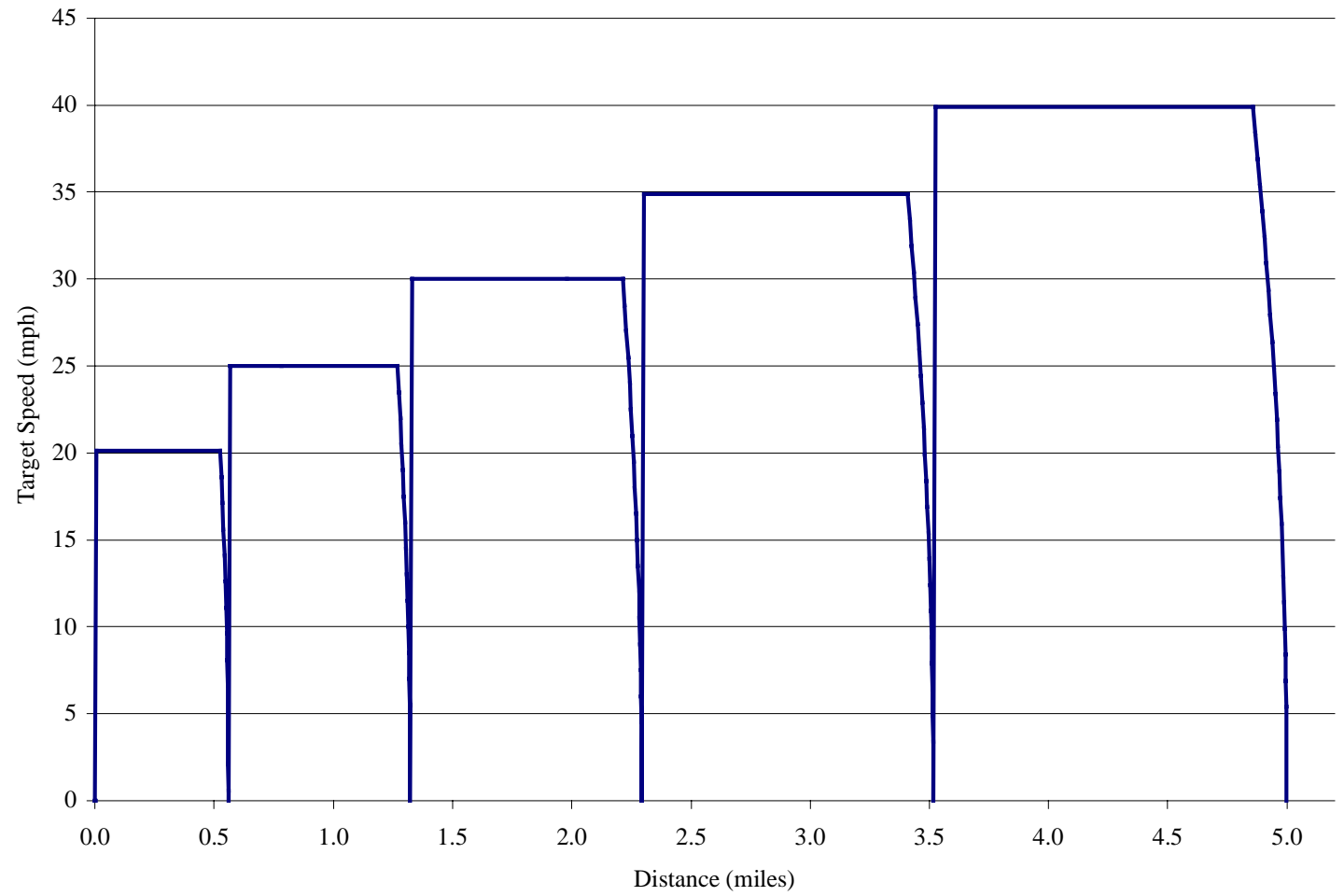

A cycle titled Urban Bus Driving Cycle, developed by TNO Road-Vehicles Research Institute, was created as a realistic driving cycle for heavy duty buses in Europe (van de Weijer et al., 1993). This cycle was created using data collected on inner-city buses during normal operation. The database was reduced and criteria were selected to develop the new chassis dynamometer driving cycle. The database consisted of over 500 hours of data from 4 different cities using over 50 drivers. Some of the criteria used in developing the Urban Bus Driving Cycle were parameters like maximum acceleration and deceleration, maximum speed, average speed, standard deviation of speed, and number of stops. The Urban Bus Driving Cycle is over 19 minutes long and has an average driving speed of $17.98 \mathrm{mph}$ (van de Weijer et al., 1993). Even though this cycle was statistically produced from real data in order to predict accurately emissions during "real world driving", this cycle does not allow for changes in the powerto-weight ratio.

Recently the development of a European driving cycle has been undertaken by the Forschungsinstitut Geräusche und Erschütterungen (FIGE) in Aachen, Germany resulting with development of the FIGE Transient Cycle. The FIGE Transient Cycle was derived from data collected from heavy duty vehicles (FIGE, 1998). This 
cycle is comprised of three different sections namely a city, suburban and interstate section. This cycle is currently being considered as a standard for European heavy duty engine emission standards (FIGE, 1998).

The thesis of Hoppie (1997) has a complete review of heavy duty vehicle cycles, suitable for testing vehicles on chassis dynamometers. 


\section{Data Acquisition}

\subsection{Considered Methods:}

The first step in collecting any vehicle data is to determine those data parameters which are important to the research being performed. For the development of a heavy duty chassis dynamometer cycle the most important parameters are vehicle speed as a function of time, and test weight. Other data parameters to be considered are engine temperature, throttle or rack position, engine speed, manifold air pressure, distance traveled and grade, although road grade was not considered explicitly in the development of this cycle. Originally the researchers at WVU chose engine speed, rack position, manifold air pressure, vehicle speed, distance traveled and truck weight to be the main data parameters collected. After deciding which parameters are to be recorded, one must decide which method is the best to collect and save all recorded data. The three methods considered were a tachograph recorder, the Cummins Data Link and a datalogger.

\subsubsection{Tachograph Recorder}

One method that was readily available to WVU was road speed collected on tachograph recorders as a function of time. Initially tachograph data seemed to be useful because they were available from a wide variety of cities on an even wider variety of heavy duty tractor trailers. However, closer investigation revealed that it was very difficult to attain second-by-second speed and acceleration information from the tachograph recorders. Difficulty arose when trying to interpret the tachographs to calculate average speed, average acceleration, average deceleration, and idle times for the truck. The mechanical trace produced by the tachograph is quite crude and required interpretation. The width of the trace could account for minutes of time. This made it impossible to relate the tachographs precisely to recorded second-by-second data, but the tachograph data could be used to support validity of the database. The only information readily available from the tachographs was total distance traveled and traveling time. This method was rejected because of the lack of second-by-second speed and idle information (time spent at idle). 


\subsubsection{Cummins Data Link}

Another method examined employed the Cummins Data Link suitable for use on engines produced by Cummins Engine Company. This system monitored engine speed, manifold air pressure and throttle or rack position directly from the engine's electronic control module (ECM). One serious downfall to this system occurred when the engine was shut down. The Cummins Data Link would not reboot automatically, instead it requiried a manual reboot from inside the vehicle's cab. This data collection procedure was abandoned because it was feared that placing an engineer in the cab with the driver would alter the driver's driving pattern or behavior. This led to the requirement for another type of data acquisition system.

\subsubsection{Campbell Scientific 21x Micrologger}

The National Renewable Energy Laboratory (NREL) provided the use of a Campbell Scientific 21x Micrologger $(21 \mathrm{x})$ shown in Figure 4.1.1. This system can monitor the output signals from various electronic sensors. The $21 \mathrm{x}$ can be used to monitor engine torque, if a torque transducer could be installed on a heavy duty tractor in an economical fashion. Since the Cummins Engine Company requested WVU not to collect data on engine speed, manifold air pressure and throttle position, researchers at WVU felt obligated to comply with this request. The only data collected using the $21 \mathrm{x}$ was time and instantaneous distance traveled. 
Figure 4.1.1 Campbell Scientific 21x Micrologger, used to collect speed and distance data from heavy duty vehicles.

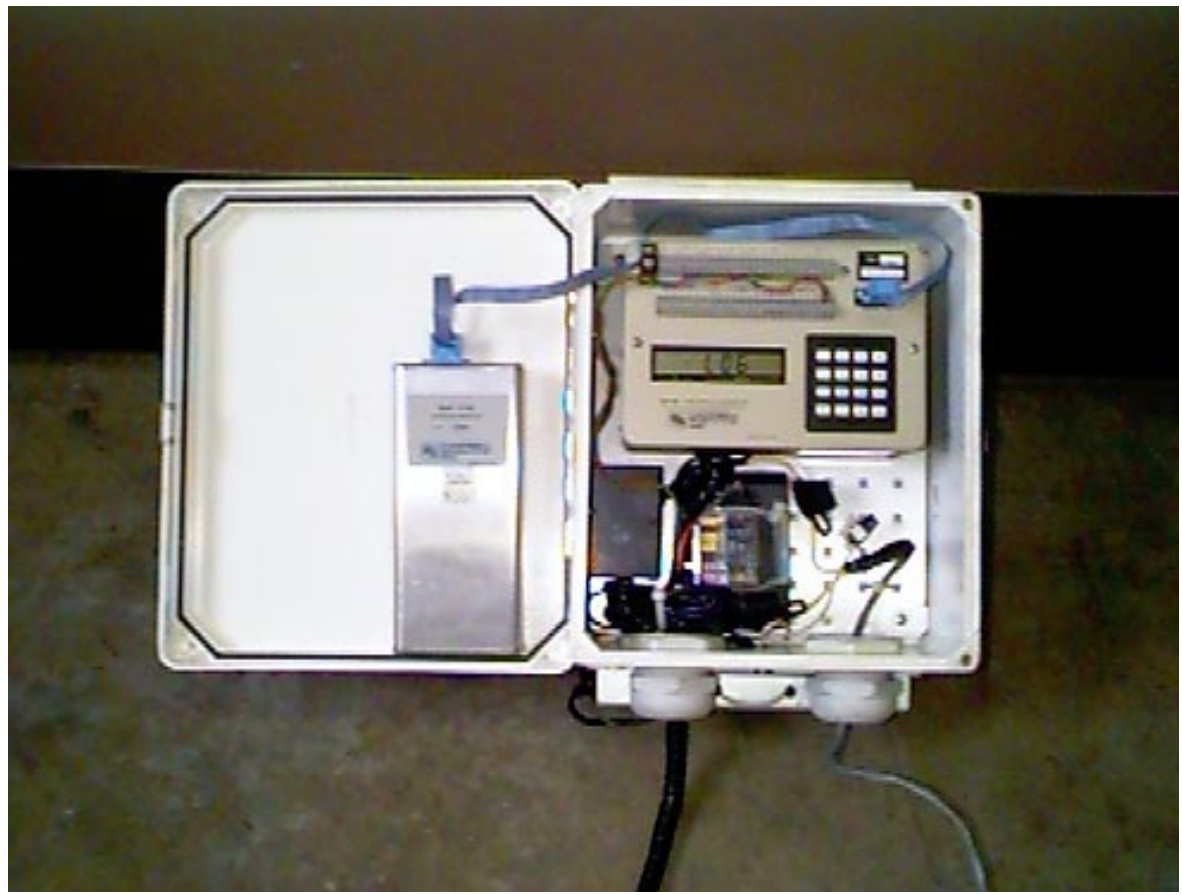

\subsection{Data Collection Procedure:}

The Campbell Scientific 21x micrologger proved to be simple to operate and to install in any type of vehicle. Powering the $21 \mathrm{x}$ was accomplished directly from the vehicle battery. Both positive and negative leads to the $21 \mathrm{x}$ were connected to fuses for power surge protection. The input sensors were connected to channel 17 on the 21x. Data storage was accomplished using Campbell Scientific SM192/716 storage modules. Data was collected with a recommended minimum sampling rate of $1 \mathrm{~Hz}$ (van de Weijer, 1997). Once data were collected they were easily removed from the SM 192/716 storage modules and converted directly into Microsoft Excel format for further data reduction.

\subsection{Instrumentation Electronics:}

Time and distance data could be collected directly from the vehicle speedometer output on the transmission. Since heavy duty vehicles have a variety of transmission configurations the data collection system was required to be flexible enough to collect data from many different transmission types. Older generation vehicles were equipped with mechanical speedometer cables while newer vehicles were equipped with electronic speedometer wiring. A adaptable data acquisition system was needed to evaluate both types of heavy duty vehicles. 


\subsubsection{Mechanical Connection}

On older generation vehicles with mechanical speedometer cables, data were collected using an in-line magnetic pulse output sensor. A series of pulses was generated each time the drive shaft of the vehicle rotated. The pulses from the magnetic sensor were in the form of a square wave. The $21 \mathrm{x}$ recorded and saved the total number of pulses per second.

\subsubsection{Electrical Connection}

On newer generation vehicles the signal from an electronic speedometer was collected by splicing into the speedometer wiring. Due to the different transmission types, the output signal could be in the form of a square, triangle, or sine wave. For each wave configuration, the number of pulses was a function of drive shaft rotation. The total number of pulses per second was collected and saved on the $21 \mathrm{x}$ using the same method as with a mechanical connection.

\subsection{Delivery Trucks Monitored:}

Two heavy duty tractors were selected by the American Trucking Association (ATA) for testing by West Virginia University. The tractors selected were fueled by liquid natural gas (LNG) and stationed at Roadway Express, Inc. in Akron, Ohio and Overnite Inc. in Richmond, Virginia. Heavy duty LNG fueled vehicles were chosen due to the mandate of the program to compare the performance of diesel and alternative fuels. The trucks are pictured in Figures 4.4.1 and 4.4.2. These tractors had daily operating routes, which included 4-lane interstate commuting, inner city pickups and deliveries, 2-lane suburban road driving, and industrial park pickups and deliveries. The Roadway Express, Inc. tractor was a single axle tractor which pulled a 48 foot van trailer and doubles (twin 28 foot trailers) on one occasion. The tractor at Overnite Transportation Co. also pulled a 48 foot van trailer. A 5.9 liter Cummins engine operating on liquid natural gas (LNG) powered the Roadway Express, Inc. tractor and shifting was accomplished through an unsynchronized 6-speed manual transmission. An 8.3 liter Cummins engine operating on LNG powered the Overnite Transportation tractor and shifting was accomplished through 5-speed automatic transmission. 
Figure 4.4.1 Test Vehicle at Roadway Express, Inc. in Akron, Ohio. This vehicle pulled both double and single trailers.

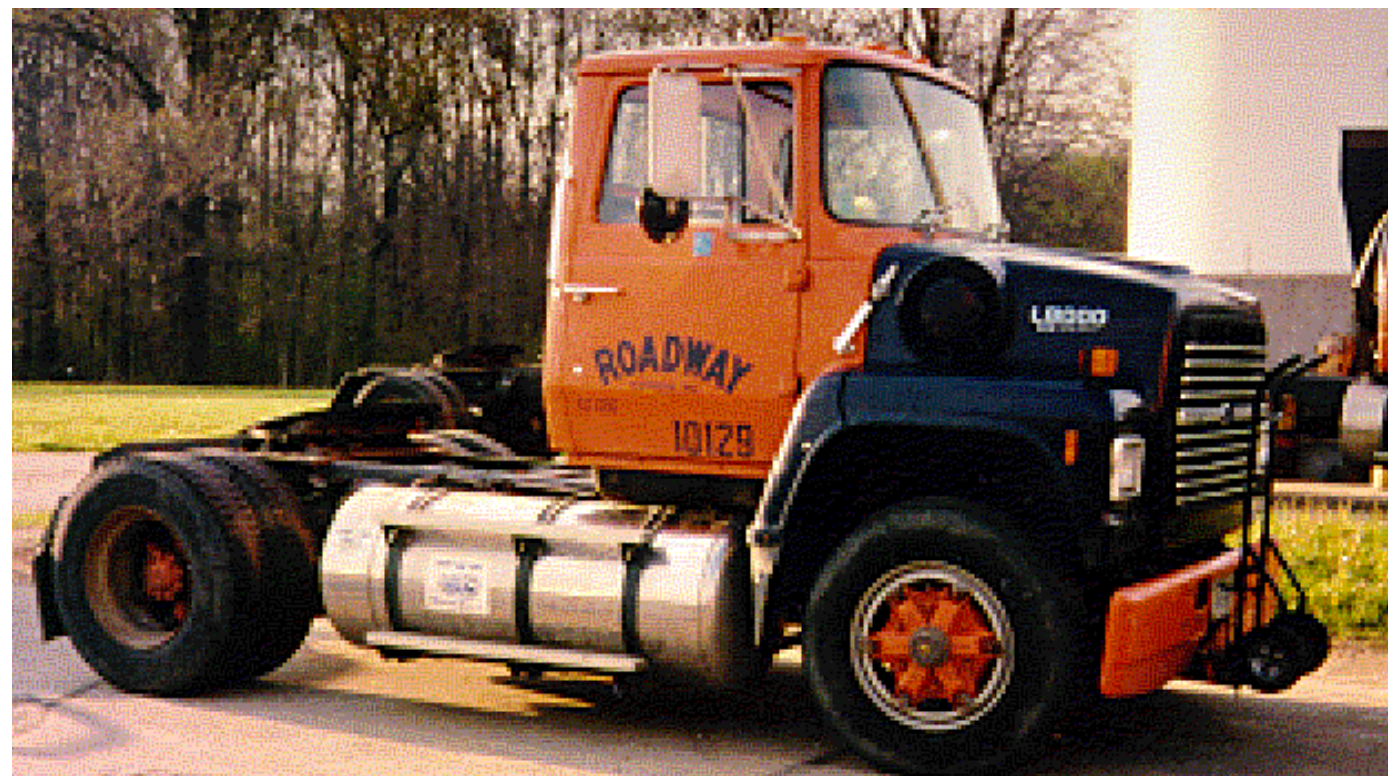

Figure 4.4.2 Test Vehicle at Overnite Transportation Co. Richmond, Virginia. The author is holding a Campbell Scientific 21x micrologger next to the truck.

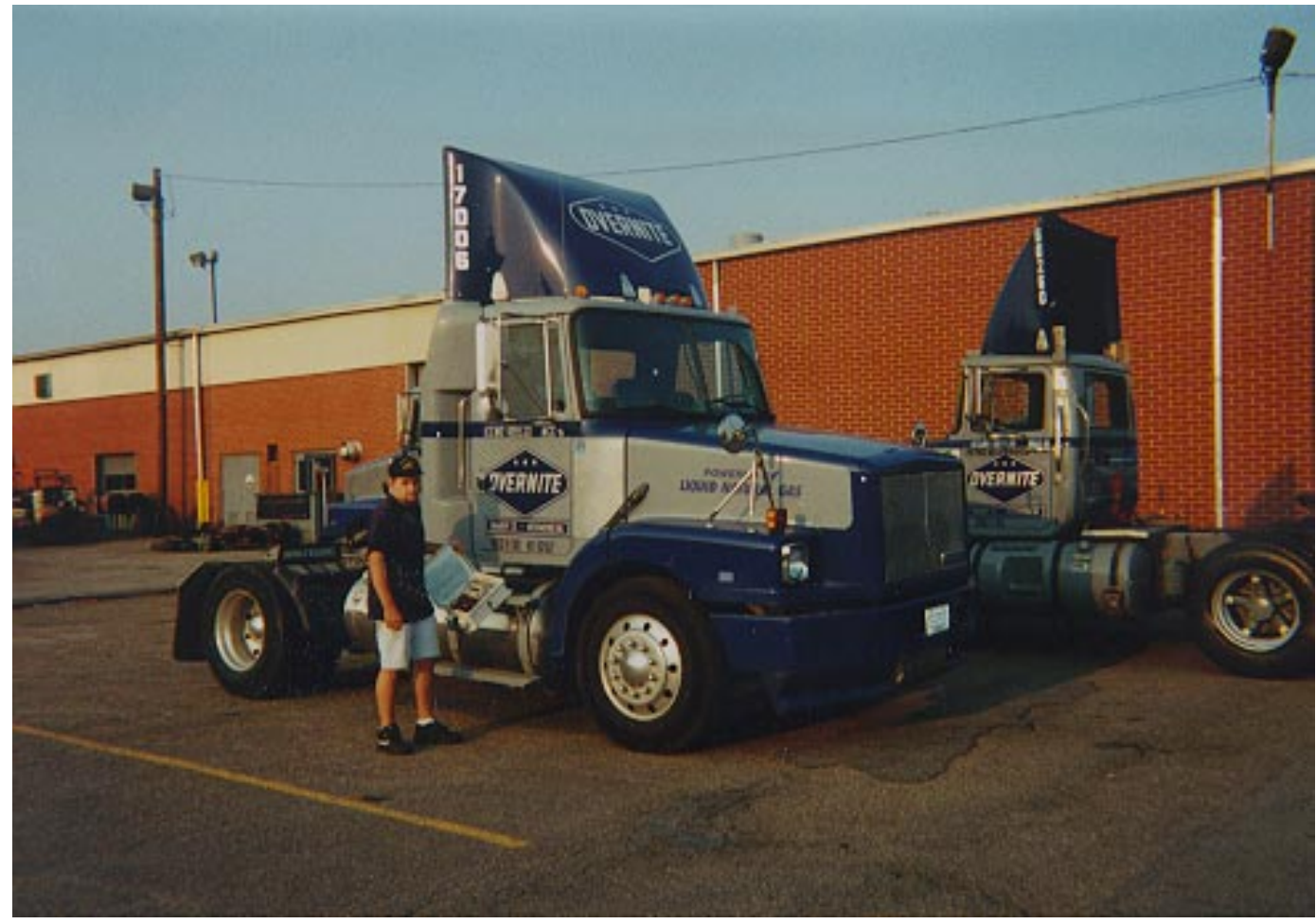




\subsection{Videotape Records:}

The delivery routes driven by these tractors were also recorded on video camera. The video data were collected only when the tractor was traveling between delivery sites. Since some delivery sites were in secured areas, no video data was collected in these areas. These occurrences were of very short duration and were not during the main parts of the delivery route. Video data were collected so that the delivery routes could be repeated later by another heavy duty tractor trailer with a different power-to-weight ratio or so that road grade information could be collected at a later time. Video data also recorded the types of road and traffic conditions that were encountered by these tractors and were used to convert cycles into routes, as discussed below. Route conversion was accomplished by separating accelerations inhibited by other vehicles from accelerations that were uninhibited.

\subsection{Data Collected:}

The sensors and $21 \mathrm{x}$ were installed in both single axle tractors. Data were collected from the time the driver left the terminal in the morning until the time he returned to the terminal at the end of his workday. Data were collected on these tractors over six days of operation for a total of 59.5 hours of data logging. Approximately $15 \%$ of the hours recorded on videotape are when the tractor was driving en route to a delivery stop.

\subsection{Datalogger Calibration:}

Before the distance data could be interpreted, the error attained from the tractor speedometer needed to be eliminated. A calibration constant (CC) for the each individual tractor being observed was calculated. The signal collected from the speedometer by the $21 \mathrm{x}$ micrologger was a square wave. Simply stated, the higher the velocity of the tractors movement, the more pulses the speedometer produced per unit time. In order to calibrate the $21 \mathrm{x}$, a set distance was measured. Each vehicle was driven over that distance, and the number of pulses produced was collected. In order to assure accurate results Interstate markers were used as reference points for both tractors. This method was repeated over 27 miles using the Roadway Express, Inc. vehicle and 9 miles using the Overnite Transportation Co. vehicle. This produced a calibration constant in pulses per mile, which could be used to attain

$$
\mathrm{CC}\left(\frac{\text { pulses }}{\text { mile }}\right)=\frac{\sum \text { total pulses }(\text { pulses })}{\sum \text { total distance }(\text { miles })}
$$

accurate distance data. Results are shown in Table 4.7.1. 
Table 4.7.1 Calibration constants used to calibrate the Campbell Scientific 21x micrologger.

\begin{tabular}{|c|c|c|c|}
\hline Delivery truck monitored & $\begin{array}{c}\text { CC } \\
\text { (pulses per mile) }\end{array}$ & $\begin{array}{c}\text { Standard deviation of pulses counted } \\
\text { (pulses per mile) }\end{array}$ & $\begin{array}{c}\text { COV of pulses counted } \\
(\%)\end{array}$ \\
\hline Roadway Express Inc. & 37284 & 347.9 & 0.933 \\
\hline Overnite Transportation Co. & 9854 & 108.8 & 1.10 \\
\hline
\end{tabular}

Instantaneous distance (ID) traveled by the tractor was calculated by dividing the number of pulses obtained while collecting data by the calibration constant.

$$
\operatorname{ID}(\text { miles })=\frac{\text { instantaneous pulses }(\text { pulses })}{\operatorname{CC}\left(\frac{\text { pulses }}{\text { mile }}\right)}
$$




\section{Data Reduction}

Once the data were collected using the 21x they were converted into Microsoft Excel format for further data reduction. Two columns of data were downloaded into Microsoft Excel, namely time of day in seconds and number of pulses. After being downloaded, the number of pulses was converted into miles using the CC. This database was divided into microtrips using the video data. The video data were then reviewed to determine which accelerations were obstructed by traffic and which were free. Next, the instantaneous speed and instantaneous acceleration were calculated followed by an acceleration smoothing technique. Different statistical criteria were accessed in order to distinguish between modes of acceleration, deceleration and cruise. Average microtrip values for velocity, acceleration, and deceleration, were calculated along with microtrip times, idle times, cruise times, deceleration times, microtrip length and standard deviation of velocity. All of these methods are described in detail in the following sections.

\subsection{Microtrip Partitioning:}

A microtrip is defined as a period of driving activity typically due to driving from one delivery site to another (Clark, 1998). An example of a microtrip is shown in Figure 5.1.1. Some authors have used the term microtrip to describe a shorter period of activity.

The whole database was divided into microtrips using the video data. Each microtrip starts and stops at a delivery dock. The database consists of 130 microtrips, with 77 microtrips from Roadway Express, Inc. and 53 microtrips from Overnite Transportation Co. Each microtrip was classified in one of four following driving modes: interstate, suburban, city and yard. This was done using the video data and the opinions of the researchers. Interstate microtrips included four-lane highways with entrance and exit ramps. City microtrips encountered denser traffic and multiple stop lights. Suburban microtrips were delivery routes on the outskirts of the city, which included industrial parks and some rural areas as well. Yard microtrips were considered any microtrips that involved changing trailers, changing tires or driving to fueling sites. 
Figure 5.1.1 Example of a suburban microtrip recorded in Akron, Ohio using the Roadway Express Inc. vehicle pulling a 48 foot van trailer.

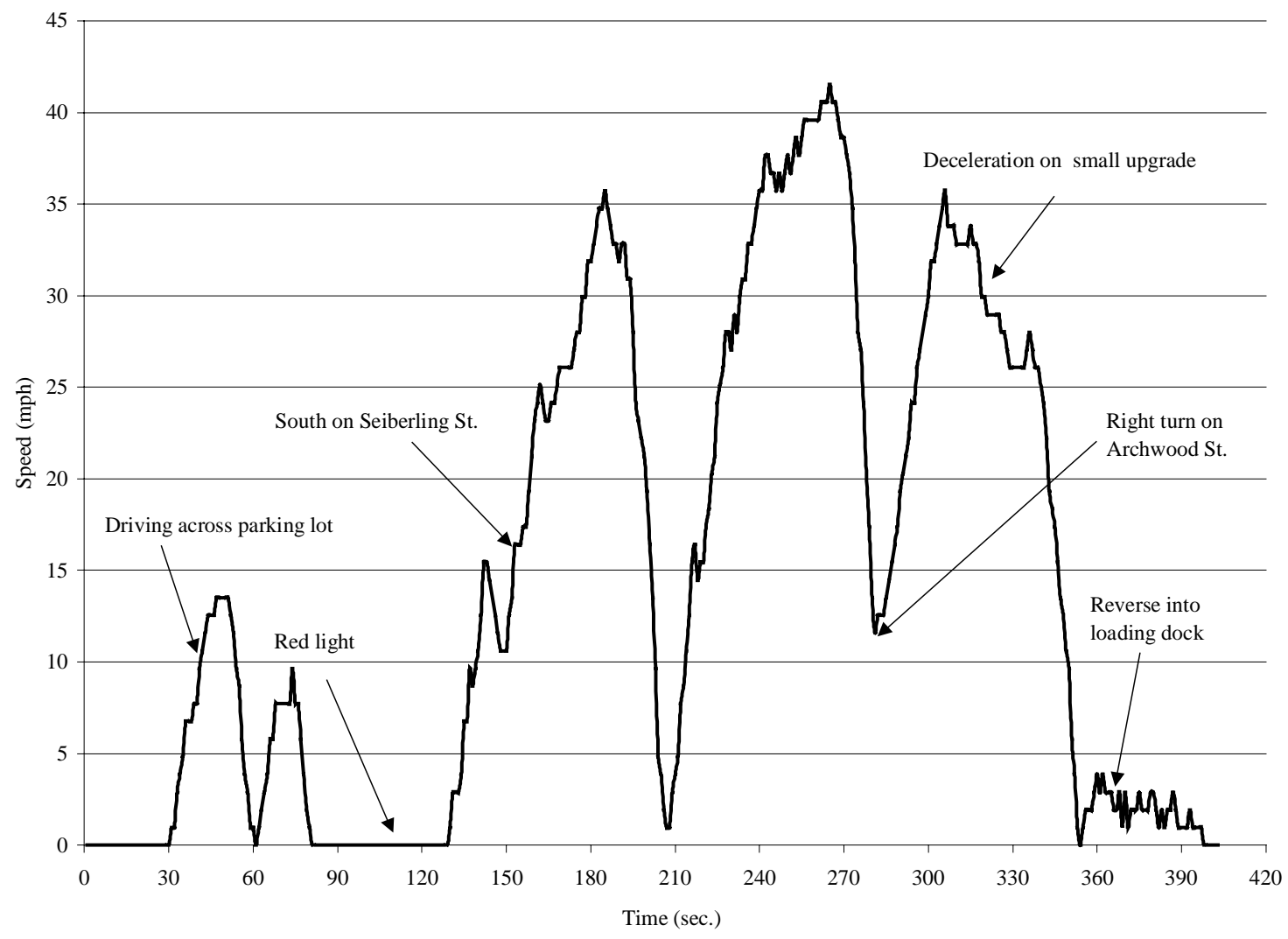

\subsection{Instantaneous Speed and Instantaneous Acceleration:}

Once the CC was calculated, the raw data were reduced by calculating the instantaneous distance (ID). Some of the data encountered while following the delivery vehicles, included segments in reverse. All reverse data were considered to be forward motion. Next, first and second derivatives of distance were taken to calculate the instantaneous speed (IV) and instantaneous acceleration (IA) of the tractor.

$$
\begin{aligned}
& \mathrm{IV}(\mathrm{mph})=\frac{\mathrm{d}}{\mathrm{dt}}(\mathrm{ID}) \\
& \mathrm{IA}(\mathrm{mph} / \mathrm{s})=\frac{\mathrm{d}}{\mathrm{dt}}(\mathrm{IV})
\end{aligned}
$$




\subsection{Smoothed Acceleration:}

In order to obtain accurate accelerations and decelerations for reduction purposes it is essential to smooth the IA data. The data were smoothed in order to eliminate sudden IA "spikes" from shifting, braking, double clutching and environmental surroundings such as railroad tracks. Once these spikes were removed, the only remaining accelerations were from the heavy duty vehicle and were not due to outside prevailing conditions. A graph of smoothed acceleration is shown in Figure 5.3.1. By using a five-point center-predicting average one can smooth the IA data enough to eliminate noise in the data. Note that only the IA data was smoothed. The vehicle speed was left unmodified as the instantaneous acceleration was smoothed.

$$
\text { Smoothed IA }(\mathrm{mph} / \mathrm{s})=\left\{\frac{\left(\mathrm{IA}_{-2}\right)+3\left(\mathrm{IA}_{-1}\right)+5(\mathrm{IA})+3\left(\mathrm{IA}_{+1}\right)+\left(\mathrm{IA}_{+2}\right)}{13}\right\}
$$

Figure 5.3.1 Instantaneous vehicle speed and acceleration before and after smoothing.

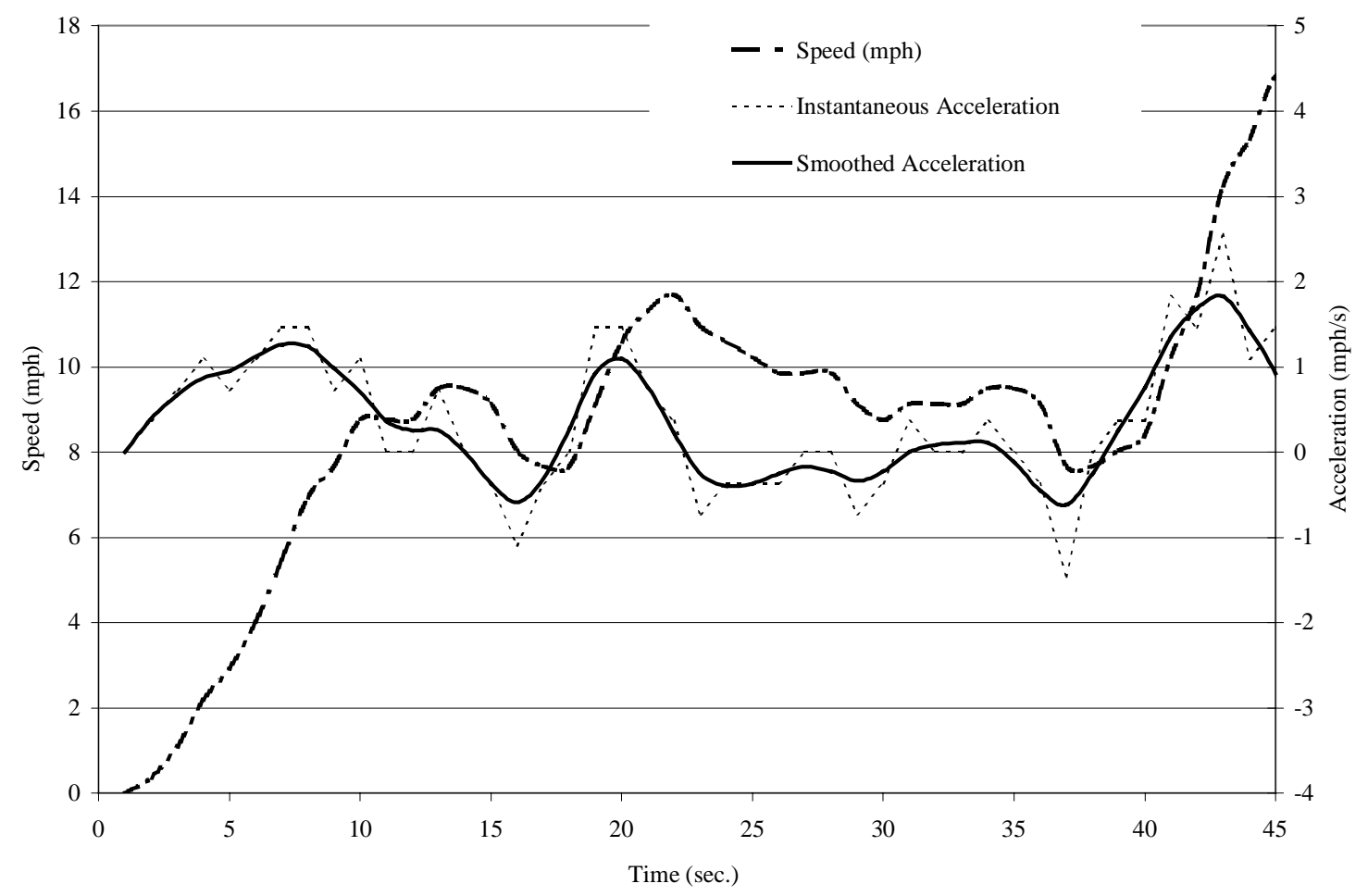

\subsection{Definition of Vehicle Driving Categories:}

In order to analyze the database further, the smoothed acceleration and speed data were separated into vehicle acceleration (VA), vehicle deceleration (VD), vehicle cruise (CR) and idle segments. Idle was defined to be 
any time the vehicle speed equaled $0 \mathrm{mph}$ and smoothed acceleration equaled $0 \mathrm{mph} / \mathrm{s}$. In order to distinguish between VA, VD, and CR, different values of smoothed acceleration were selected as cutoff values. Obtaining these cutoff values was accomplished using graphical methods. The cutoff values used are shown in Table 5.4.1. Cruise occurred when the vehicle was not accelerating, decelerating or idling according to the criteria set by the researchers. Different rates of smoothed acceleration were chosen until the researchers agreed subjectively which segments should be considered VA, VD, and CR. Figure 5.4.1 shows which segments of a microtrip were assigned as VA, VD and CR. Some parts of Figure 5.4.1 show increases in vehicle speed, but are not labeled to be VA. This is because the increases in vehicle speed were not rapid enough to be considered as VA.

Table 5.4.1 Vehicle acceleration and vehicle deceleration cutoff values.

\begin{tabular}{|c|c|c|}
\hline Vehicle Speed $(\mathbf{m p h})$ & Less than or equal to 10 & Greater than 10 \\
\hline Vehicle Acceleration $(\mathbf{m p h} / \mathbf{s})$ & 0.4 & 0.1 \\
\hline Vehicle Deceleration $(\mathbf{m p h} / \mathbf{s})$ & -0.4 & -0.18 \\
\hline
\end{tabular}

Figure 5.4.1 VA, VD, and CR segments during a microtrip.

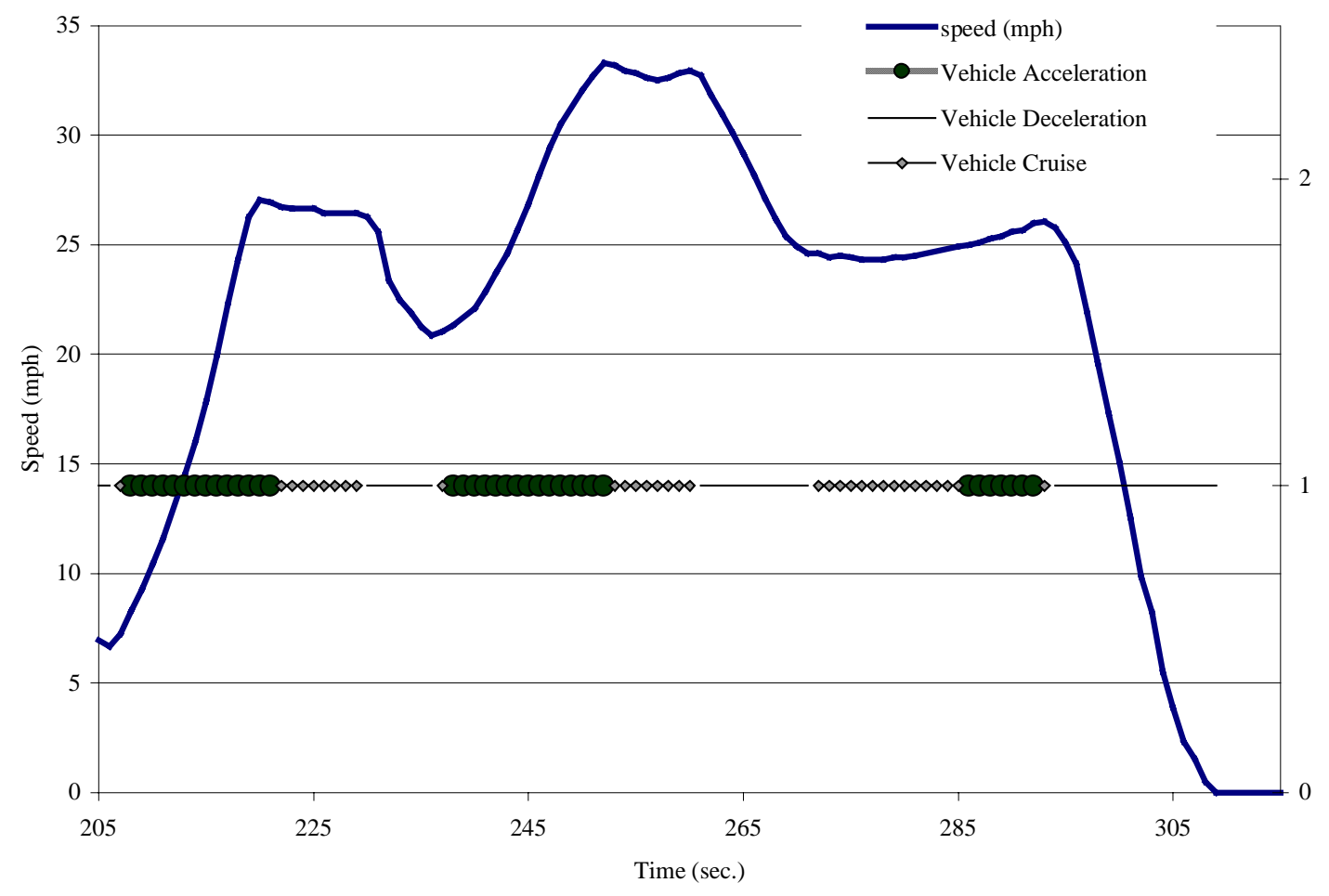


The durations of the four driving categories were also recorded as database statistics. Idle time is the total time during a microtrip that the vehicle spent at an idle. Acceleration time, deceleration time and cruise time are the total times the vehicle was accelerating, decelerating or cruising according to the cutoff values.

\subsection{Test Weight:}

Weight data were collected by researchers at WVU over the six days of operation in Akron, Ohio and Richmond, Virginia. In addition, 39 days of data were provided by Roadway Express, Inc. in Akron for a representative truck delivering in the same area (the original Roadway Express Inc. truck was no longer operating in the observed area). The data showed the average gross vehicle weight (GVW) to be $58 \%$ of the gross vehicle weight rating (GVWR), which for a Class 7 tractor, was found to be 33,373 pounds. Using this percentage, a class 8 tractor would be tested at a maximum of 46,839 pounds.

The United States Department of Commerce and the Bureau of Transportation Statistics release a Census of Transportation report every five years (Census of Transportation, 1992). The Truck Inventory and Use Survey for 1992 was consulted to determine the number of trucks representing various classes of delivery trucks. For example, 226,700 trucks hauled weights between 50,001 lbs. and 60,000 pounds. The Truck Size and Weight Study, performed by the United States Department of Transportation (USDOT), reported that the average tare weight of a tractor trailer with 5 axles or more is 30,500 pounds and the average payload of a truck with 5 axles or more is 36,200 pounds (Truck Size and Weight Study, 1992).

Researchers attempted to obtain average truck weights from State Weigh Stations and Motor Carrier units. However, only the trucks receiving a citation were recorded for future reference. A local survey of delivery agencies for North Central West Virginia was conducted. These agencies include Little Debbie, Blue Ridge Beverage, United Van Lines, and J.B. Hunt. Most drivers acknowledged that they were under the maximum allowable gross truck weight and were loaded 50-75 percent by volume. United Van Lines estimated the average weight of a single axle tractor and trailer to be 34,000 pounds and a tandem axle tractor and trailer to be 40,00060,000 pounds. The consensus was that the volume of the truck or trailer and not the maximum allowable weight dictated the weight of the load.

Companies that deliver interstate before delivering to suburban areas, such as petroleum companies (Exxon Co., U.S.A., Ashland Inc., Texaco Refining and Marketing Co., Citgo Petroleum Corp., Amoco and BP America 
Inc.), mail delivery (United Parcel Service (UPS)), fast food (McDonalds, Burger King and Hardees), grocery stores (Kroger, Raley's Distribution Center) and office supplies (OfficeMax) were contacted to determine the average weight of their respective delivery trucks. Exxon and BP stated that tankers loaded at $80,000 \mathrm{lb}$. GVW are sent to a local gas station where one delivery is made and the truck then returns to the refinery. McDonalds loads their class 8 tractors with 44,000 pounds of cargo and the truck makes multiple deliveries. In other words, the weight of a McDonald's truck might vary from about $68,000 \mathrm{lb}$. to $24,000 \mathrm{lb}$. The remainder of the companies either would not participate in research projects or responded that their products were delivered by a third party carrier. The ATA/TRI researchers contacted the Transportation Research Information Service and concluded that no pertinent weight data were available in the TRIS database.

After performing a survey to determine average weights for typical light-heavy and heavy-heavy delivery trucks delivering in suburban areas, the researchers have observed that the trucks of interest in this project are not subjected to rigorous weight enforcement. The trucks operate in areas inside the infrastructure of state weigh scales. It was noted by the California Trucking Association that trucks operating on the west coast (CA) are more likely to encounter state weigh scales. When these trucks encounter a weigh scale and are under the maximum GVW, no record of the truck's weight is made. Only the trucks receiving a citation are recorded. The California Highway Patrol, West Virginia Highway Patrol, Pennsylvania Highway Patrol and the Minnesota Highway Patrol were surveyed on this matter.

Another observation of the researchers, while taking data in the field, was that the truck weight limit was regulated by the volume and not the GVWR. The drivers acknowledged that they were rarely weighed and had little concern for the total truck weight. Previously, the WVU laboratories had determined truck emissions at $70 \%$ of the GVW, up to a GVW of 60,000 lb. For a higher GVW, a test weight of 42,000 lb. was used. There is no compelling evidence to deviate from this practice based upon the research conducted. It is noted that the gathering of reliable truck weight data remains an important research area. Some preliminary research, performed on the WVU database, concluded an average test weight of 46,400 lb. Subsequent data have been gathered using a 42,000 lb. test weight for class 8 tractors with an $80,000 \mathrm{lb}$. GVW, since this weight was previously favored in conducting 5-mile route emissions measurements (Clark et al., 1998). 


\section{Microtrip and Database Statistics}

After the second by second distance data were reduced into speed, VA, VD, CR, idle times, acceleration times, deceleration times and cruise times, two separate sets of statistics were generated in order to produce statistically Interstate, Suburban, City, Yard and City-Suburban cycles. First, a set of statistics was generated for each individual microtrip. Next, the same set of statistics was generated for each of the four driving modes in the whole database. Each set of statistics was generated without including idle times.

\subsection{Idle Exclusion:}

All statistics used in the development of these five cycles excluded idle times. It was found by the investigators that idle times vary widely among heavy duty vehicles. Some trucking companies have devices that shut down a vehicle when it idles for a certain length of time. These types of systems are very common on modern tractors. Other companies simply remind the drivers not to waste fuel and turn their trucks off at standstill. Although there are many methods used to save fuel, no two drivers execute the same routine for starting and shutting off a vehicle. Even with the electronically controlled shut-off mechanisms, many drivers bypass this energy saving device in order to save time on their daily driving routines. Many tractors have different idling periods between summer and winter months. In extreme cold many tractors run 24 hours a day, due to difficulty in starting cold compression ignition engines. With all of these different idling conditions, it was concluded at WVU that idle time would be added to the cycle after the active portions were developed. This would in no way effect the statistics of the cycle since the idle time was excluded during the calculations of the statistics.

\subsection{Statistical Criteria Based Selection:}

Criterion selection is crucial to the development of a cycle simulating "real world" behavior. Using the wrong criteria can lead to a cycle with good statistical averages but may not encompass the desired driving conditions. A very simple example would be time. If cycle time were the only criterion used and the statistical average time of the database was 500 seconds, a cycle could be developed with 500 seconds of idle or 500 seconds of cruising at $50 \mathrm{mph}$. Both of these cycles would produce drastically different emissions results. This explains 
why statistical means are only good if the selection criteria are good. The first cycle criterion chosen was average vehicle velocity. This was calculated with the following formula.

$$
\text { Average Vehicle Velocity }(\mathrm{mph})=\frac{\text { Total distance }(\mathrm{miles}) * 3600(\mathrm{sec} . / \mathrm{hour})}{\text { Total time }(\mathrm{sec} .)-\text { Idle time }(\mathrm{sec} .)}
$$

The average database velocity should be close to the average cycle velocity. The next criterion selected was the standard deviation of velocity. Reasoning behind this criterion was quite simple; it eliminates microtrips that are too aggressive or that contain cruise at a constant speed. Maintaining a representative speed profile is crucial to the validity of the test cycle. This was calculated using the following formula.

Stdev. of Velocity $=\sqrt{\frac{\{\text { Total time }(\text { sec. })-\text { Idle time }(\text { sec. })\} \times\left\{\frac{1(\mathrm{~h})}{3600(\mathrm{sec} .)}\right\} \times\left\{\sum[\text { Velocity }(\mathrm{mph})]^{2}-\left[\sum \text { Velocity }(\mathrm{mph})\right]^{2}\right\}}{\{\text { Total time (sec.) }- \text { Idle time }(\mathrm{sec} .)\} \times\left\{\frac{1(\mathrm{~h})}{3600(\mathrm{sec} .)}\right\} \times\{[\text { Total time (sec.) }- \text { Idle time (sec.) }]-1 \text { (sec.) }\}}}$

The final criterion used in developing these heavy duty cycles was cruise time. Cruise time is the duration during a microtrip that the vehicle cruised at similar speeds. This criteria is another way to eliminate microtrips that are overly aggressive, but it is based solely on time is not a function of the truck. Adding in average acceleration and deceleration rates was not used for two reasons. One, the deceleration rates are limited by constraints on the chassis dynamometer. Two, if a vehicle starts the test at an idle and then accelerates, there must be an equivalent deceleration in order to end the test at an idle. Average values for each driving mode are listed in Table 6.2.1.

Table 6.2.1 Average values for each driving mode in the WVU database.

\begin{tabular}{|c|c|c|c|}
\hline Microtrip Type & Total Distance (miles) & Total Time (seconds) & Total Cruise Time (\%) \\
\hline Interstate & 197.92 & 25,132 & 34.69 \\
\hline Suburban & 152.80 & 40,443 & 30.15 \\
\hline City & 26.54 & 14,785 & 40.47 \\
\hline Yard & 5.51 & 13,980 & 52.08 \\
\hline Suburban \& City & 179.34 & 55,228 & 32.56 \\
\hline & & & \\
\hline Microtrip Type & Average Vehicle Speed (mph) & Stdev. Of Vehicle Speed (mph) & Total Idle Time (\%) \\
\hline Interstate & 32.60 & 19.14 & NA \\
\hline Suburban & 17.84 & 13.93 & NA \\
\hline City & 10.19 & 9.95 & NA \\
\hline Yard & 6.34 & 6.24 & NA \\
\hline Suburban \& City & 16.05 & 13.51 & NA \\
\hline
\end{tabular}




\subsection{Comparison of WVU Database to TRI Data and CARB Data:}

TRI has access to a wealth of information collected on hard copy tachograph recorders. This information was recorded by numerous freight delivery companies throughout the United States. Tachographs provide a continuous trace, by a mechanical recorder, of a truck's daily pattern.

TRI translated a sample of tachographs, as best as was possible, into speed-time plots. These plots were then used to relate visually the trends of the truck activity to the recorded micrologger data. The micrologger and tachograph data were compared in order to analyze the database used to develop the CSHVR. This comparison revealed that trends in both data sets were similar. These trends included microtrip time, acceleration patterns, deceleration patterns, and cruise patterns. The average truck speed from the tachograph data was found to be 21 $\mathrm{mph}$ (excluding idle times), while the average truck speed from the micrologger data was found to be $20 \mathrm{mph}$ (excluding idle times). Idle times were not available from the tachograph because it was impossible to determine if the truck was idling or if the engine was turned off.

California Air Resources Board (CARB) also has a large database of vehicle speed collected using global positioning systems. This database consists of a large amount of line-haul (interstate) operation along with city, suburban, and yard driving. However, no video data were collected so the different driving categories of this database could not be distinguished. This made it necessary to compare the entire WVU database with the entire CARB database. CARB calculated statistics for their database and sent these statistics to WVU. These statistics were calculated for the WVU database and are listed in Table 6.3.1. Many of the differences between the CARB and WVU databases are due to the amount of interstate data. The average speed is $21 \%$ higher in the CARB database while the average trip distance is significantly higher by a factor of 17.6. These two factors show the influence of the interstate driving mode which directly affects the differences between the two databases. CARB data implies substantial interstate driving while the WVU data is city-suburban driving and limited interstate driving. 
Table 6.3.1 Comparison between CARB and entire WVU databases with idle times excluded.

\begin{tabular}{|c|c|c|}
\hline & CARB & WVU \\
\hline Average speed (mph) & 26.60 & 21.13 \\
\hline Stdev. Speed (mph) & 9.12 & 17.54 \\
\hline Average Microtrip Distance (miles) & 51.60 & 2.94 \\
\hline
\end{tabular}




\section{Cycle Creation}

\subsection{Basic Program:}

A program was written in Basic to calculate the average velocity, standard deviation of velocity and cruise time for different combinations of microtrips that would create a cycle. The microtrips chosen were selected out of each respective driving mode. One or more microtrips were randomly added together until the total time of the combined microtrips was between 1000 seconds and 1600 seconds. Next, this combination of microtrips (termed a "cycle") was analyzed for the average velocity (mph), standard deviation of velocity (mph), and cruise time (sec.). The flowchart in Figure 7.1.1 depicts this sequence of events.

Once all of these values for the cycle were computed, they were compared to the average values of the entire driving mode category. This comparison was done using a root mean square (RMS) error method. This method is as follows:

$$
\text { RMS error }=\left[\left(\frac{\text { database speed }- \text { speed }}{\text { database speed }}\right)^{2}+\left(\frac{\text { database stdev. speed }- \text { stdev. speed }}{\text { database stdev. speed }}\right)^{2}+\left(\frac{\text { database cruise time }- \text { cruise time }}{\text { database cruise time }}\right)^{2}\right]^{0.5}
$$

Each combination of microtrips or cycle has a RMS error value. Cycles with the lowest RMS error values were considered as possible candidates for the final cycle. It is understood that a large number of other RMS combinations are possible, but that the weighting factors used are always arbitrary. In this case the standard deviation of speed was used as a criterion to insure that the range of vehicle speeds encountered in the database was reflected by the range embodied in the cycle and eventually in the route. 
Figure 7.1.1 Flowchart used in the Basic program to develop randomly a cycle for each driving mode.

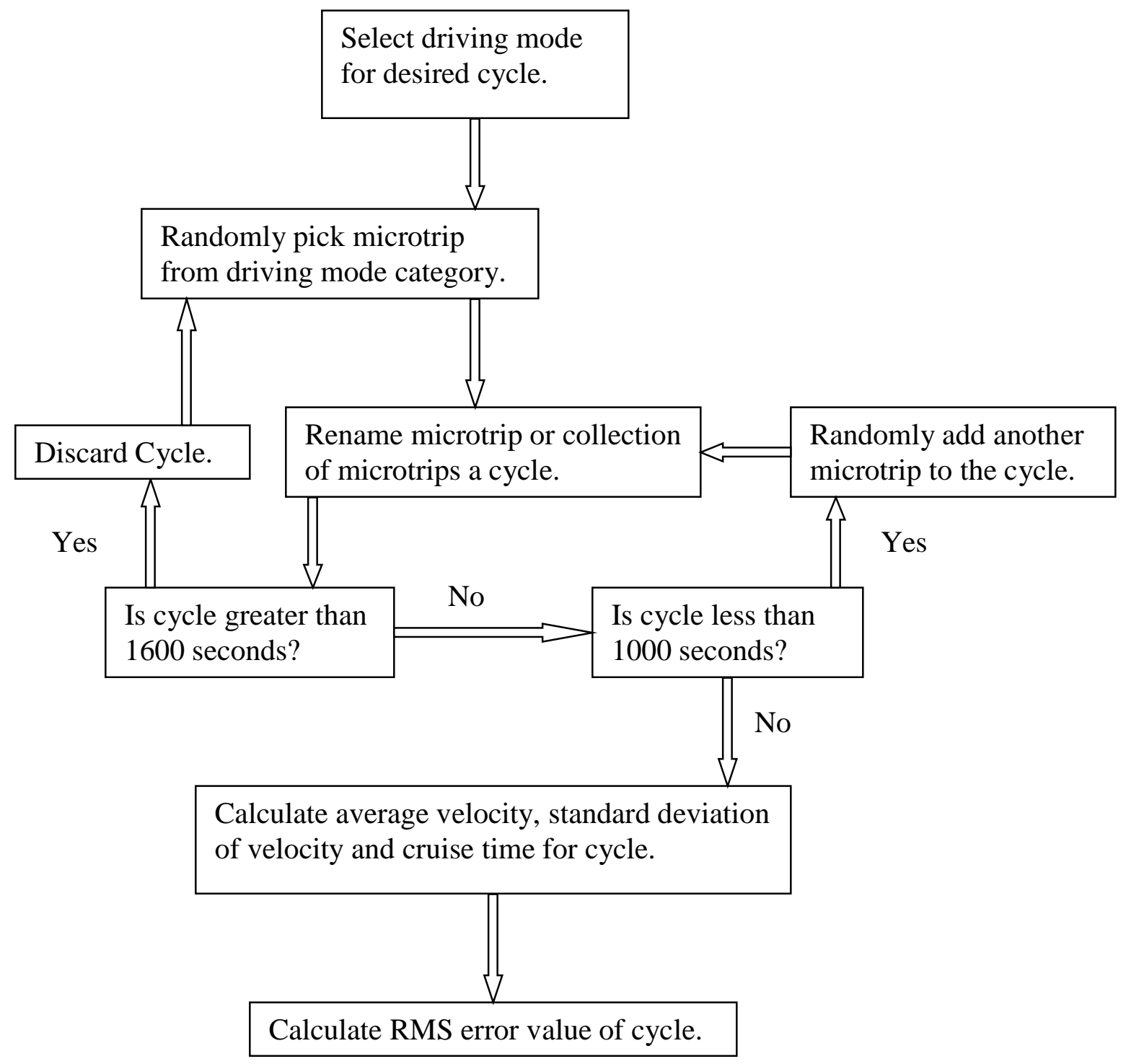

\subsection{Cycles Created:}

Using the microtrip statistics and Basic program, five different cycles were created. Creating each cycle was accomplished by iterating the Basic program 60,000 times. Each iteration produced a randomly generated cycle with an RMS error value. Some cycles were chosen by the Basic program more than once. The RMS error values of all the different cycles were compared and the one with the lowest RMS error value was selected to be the cycle for that driving mode. One cycle was created from each driving mode and one cycle was created from a concatenation of the suburban and city microtrips. After a cycle was created the original idle times were added back into the microtrips of which the cycle was comprised. Next, one minute of idle at the beginning of each individual 
microtrip and at the end of the cycle. The first cycle created was the Yard Cycle shown in Figure 7.2.1. The other cycles created included the City, Suburban, City-Suburban and Interstate Cycles and are shown in Figures 7.2.27.2.5.

The Yard Cycle (Figure 7.2.1) is intended to simulate driving at a freight yard. More specifically such activities as picking up and dropping off trailers, switching between the front and back trailers when hauling two trailers, and driving the vehicle to the fueling station. Statistics on the Yard Cycle and all the other cycles developed are given in Table 7.2.1. Some pertinent factors of this cycle are extended periods of idle, high accelerations and decelerations due to the light or empty trailers and low speeds due to short distances between stops.

Figure 7.2.1 Final Yard Cycle with suitable idle times added.

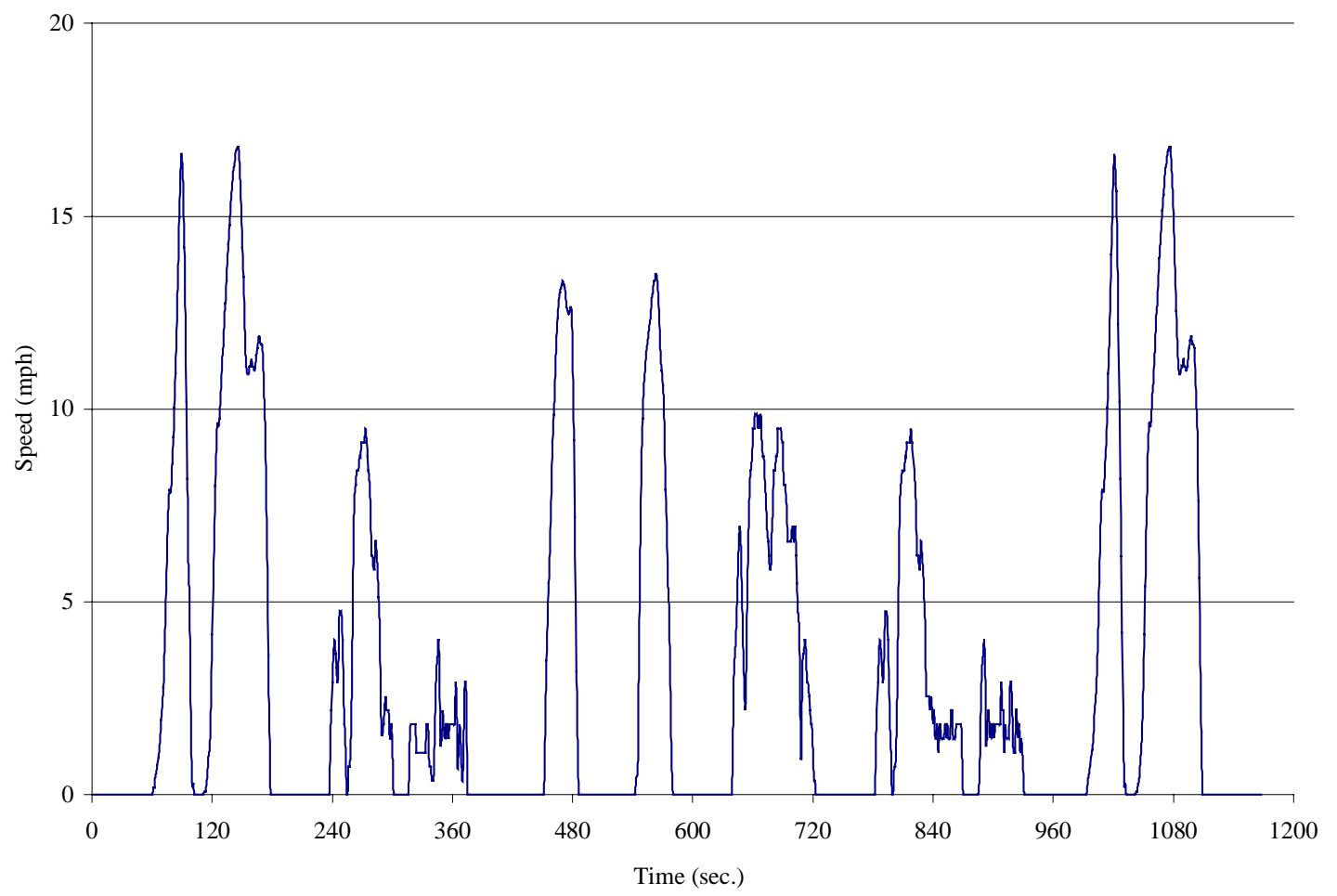

The City Cycle (Figure 7.2.2) is intended to represent downtown heavy traffic with numerous stop lights. Typical factors involved are slow turning on side streets, short distances between deliveries, slow vehicle speeds from traffic jams and railroad crossings and extended periods of idle due to stop lights. It should also be noted that during some of the deliveries the vehicle may not be shut off because it is parked in the middle of the street to make the delivery and drivers were in a hurry. 
Figure 7.2.2 Final City Cycle with suitable idle times added.

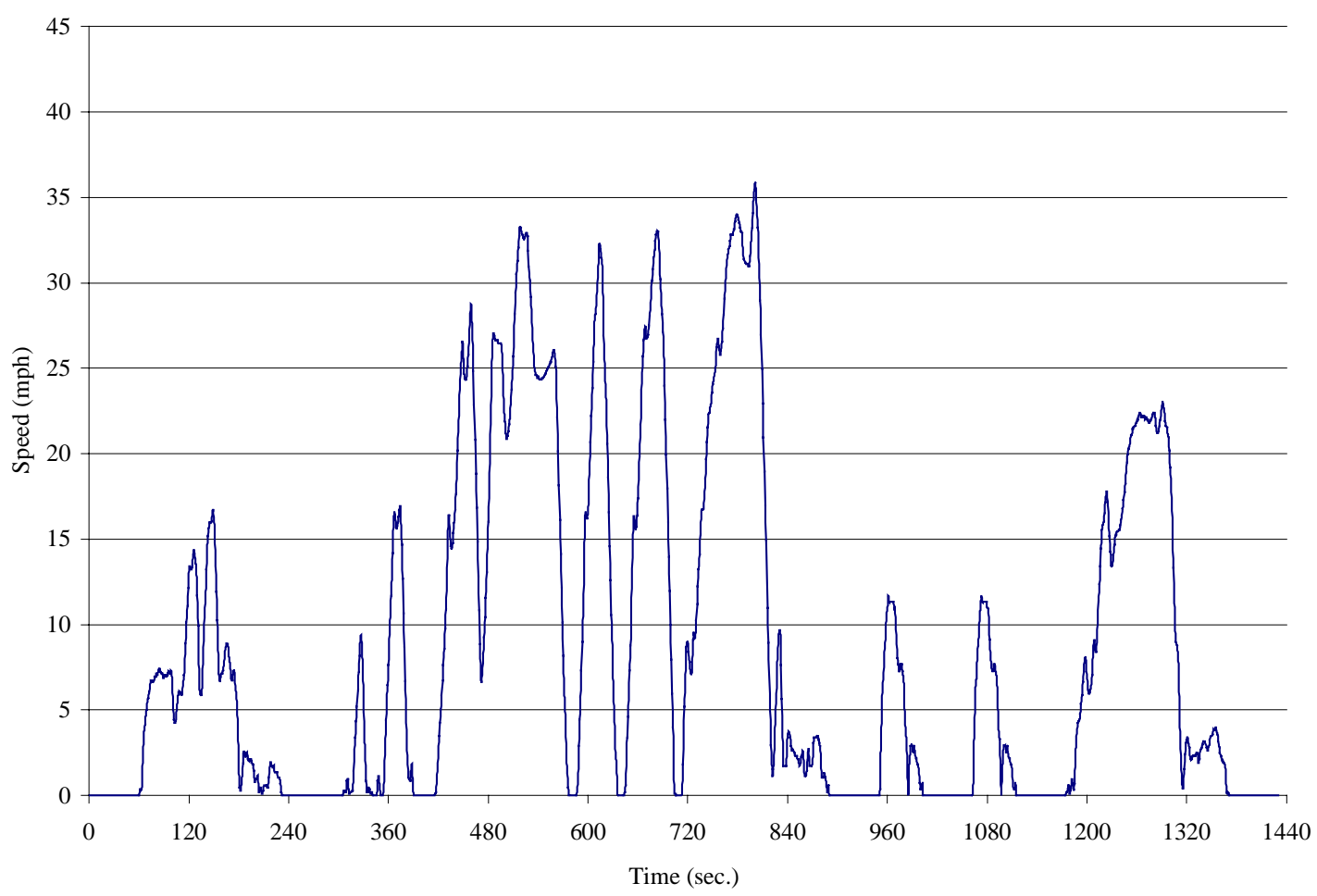

Figure 7.2.3 Final Suburban Cycle with suitable idle times added.

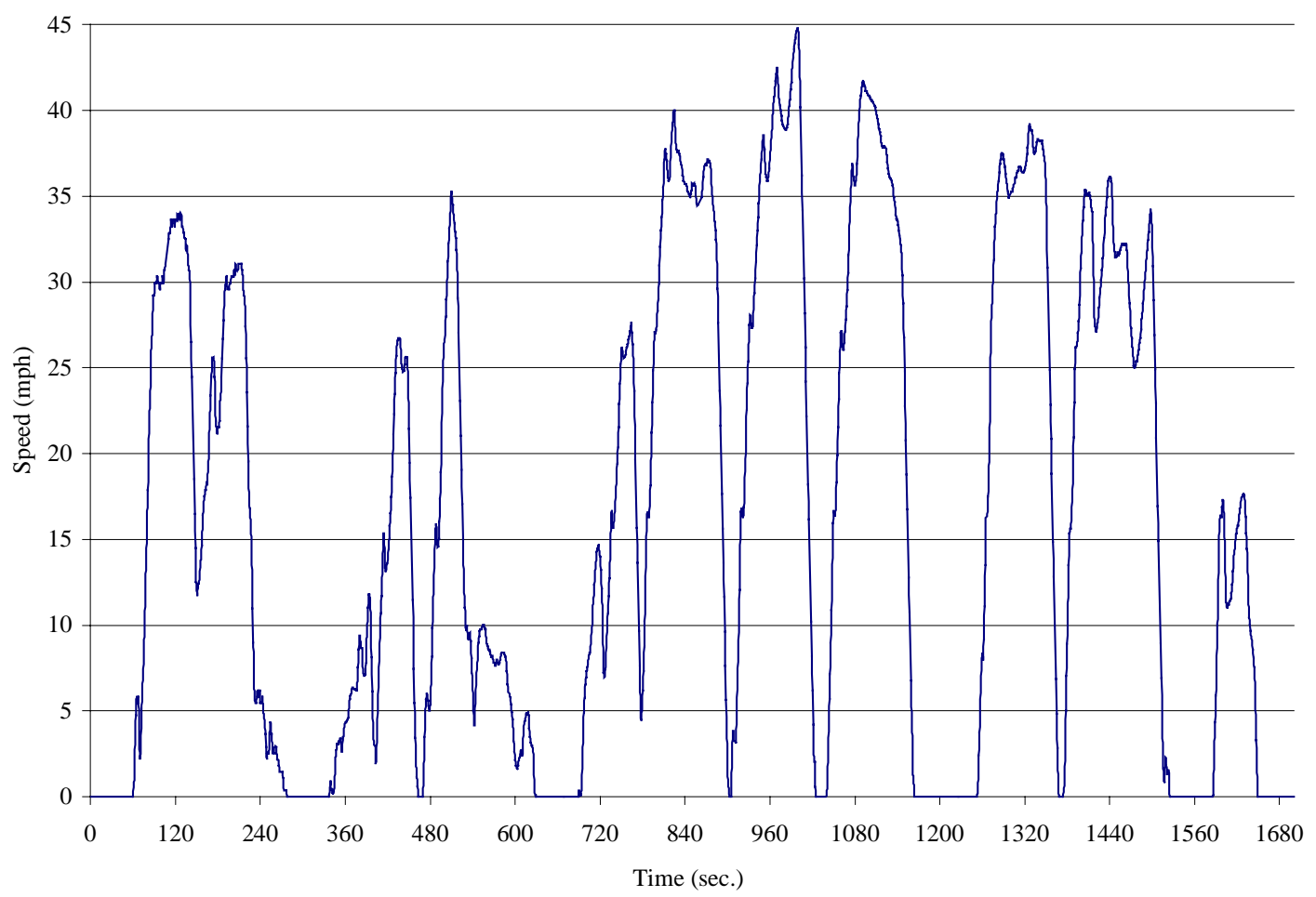


The City-Suburban Cycle (Figure 7.2.4) is made from a concatenation of the suburban and city microtrips. The reasoning behind this cycle is due to the fact that delivery vehicles typically do not just deliver in the city or in suburban areas. Usually they deliver in both settings and hence a cycle was developed in order to capture the pattern of both driving conditions.

Figure 7.2.4 Final City-Suburban Cycle with suitable idle times added.

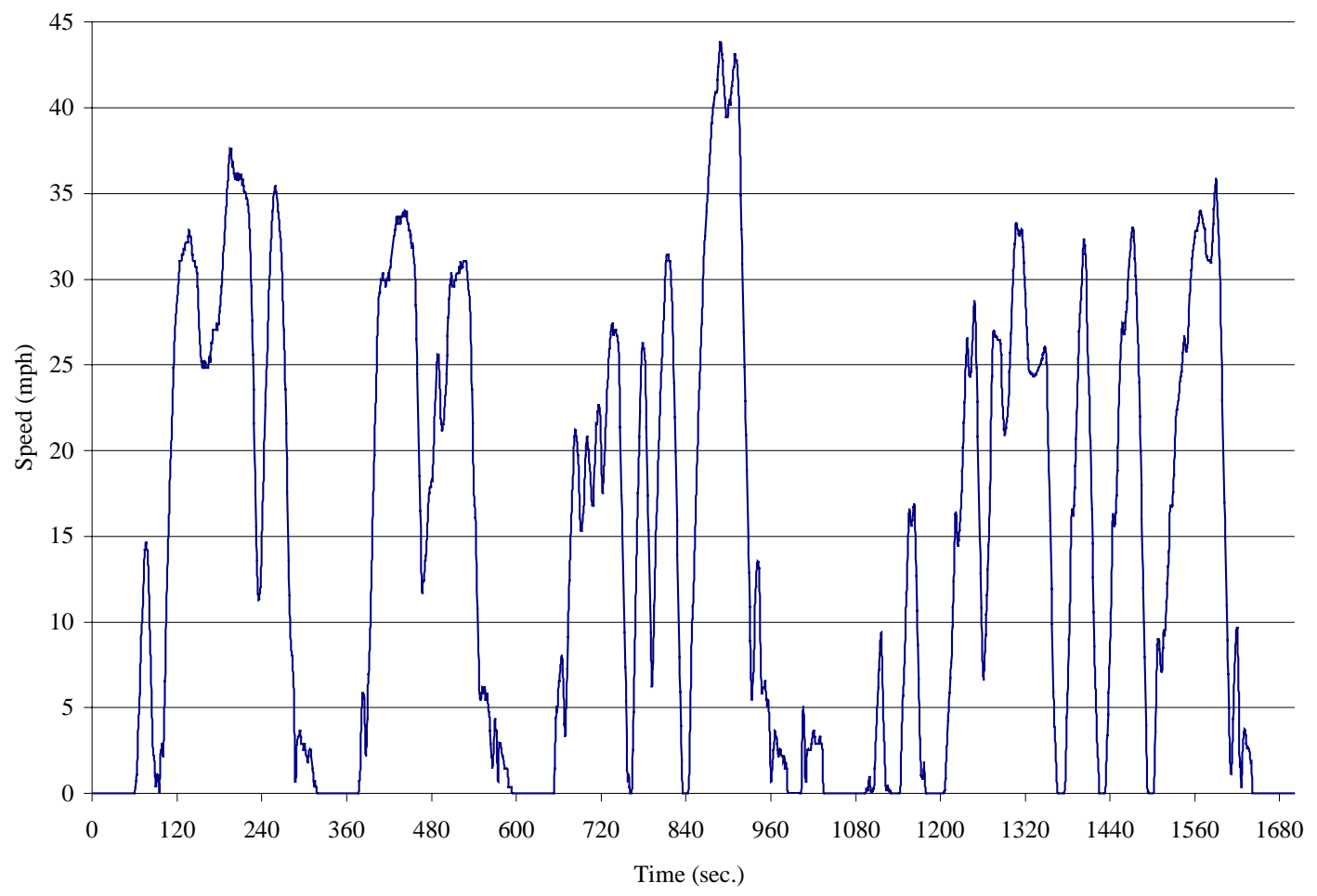

The Interstate Cycle (Figure 7.2.5) was designed to simulate high speed interstate travel with few stops between deliveries. Many times the delivery vehicle travels along the interstate in order to go to a designated delivery area then returns home again by the same interstate. This cycle also includes the travel off the interstate exit ramps and so a few slow speed segments are included.

Approximately two thirds (69\%) of the interstate microtrips in the WVU database were longer than 1600 seconds. Since, time was the first criterion used in the Basic Program the Interstate Cycle was chosen largely because it was less than 1600 seconds. The remaining $31 \%$ of the interstate microtrips were all longer than 1000 seconds in duration. This eliminated the combination of two microtrips to form an Interstate Cycle. 
Figure 7.2.5 Final Interstate Cycle with suitable idle times added.

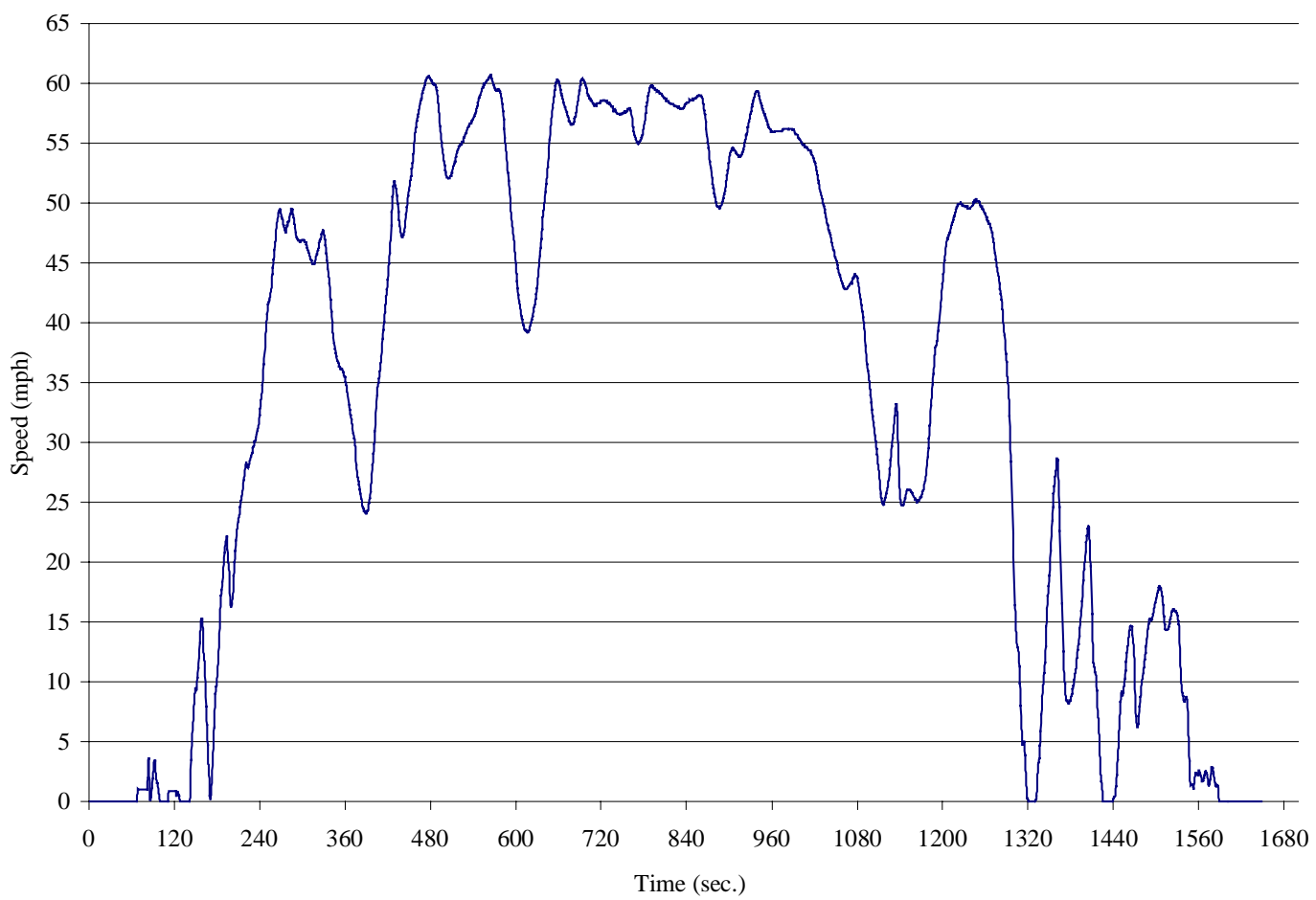


Table 7.2.1 Cycle Statistics for Yard, City, Suburban, City-Suburban and Interstate Cycles.

\begin{tabular}{|c|c|c|c|c|}
\hline Driving Cycle & Distance (miles) & $\begin{array}{l}\text { Percent Idle Time } \\
\text { (added into cycle) }\end{array}$ & $\begin{array}{l}\text { Average Velocity } \\
\text { (mph) }\end{array}$ & $\begin{array}{l}\text { Standard Deviation of } \\
\text { Velocity (mph) }\end{array}$ \\
\hline Yard & 1.08 & 38.83 & 3.33 & 4.64 \\
\hline City & 3.30 & 25.99 & 8.45 & 10.25 \\
\hline Suburban & 7.44 & 22.70 & 16.08 & 14.67 \\
\hline City-Suburban & 6.68 & 19.82 & 14.15 & 13.06 \\
\hline Interstate & 15.51 & 7.87 & 34.05 & 21.85 \\
\hline Driving Cycle & $\begin{array}{l}\text { RMS error } \\
\text { Value }\end{array}$ & $\begin{array}{c}\text { Percent Deceleration } \\
\text { Time }\end{array}$ & $\begin{array}{c}\text { Average } \\
\text { Deceleration (mph/s) }\end{array}$ & $\begin{array}{l}\text { Standard Deviation of } \\
\text { Deceleration }(\mathrm{mph} / \mathrm{s})\end{array}$ \\
\hline Yard & 42.77 & 11.60 & -0.989 & 0.650 \\
\hline City & 11.97 & 16.19 & -1.203 & 0.935 \\
\hline Suburban & 12.88 & 20.96 & -1.171 & 1.025 \\
\hline City-Suburban & 14.20 & 23.94 & -1.183 & 0.651 \\
\hline Interstate & 16.09 & 24.02 & -0.642 & 0.541 \\
\hline Driving Cycle & $\begin{array}{c}\text { Percent Cruise } \\
\text { Time }\end{array}$ & $\begin{array}{c}\text { Percent Acceleration } \\
\text { Time }\end{array}$ & \begin{tabular}{|c|} 
Average \\
Acceleration $(\mathrm{mph} / \mathrm{s})$ \\
\end{tabular} & $\begin{array}{c}\text { Standard Deviation of } \\
\text { Acceleration }(\mathrm{mph} / \mathrm{s})\end{array}$ \\
\hline Yard & 31.70 & 17.87 & 0.6828 & 0.3544 \\
\hline City & 31.61 & 26.21 & 0.7654 & 0.4517 \\
\hline Suburban & 24.32 & 32.01 & 0.7788 & 0.5038 \\
\hline City-Suburban & 22.06 & 34.18 & 0.8510 & 0.4984 \\
\hline Interstate & 36.04 & 32.07 & 0.5071 & 0.3117 \\
\hline
\end{tabular}




\section{Route Conversion}

The City-Suburban Cycle was converted into the City-Suburban Heavy Vehicle Route (CSHVR) by examining the videotape information. The City-Suburban Cycle needed to be altered in order to account for the power-to-weight ratio of typical heavy duty vehicles.

\subsection{Videotape Information:}

Once each cycle was created, the video data were reviewed in order to see how the driving performance of the original truck was influenced during each section of the cycle. Outside influence on the vehicle was the main consideration when the City-Suburban Cycle was converted into a route. Reasons for accelerations, decelerations and stops needed to be understood before the cycle was converted into a route. During accelerations the main condition of interest was if the vehicle's travel was obstructed or not. If the vehicle was not obstructed on the videotape then the acceleration was left unobstructed in the cycle.

\subsection{Free Acceleration:}

Since, the power-to-weight ratio has a profound influence on CO and PM (Clark and Lyons, 1998). In order to include the effect of power-to-weight ratio in the route, the accelerations needed to be adjusted so that all heavy duty tractors would be operating at full power while accelerating. This was accomplished by comparing the microtrips in the cycle with the videotape of each microtrip. If the truck was not inhibited by outside conditions when accelerating, the acceleration was said to be "free". When the vehicle's progress was inhibited, then that acceleration ramp portion was left exactly as recorded. The free accelerations were altered so that no heavy duty vehicle could keep up with the acceleration ramp. Since, the route driver is instructed to follow the trace as closely as possible, maximum vehicle acceleration is assured during the free acceleration portions of the route. These free accelerations require that the vehicle is always accelerating at maximum power no matter what the power-to-weight ratio. Free accelerations were created by converting an acceleration ramp into an instantaneous speed jump to the desired speed as shown in Figure 8.2.1.

At the end of each free acceleration there is a steady speed portion until the original speed trace is met. This steady state speed was determined by researchers to be the speed at the end of the original driver's acceleration. 
In some instances at the end of the steady state speed the scheduled speed increases. These increases in speed were viewed as cruise portions and not included in the free acceleration ramp.

Figure 8.2.1 Example of free accelerations and steady state speeds as compared to original acceleration ramp.

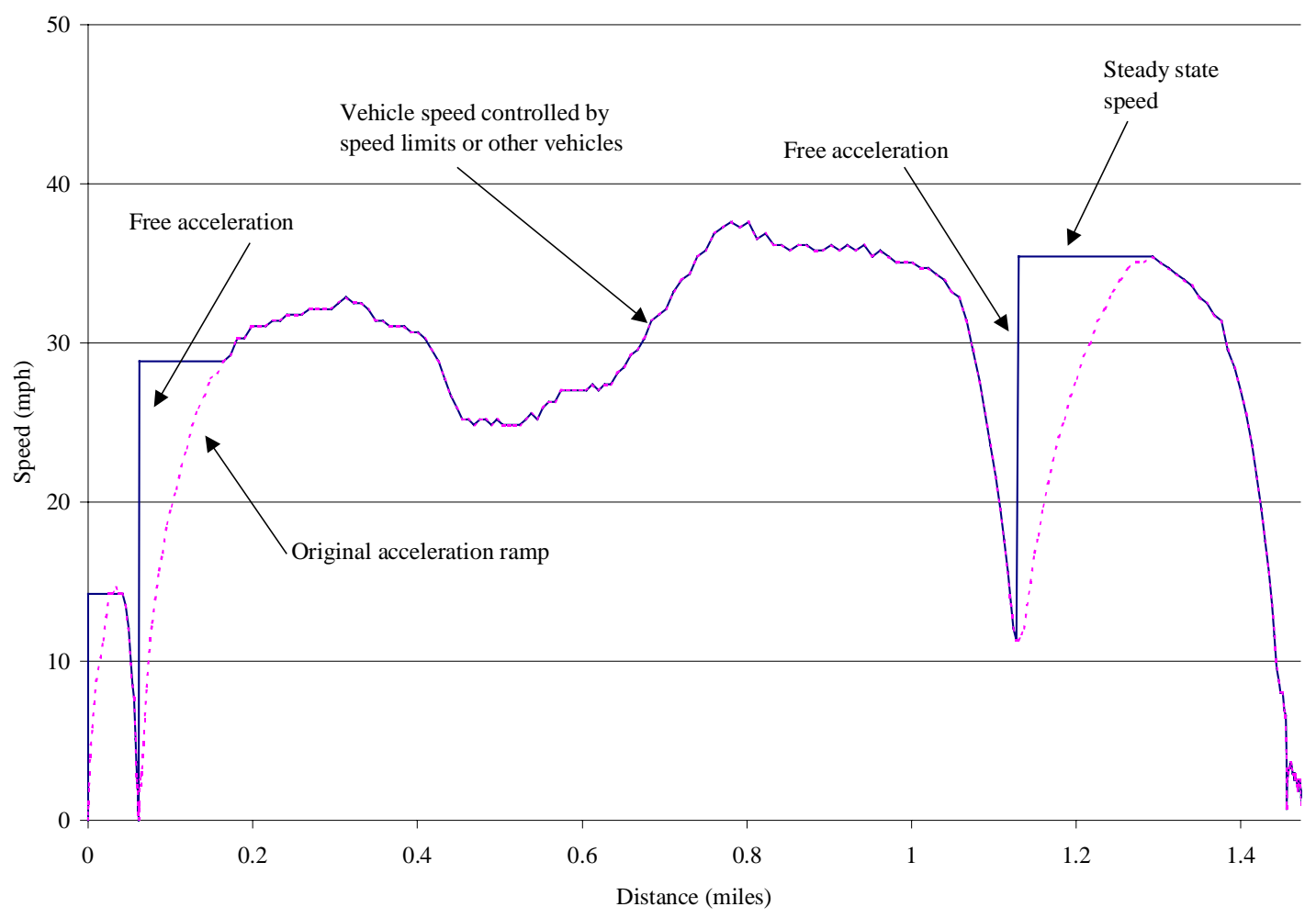

\subsection{Braking Rate Adjustment:}

Due to the physical design limitations of all heavy duty chassis dynamometers, decelerations were limited to $-2 \mathrm{mph} / \mathrm{s}$. Higher deceleration rates could be achieved if dynamometer assisted braking was used. Before the route could be used to evaluate the emissions between various heavy duty vehicles, all deceleration rates that were more rapid than $-2 \mathrm{mph} / \mathrm{s}$ were modified to equal $-2 \mathrm{mph} / \mathrm{s}$. Figures 7.2.1-7.2.5, shown above, include braking rate adjustment.

\subsection{Low Velocity Adjustment:}

Some of the data collected in Akron, Ohio and Richmond, Virginia include very slow segments of vehicle driving. These segments were typically the tractor backing up to a loading dock and at speeds less than 5 mph. 
These segments were excluded due to the extreme difficulty encountered driving at slow speeds with heavy loads on the chassis dynamometer.

\subsection{Route Created:}

Because free accelerations were added to include the variation in the power-to-weight ratio of different heavy duty tractor trailers it was necessary to base the route on distance traveled. When the CSHVR is driven on a chassis dynamometer, the route will not be completed until the driver stops at the end of the last deceleration ramp.

There are 13 free acceleration ramps during the CSHVR while the total number of acceleration ramps is 18 . The total distance traveled for the CSHVR is 6.68 miles, and the route is shown in Figure 8.5.1.

Figure 8.5.1 City-Suburban Heavy Vehicle Route: speed vs. distance.

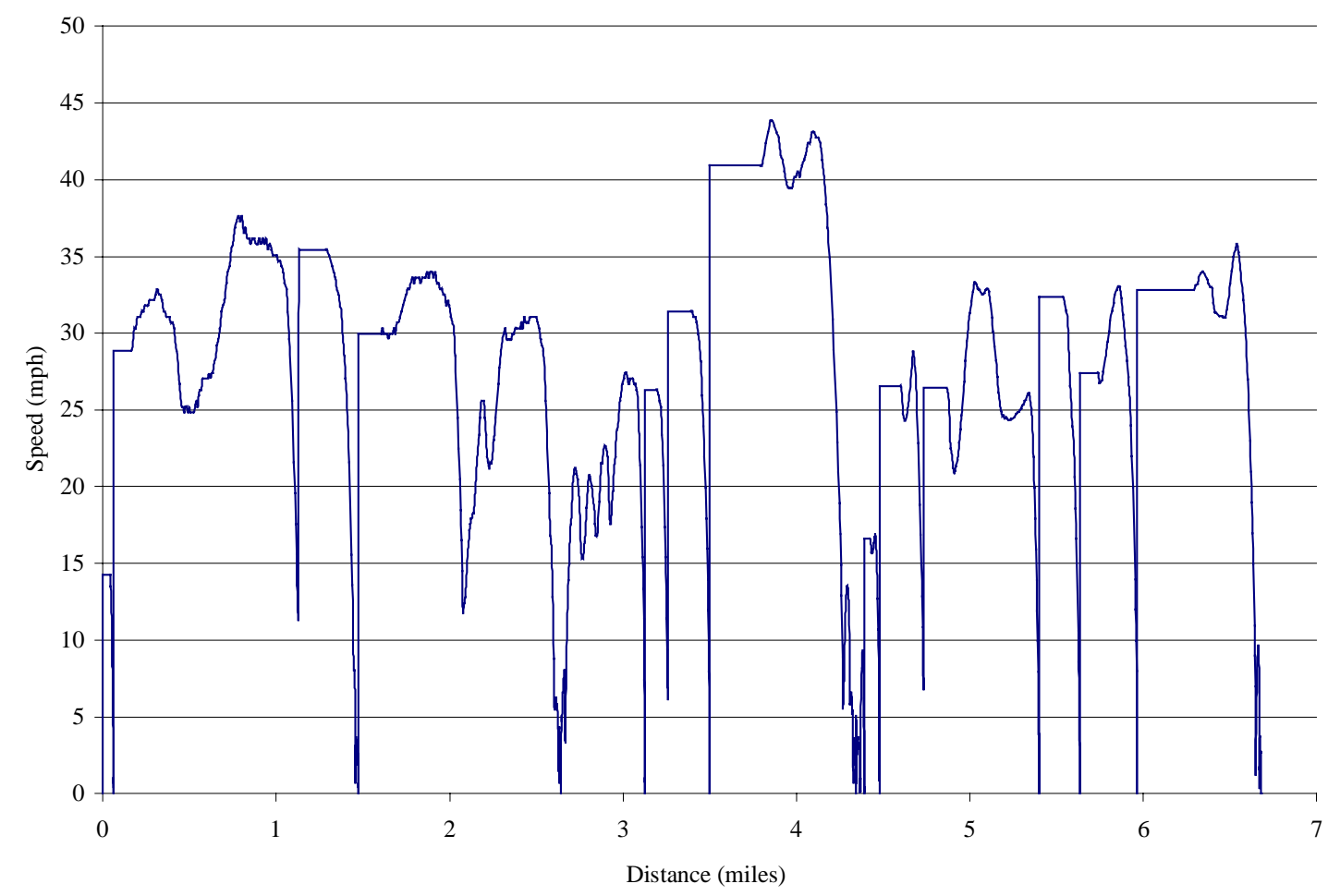


Figure 8.5.2 Scheduled speed vs. time trace of CSHVR used only to show the lengths of the idle periods during the CSHVR.

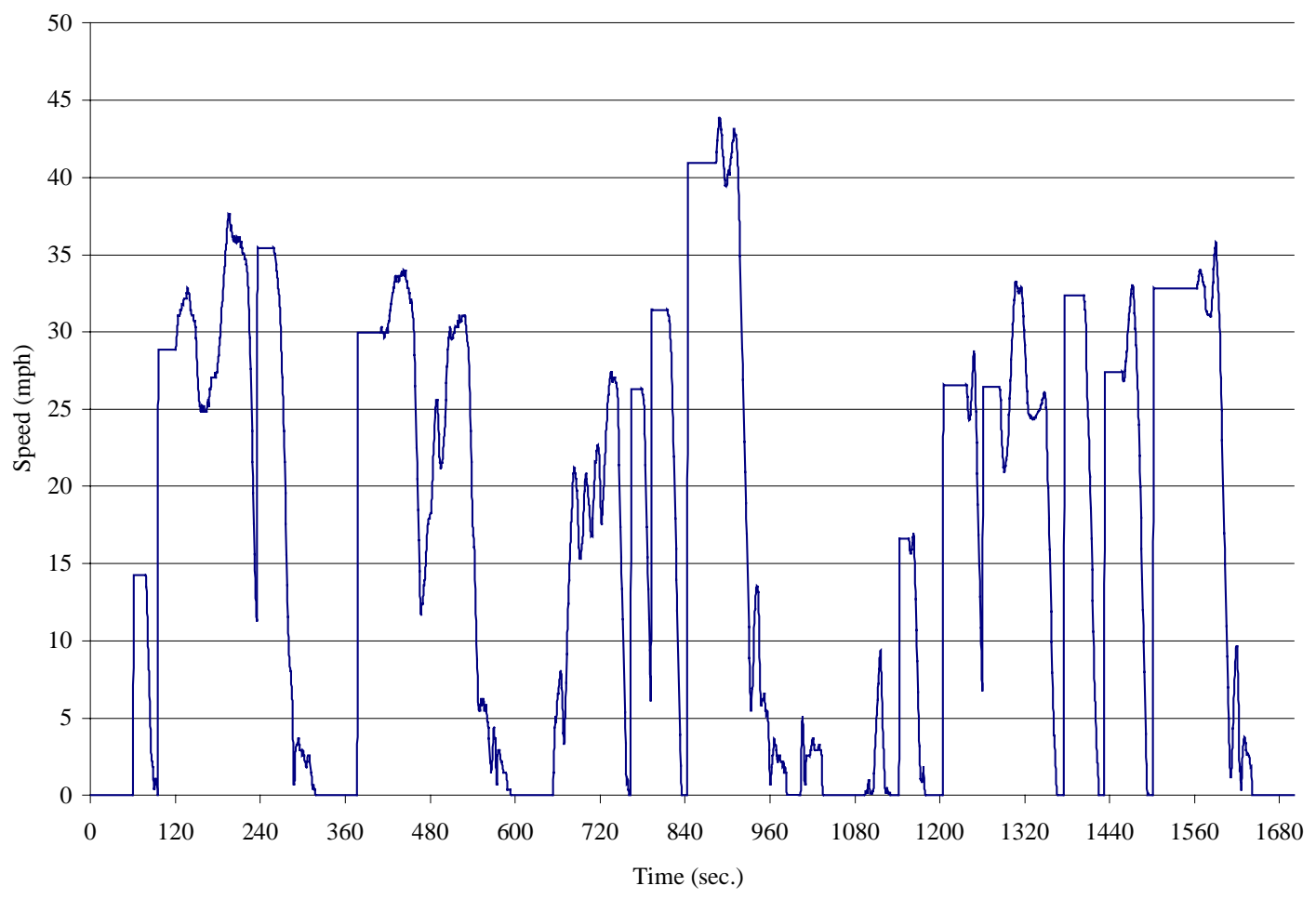




\section{Emissions Results}

\subsection{Test Procedures:}

Testing of the CSHVR was accomplished using the two WVU Transportable Heavy Duty Vehicle Emissions Testing Laboratories. Initial testing was performed with WVU Laboratory \#1 based in Morgantown, WV. Field testing was completed using WVU Laboratory \#2 in Riverside, CA.

A 1985 Ford L9000 road tractor, powered by an older technology Cummins 350 horsepower engine using \#2 diesel fuel, was used to perform the initial cycle development. A 1998 International Eagle road tractor, powered by a Cummins 435 horsepower engine using \#2 diesel fuel, was used to show repeatability of test-to-test emissions results, show driver-to-driver variability in emission results due to differing driver behavior patterns, and to determine the effect of changing the simulated test weight.

Field testing was done using WVU Laboratory \#2 on a 1992 White GMC road tractor, powered by a Caterpillar 365 horsepower engine using \#2 diesel fuel. The tests were performed using the CSHVR and were administered to show differences between \#2 diesel fuel and alternative fuels.

\subsection{Driver Learning CSHVR:}

The Ford L9000 road tractor was placed on the dynamometer to begin evaluations of the CSHVR. Initial testing was performed at a test weight of 46,400 pounds. This test weight was determined from the average truck weight during the data acquisition phase of this research work. A total of four tests was performed to investigate the changes in emissions results as the driver becoming more accustomed to following the route. Results for the four runs, shown in Table 9.2.1, have a substantial degree of variation for $\mathrm{CO}$ and $\mathrm{PM} . \mathrm{NO}_{\mathrm{X}}, \mathrm{CO}_{2}$ and $\mathrm{HC}$ varied to a much lesser degree.

A higher variance of the $\mathrm{CO}$ and PM indicates the initial overly aggressive driving pattern of the operator in an attempt to follow an unknown test. As the driver became more accustomed to the route, less aggressive driving was need to correct for under/over shooting of the target speed resulting in reduced CO and PM. A portion of the CSHVR is shown in Figure 9.2.1. Figure 9.2.1 shows the difference in driving patterns for runs 1091-1 and 
1091-2. The first run (1091-1) is more erratic than the last run (1091-2), showing the changes in driving behavior as the driver learns the CSHVR.

Table 9.2.1 Data collected from the first four runs of the CSHVR. Driver was learning how to drive the CSHVR using a Ford tractor at a 46,400 lb. test weight.

\begin{tabular}{|l|c|c|c|c|c|c|c|}
\hline & $\mathbf{1 0 9 1 - 1}$ & $\mathbf{1 0 9 1 - 2}$ & $\mathbf{1 0 9 1 - 3}$ & $\mathbf{1 0 9 4 - 1}$ & Average & Stdev. & COV \\
\hline $\mathbf{C O}$ (g/mile) & 34.76 & 29.55 & 30.75 & 27.02 & 30.52 & 3.23 & $10.6 \%$ \\
\hline $\mathbf{N O}_{\mathbf{X}}$ (g/mile) & 32.2 & 34.1 & 32.1 & 30.8 & 32.3 & 1.4 & $4.3 \%$ \\
\hline $\mathbf{H C}$ (g/mile) & 4.43 & 3.91 & 4.01 & 3.67 & 4.01 & 0.32 & $7.9 \%$ \\
\hline $\mathbf{P M}$ (g/mile) & 7.69 & 6.02 & 6.34 & 5.38 & 6.35 & 0.97 & $15.3 \%$ \\
\hline $\mathbf{C O}_{\mathbf{2}}$ (g/mile) & 2987 & 2843 & 2925 & 2936 & 2923 & 59.79 & $2.0 \%$ \\
\hline Distance (miles) & 6.69 & 6.69 & 6.69 & 6.69 & 6.69 & 0.00 & $0.0 \%$ \\
\hline
\end{tabular}

Figure 9.2.1 Comparing two runs while the driver is learning the CSHVR. Tests performed driving a Ford road tractor at a $46,400 \mathrm{lb}$. test weight.

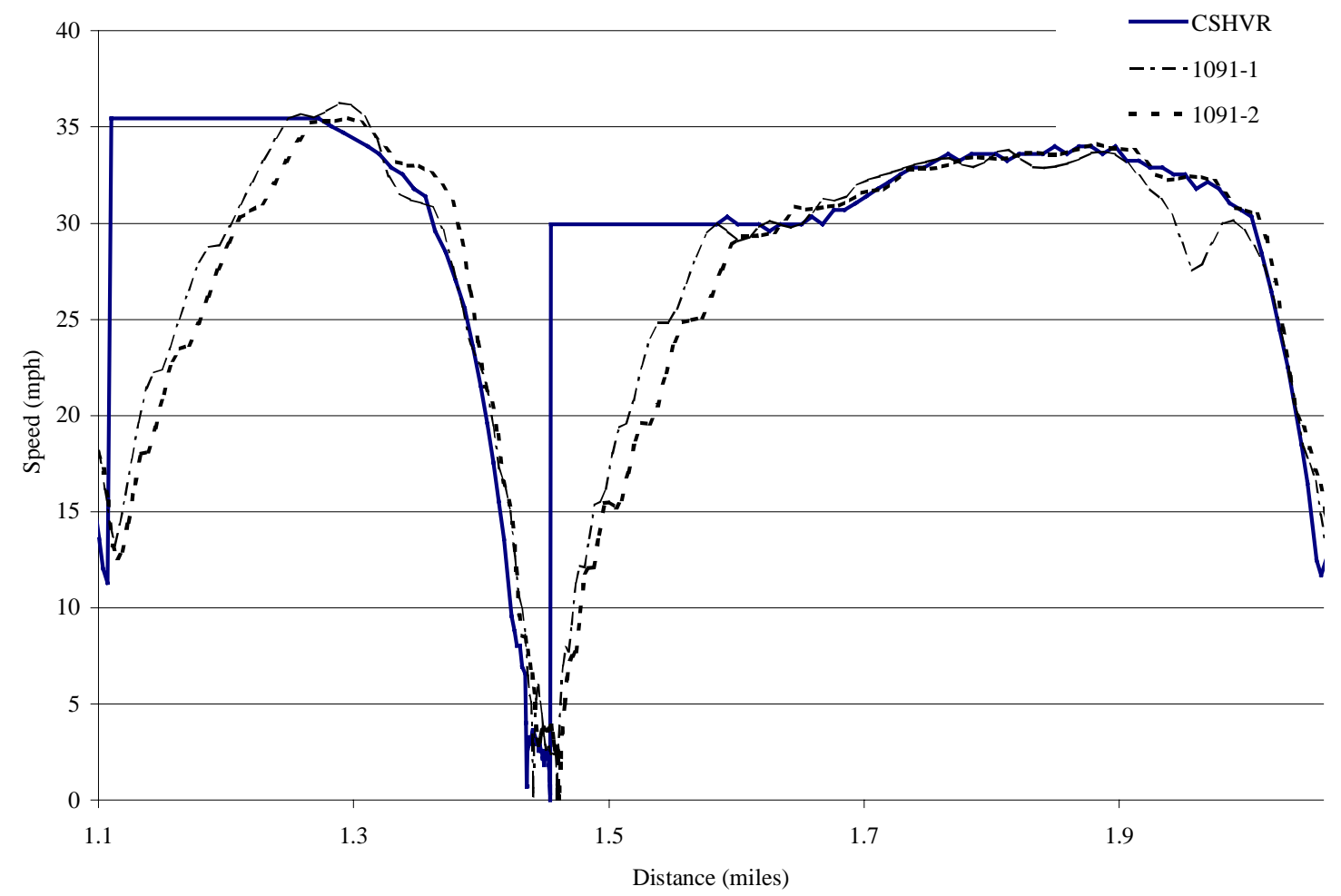

\subsection{Repeatability After Route is Learned:}

Once initial data were collected on the driver learning the new route, another set of data was collected in order to show route-to-route repeatability. This group of tests included five CSHVRs recorded on two different 
days. Table 9.3.1 shows CSHVR results from the first day of testing. Day one has a $6.9 \%$ coefficient of variance $(\mathrm{COV})$ in $\mathrm{CO}$ while all other regulated emissions were under $2.7 \% \mathrm{COV}$.

Table 9.3.1 Day one CSHVR repeatability: International tractor 46,400 lb. test weight.

\begin{tabular}{|l|c|c|c|c|c|c|}
\hline & $\mathbf{1 1 2 2 - 1}$ & $\mathbf{1 1 2 2 - 2}$ & $\mathbf{1 1 2 2 - 3}$ & Average & Stdev. & $\mathbf{C O V}$ \\
\hline $\mathbf{C O}$ (g/mile) & 6.48 & 5.93 & 5.67 & 6.03 & 0.41 & $6.9 \%$ \\
\hline $\mathbf{N O}_{\mathbf{X}}$ (g/mile) & 23.6 & 23.2 & 23.0 & 23.3 & 0.31 & $1.3 \%$ \\
\hline $\mathbf{H C}$ (g/mile) & 1.95 & 2.01 & 1.98 & 1.98 & 0.03 & $1.5 \%$ \\
\hline $\mathbf{P M}$ (g/mile) & 0.80 & 0.77 & 0.76 & 0.78 & 0.02 & $2.7 \%$ \\
\hline $\mathbf{C O}_{\mathbf{2}}$ (g/mile) & 2565 & 2572 & 2553 & 2563 & 9.61 & $0.4 \%$ \\
\hline Distance (miles) & 6.69 & 6.69 & 6.68 & 6.69 & 0.01 & $0.1 \%$ \\
\hline
\end{tabular}

Table 9.3.2 Day one and day two CSHVR repeatability: International tractor 46,400 lb. test weight.

\begin{tabular}{|l|c|c|c|c|c|c|c|c|}
\hline & $\mathbf{1 1 2 2 - 1}$ & $\mathbf{1 1 2 2 - 2}$ & $\mathbf{1 1 2 2 - 3}$ & $\mathbf{1 1 2 6}$ & $\mathbf{1 1 3 1}$ & Average & Stdev. & $\mathbf{C O V}$ \\
\hline $\mathbf{C O}$ (g/mile) & 6.48 & 5.93 & 5.67 & 5.52 & 5.20 & 5.76 & 0.48 & $8.4 \%$ \\
\hline $\mathbf{N O}_{\mathbf{X}}$ (g/mile) & 23.6 & 23.2 & 23.0 & 24.4 & 22.5 & 23.3 & 0.71 & $3.1 \%$ \\
\hline $\mathbf{H C}$ (g/mile) & 1.95 & 2.01 & 1.98 & 1.89 & 1.82 & 1.93 & 0.08 & $3.9 \%$ \\
\hline $\mathbf{P M ~ ( g / m i l e ) ~}$ & 0.80 & 0.77 & 0.76 & 0.60 & 0.63 & 0.71 & 0.09 & $12.7 \%$ \\
\hline $\mathbf{C O}_{\mathbf{2}}$ (g/mile) & 2565 & 2572 & 2553 & 2511 & 2412 & 2523 & 66.20 & $2.6 \%$ \\
\hline Distance (miles) & 6.69 & 6.69 & 6.68 & 6.69 & 6.69 & 6.69 & 0.00 & $0.1 \%$ \\
\hline
\end{tabular}

Two CSHVR tests were performed on the following day to compare day-to-day emissions and are shown in Table 9.3.2 with the previous day's data. Again, CO and PM were found to have the greatest COV while varying in sympathy with one another. Previous research at WVU has shown a direct correlation between CO and PM (Jarrett et al., 1998). CO is indicative of the operating condition of the engine which is determined by engine speed, load and over fueling required by the driver to follow the trace. Tests 1122-1 to 1121-3 show a steady decrease in CO suggesting the engine was still warming up. A second observation might show that the driver was continuing to learn the route and so less aggressive driving is required. Figure 9.3.1 shows a speed vs. distance trace comparing the same section of the CSHVR after the route has been learned. This section of the CSHVR is the same one shown in Figure 9.2.1 and both plots can be used to compare driving patterns before and after the CSHVR is learned. 
Figure 9.3.1 Comparing two runs after the driver has learned the CSHVR. Tests performed driving an International road tractor at a $46,400 \mathrm{lb}$. test weight.

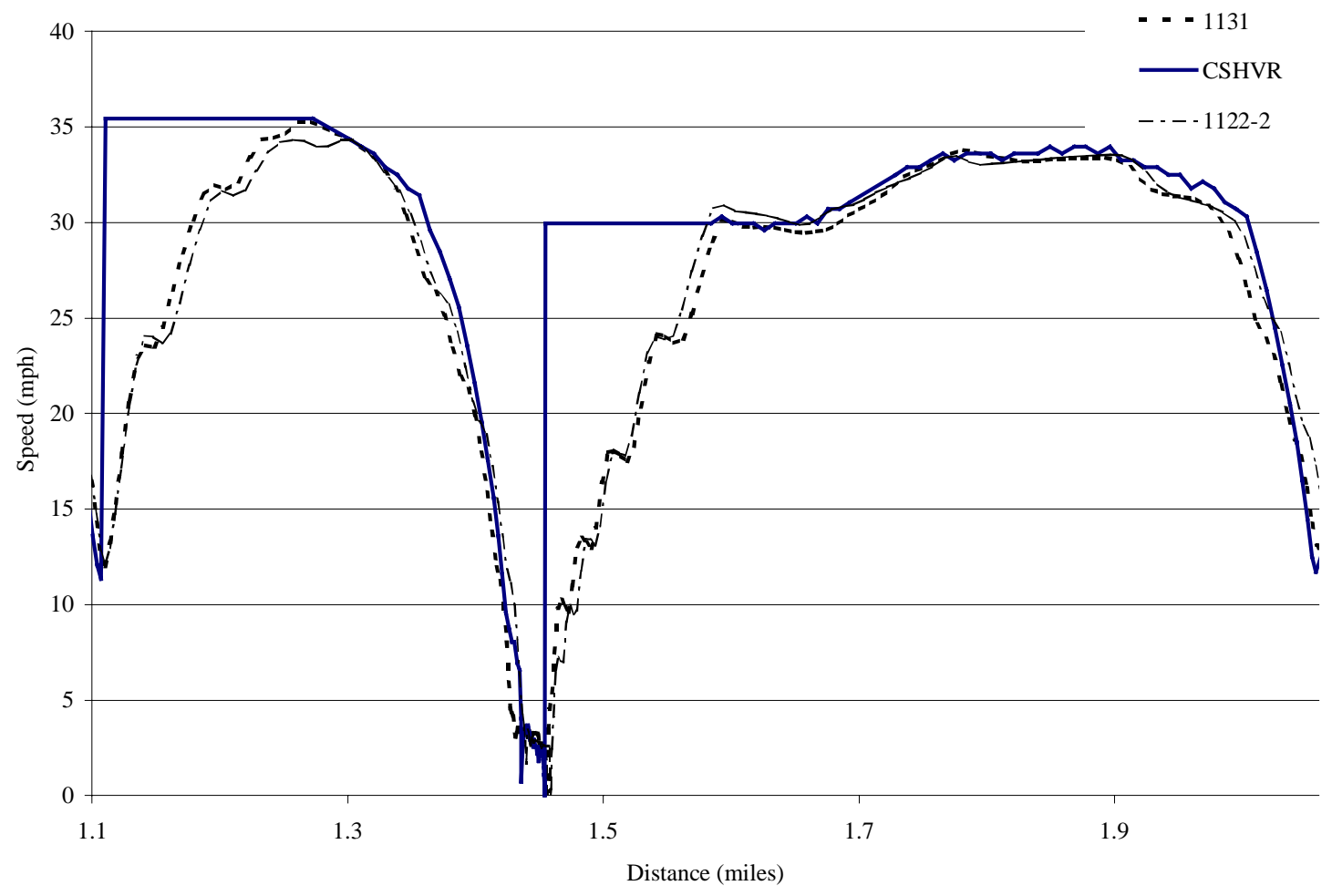

\subsection{Complete Data Set For One CSHVR Run:}

A complete set of data for the CSHVR is given in this section in order to show the continuous emissions results as they are recorded. One run of the CSHVR was chosen by researchers for use in the following Figures. The vehicle speed trace depicted in Figure 9.4.1 is of an actual completed CSHVR. 
Figure 9.4.1 Actual vehicle speed from the CSHVR using an International road tractor at a 46,400 lb. test weight.

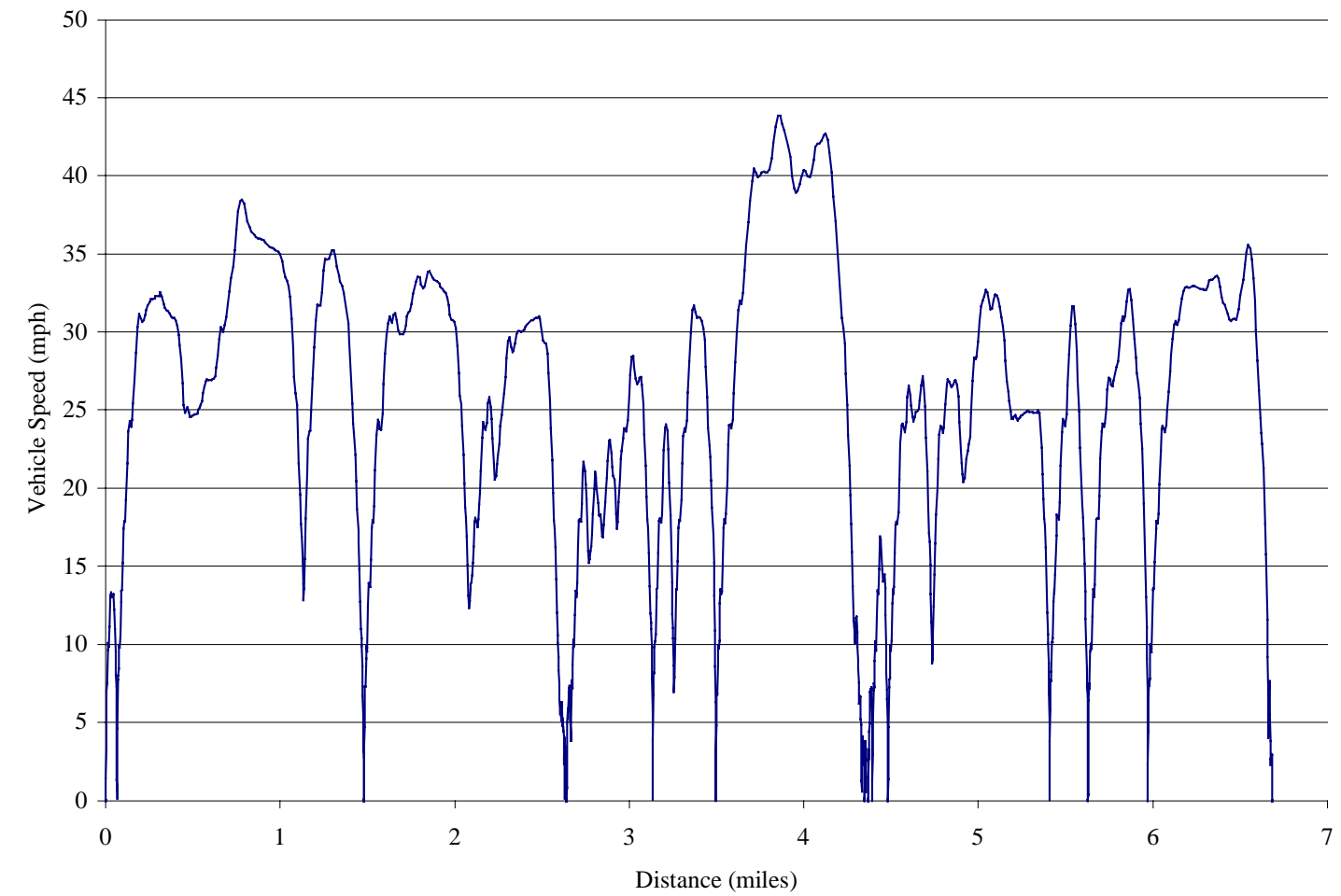

Engine speed was collected in order to monitor the shifting patterns of each driver while driving the CSHVR. The vehicle speed trace shows how well the CSHVR was followed. However, it does not give any information on how the engine was controlled during the CSHVR. Figure 9.4.2 shows a continuous engine speed trace and Figure 9.4.3 shows continuous axle torque trace for the CSHVR. From these two parameters it is easy to compare how two drivers controlled the engine throughout the CSHVR.

Figures 9.4.4 through 9.4.7 show continuous gaseous exhaust emissions levels for the CSHVR. These measured emissions are monitored as part of the WVU heavy duty transportable laboratory standard operating procedures. 
Figure 9.4.2 Engine speed from the CSHVR using an International road tractor at a 46,400 lb. test weight.

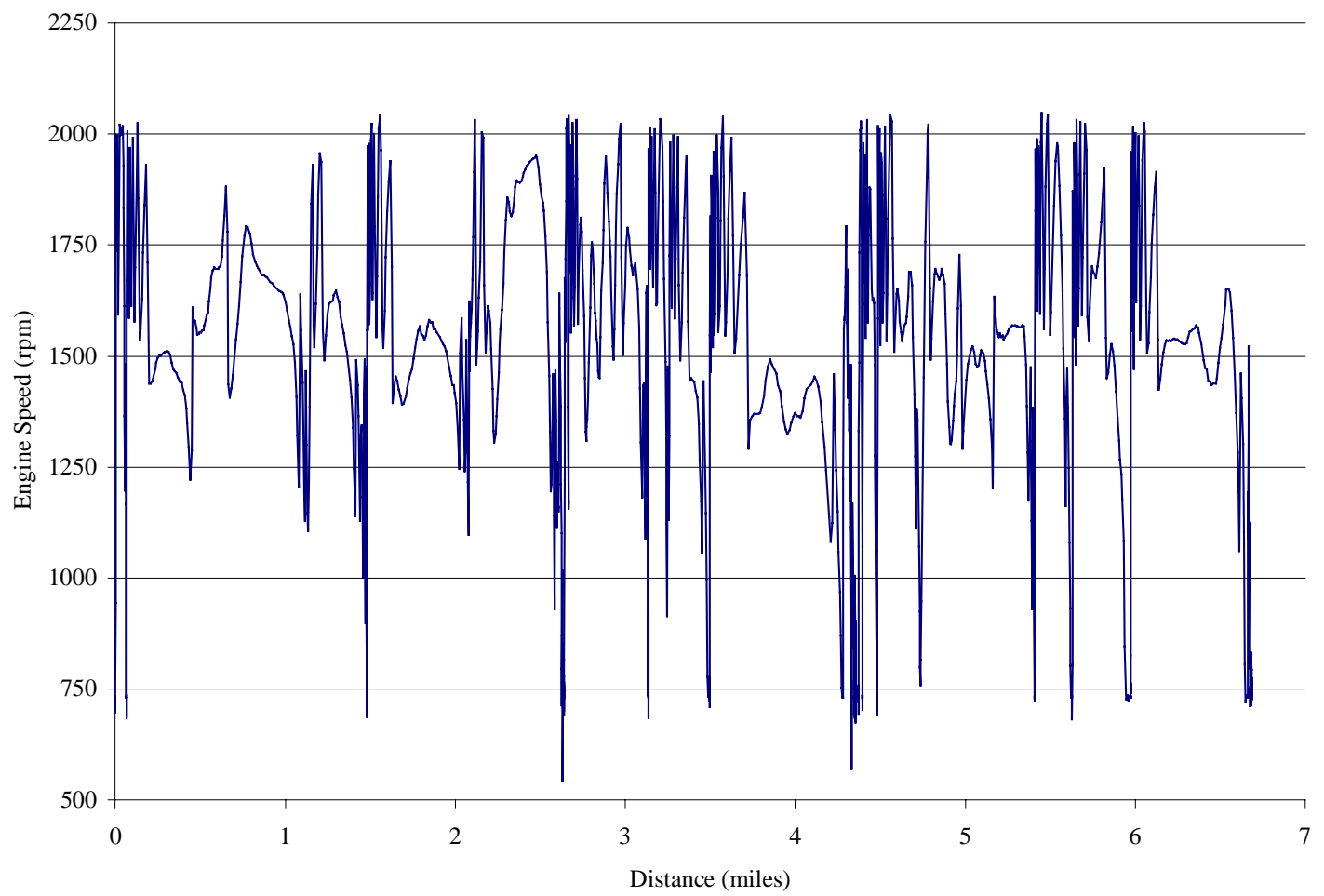

Figure 9.4.3 Axle torque from the CSHVR using an International road tractor at a 46,400 lb. test weight.

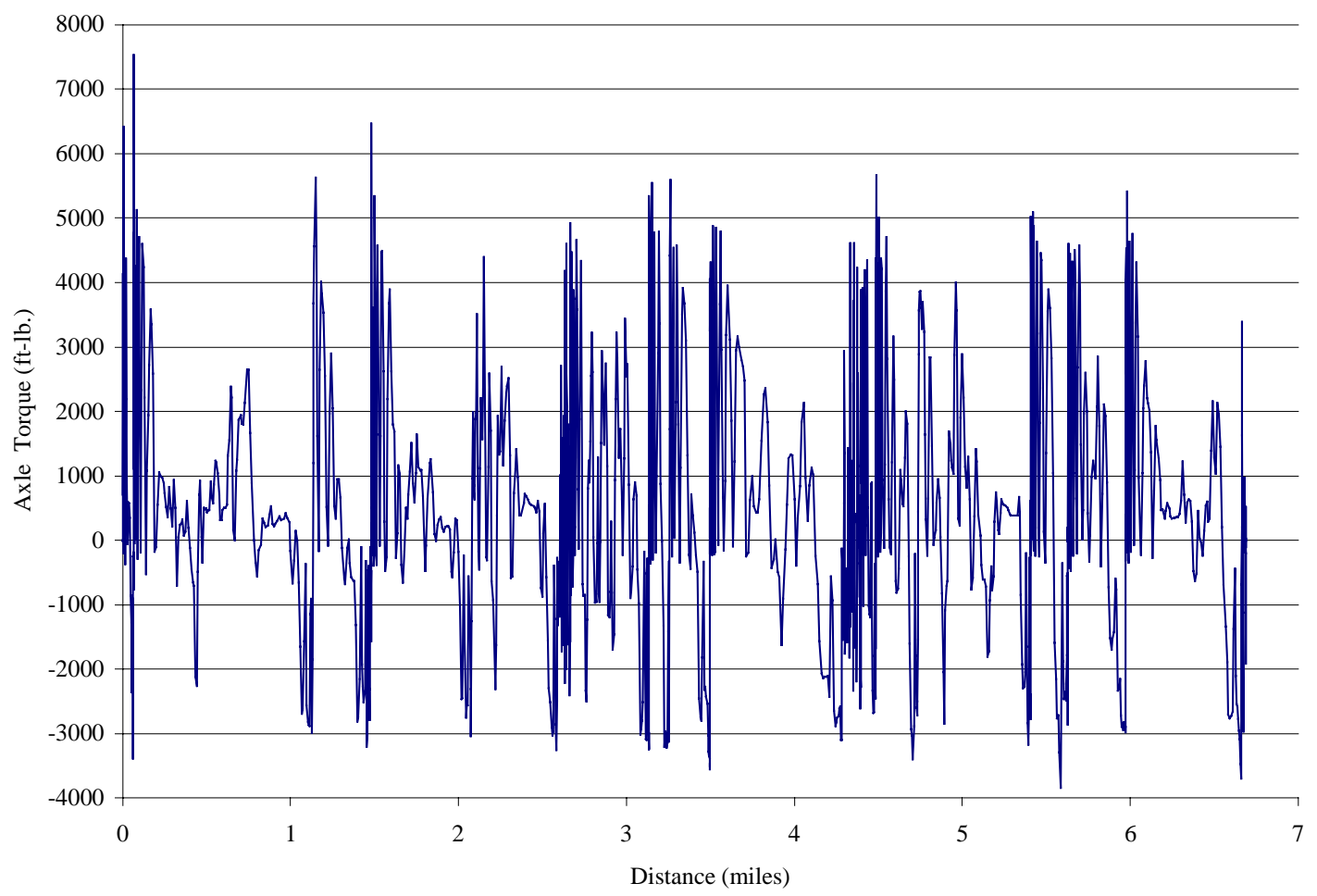


Figure 9.4.4 $\mathrm{NO}_{\mathrm{x}}$ emissions levels from the CSHVR using an International road tractor at a 46,400 lb. test weight.

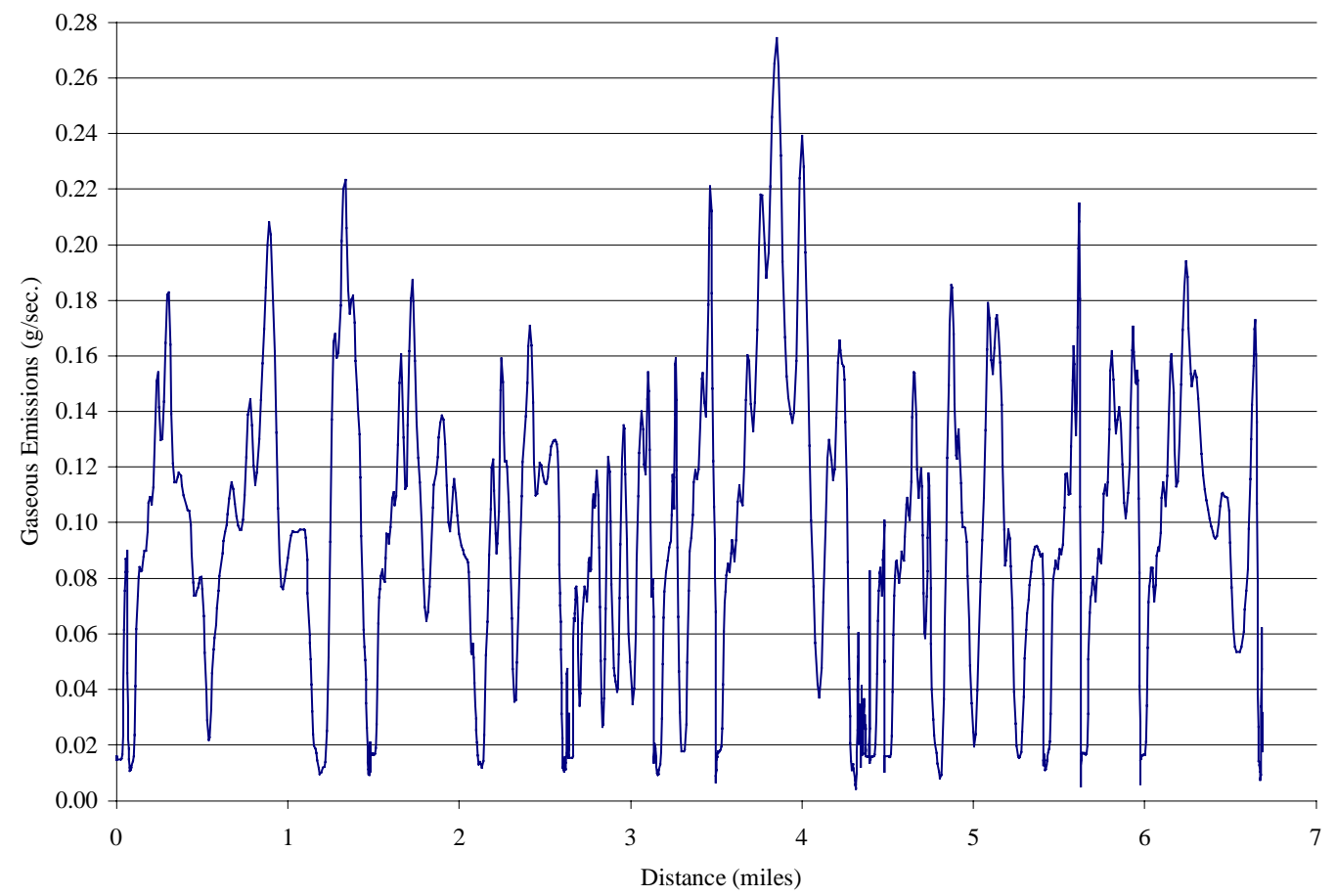

Figure 9.4.5 CO emissions levels from the CSHVR using an International road tractor at a 46,400 lb. test weight.

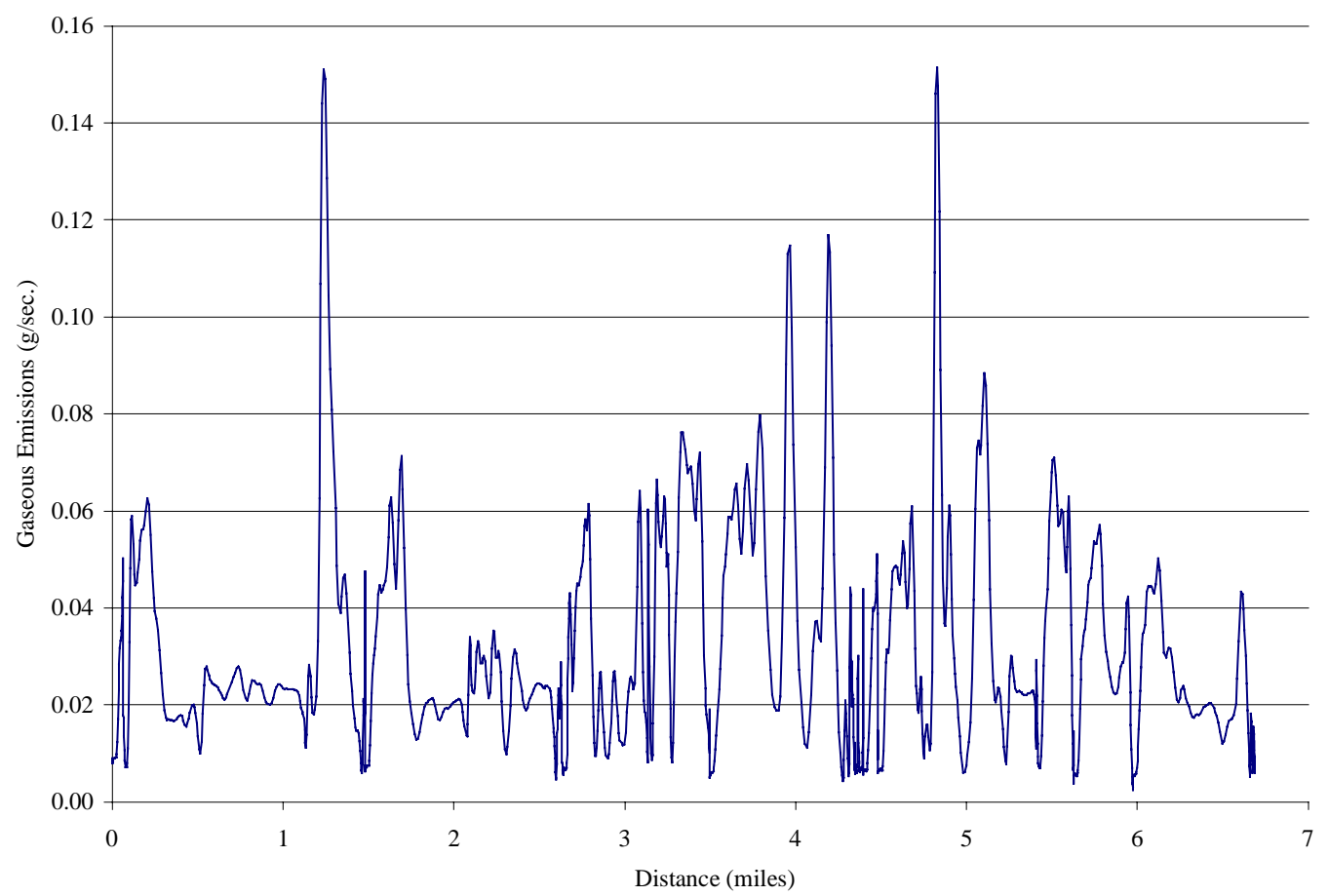


Figure 9.4.6 $\mathrm{CO}_{2}$ emissions levels from the CSHVR using an International road tractor at a 46,400 lb. test weight.

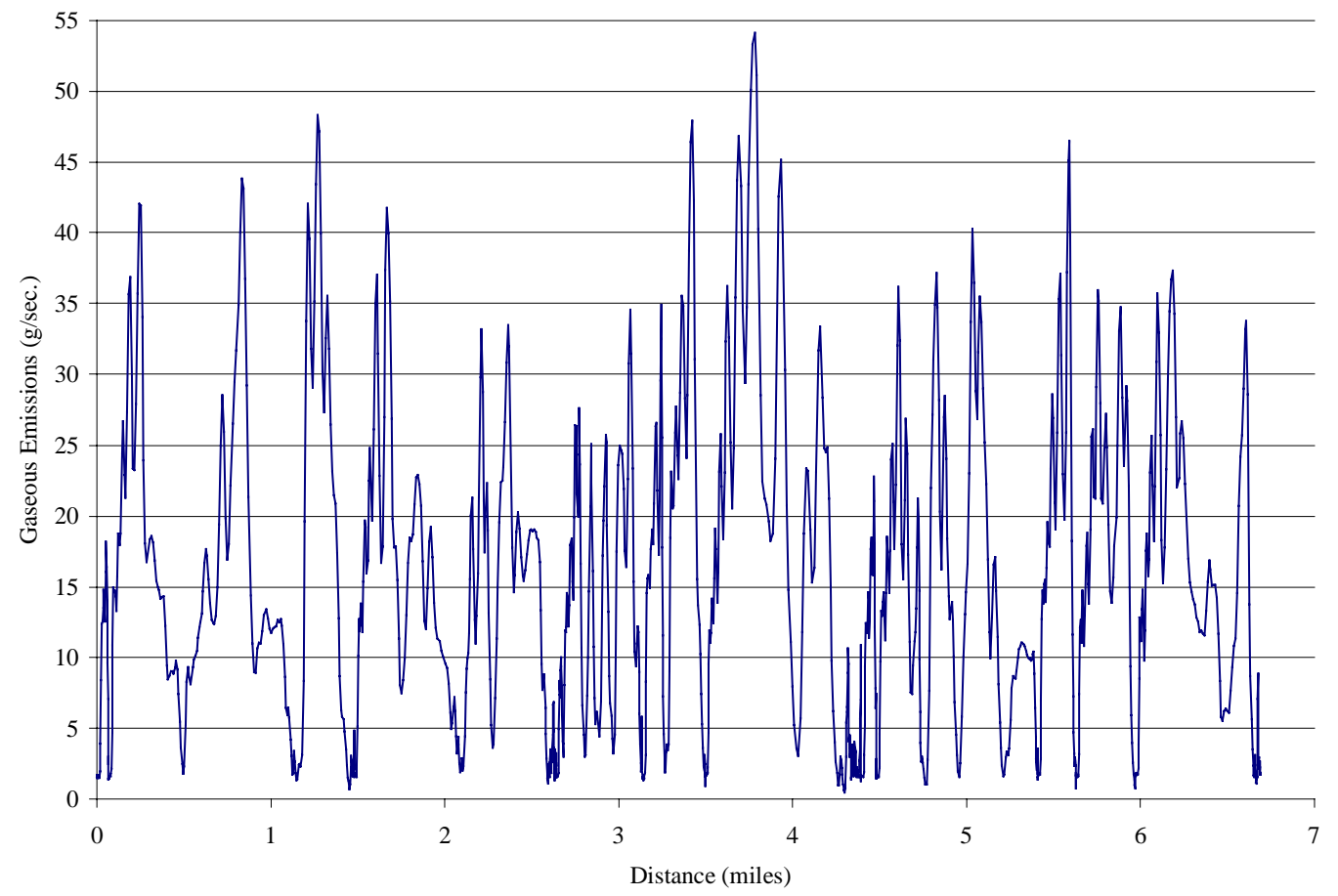

Figure 9.4.7 HC emissions levels from the CSHVR using an International road tractor at a 46,400 lb. test weight.

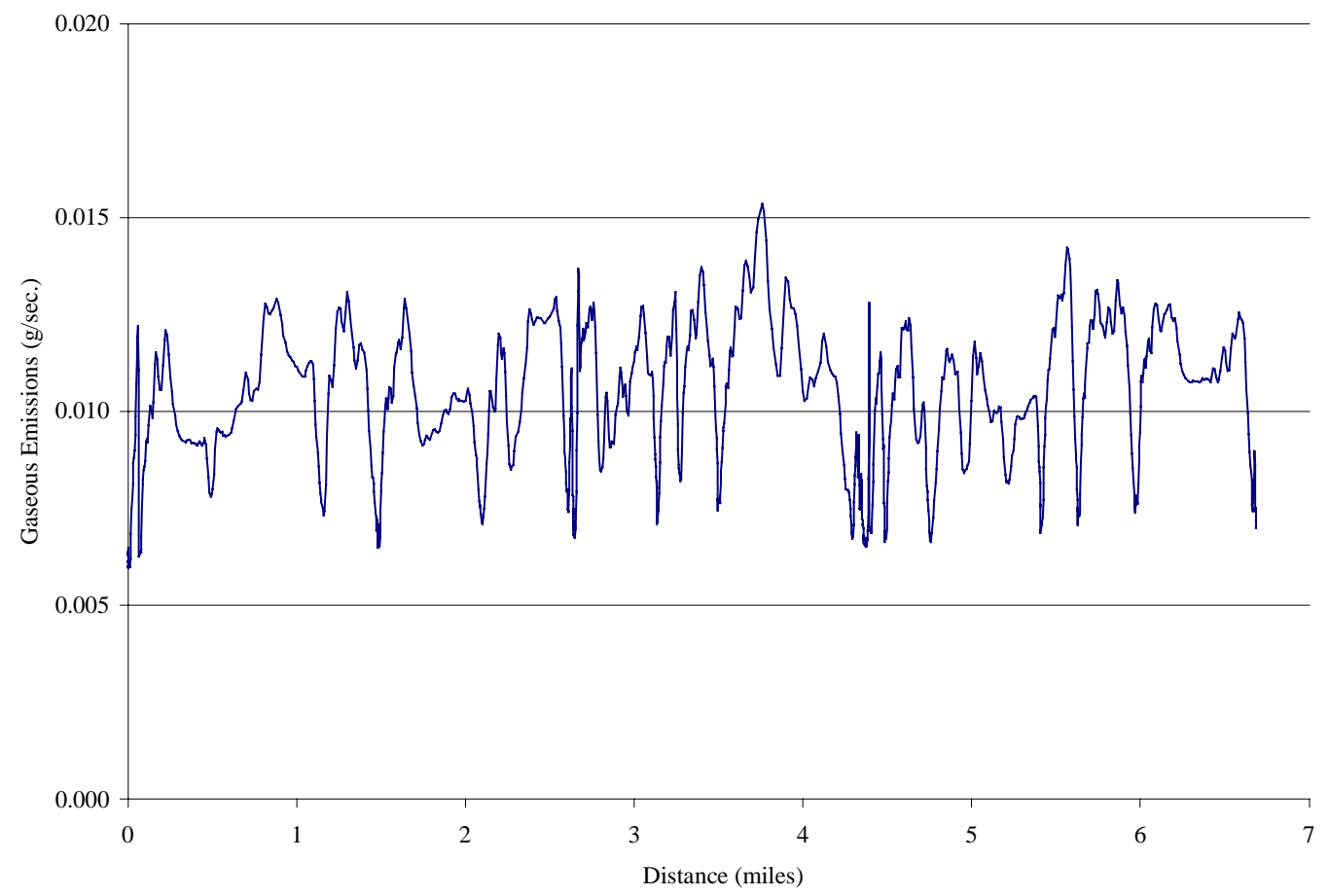


Figure 9.4.8 shows driver shifting patterns. This trace shows a ratio between vehicle speed and engine speed (Vs/Es). The Vs/Es ratio is constant for each gear ratio within a manual transmission. During shifting the ratio is not constant and is shown as an instantaneous change in the Vs/Es ratio (Figure 9.4.8). This ratio can be used when comparing a single driver for repeatable driving behavior or when comparing the driving patterns of two different drivers operating vehicles with unsynchronized transmissions. This ratio will show clear differences when drivers follow the same section of the CSHVR in a different gear.

Figure 9.4.8 Driver 1 shifting patterns during two runs of the CSHVR using an International road tractor at a 46,400 lb. test weight.

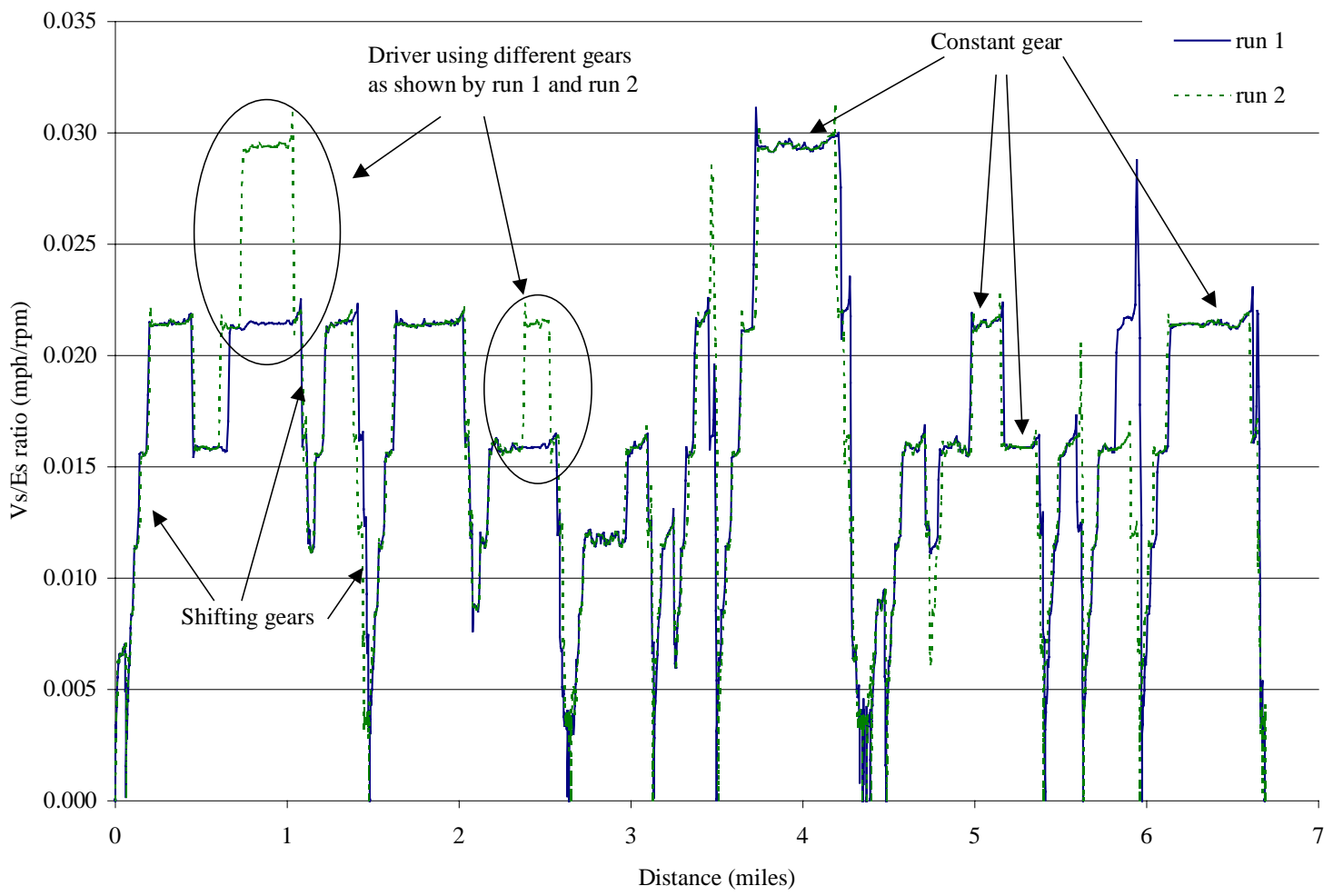

\subsection{Driver-To-Driver Variations:}

Driver-to-driver variations were evaluated using three drivers. Each driver held a class A commercial driver's license (CDL). All driver variation tests were completed during one day of testing in order to eliminate variations from day-to-day. The drivers' driving order was selected randomly by drawing names out of a hat. Table 9.5.1 shows the emissions results of each driver running the CSHVR, along with the COV between all three drivers. 
Table 9.5.1 Comparisons between three drivers, driving the CSHVR using an International road tractor at a 46,400 lb. test weight.

\begin{tabular}{|l|c|c|c|c|c|c|c|c|c|}
\hline & Driver 1 & Driver 1 & Driver 2 & Driver 2 & Driver 3 & Driver 3 & & & \\
\hline & $\mathbf{1 1 2 6}$ & $\mathbf{1 1 3 1}$ & $\mathbf{1 1 2 7}$ & $\mathbf{1 1 2 9}$ & $\mathbf{1 1 3 0}$ & $\mathbf{1 1 3 2}$ & Average & Stdev. & $\mathbf{C O V}$ \\
\hline $\mathbf{C O}$ (g/mile) & 5.52 & 5.20 & 4.62 & 4.32 & 5.46 & 5.81 & 5.16 & 0.57 & $11.1 \%$ \\
\hline $\mathbf{N O}_{\mathbf{X}}(\mathbf{g} / \mathbf{m i l e})$ & 24.4 & 22.5 & 23.2 & 22.8 & 22.5 & 21.8 & 22.87 & 0.88 & $3.8 \%$ \\
\hline $\mathbf{H C}(\mathbf{g} / \mathbf{m i l e})$ & 1.89 & 1.82 & 1.80 & 1.81 & 1.74 & 1.64 & 1.78 & 0.09 & $4.8 \%$ \\
\hline $\mathbf{P M}$ (g/mile) & 0.60 & 0.63 & 0.53 & 0.53 & 0.69 & 0.77 & 0.63 & 0.09 & $14.8 \%$ \\
\hline $\mathbf{C O}_{\mathbf{2}}$ (g/mile) & 2511 & 2412 & 2370 & 2349 & 2321 & 2306 & 2378 & 75.08 & $3.2 \%$ \\
\hline Distance (miles) & 6.69 & 6.69 & 6.68 & 6.68 & 6.69 & 6.69 & 6.69 & 0.01 & $0.1 \%$ \\
\hline
\end{tabular}

As seen from Table 9.5.1 there is good correlation among each driver individually. However, there is an increase in variance when all three drivers are compared together. Table 9.4.4 compares each run of the CSHVR using all three drivers. The main difference in the emissions is due to the aggressiveness of each driver on the chassis dynamometer. The between-driver variation is greater than single driver variation on a run to run comparison. However, trends in the emissions data are comparable between drivers.

Difference in driver patterns can be seen in Figure 9.5.2. During the driver variation tests, vehicle speed data and engine speed data were collected. By using the Vs/Es ratio, driver's shifting patterns were followed. When a driver is in a certain gear the Vs/Es ratio is constant and when the driver is shifting gears the Vs-Es ratio is transient. Each gear in a transmission has its own Vs/Es ratio. By graphing the Vs/Es ratio for all three drivers, it is easy to see when driver 1, driver 2 and driver 3 chose different gears for the same section of the CSHVR. 
Figure 9.5.2 Shifting patterns between three different drivers, driving the CSHVR using an International road tractor at a $46,400 \mathrm{lb}$. test weight.

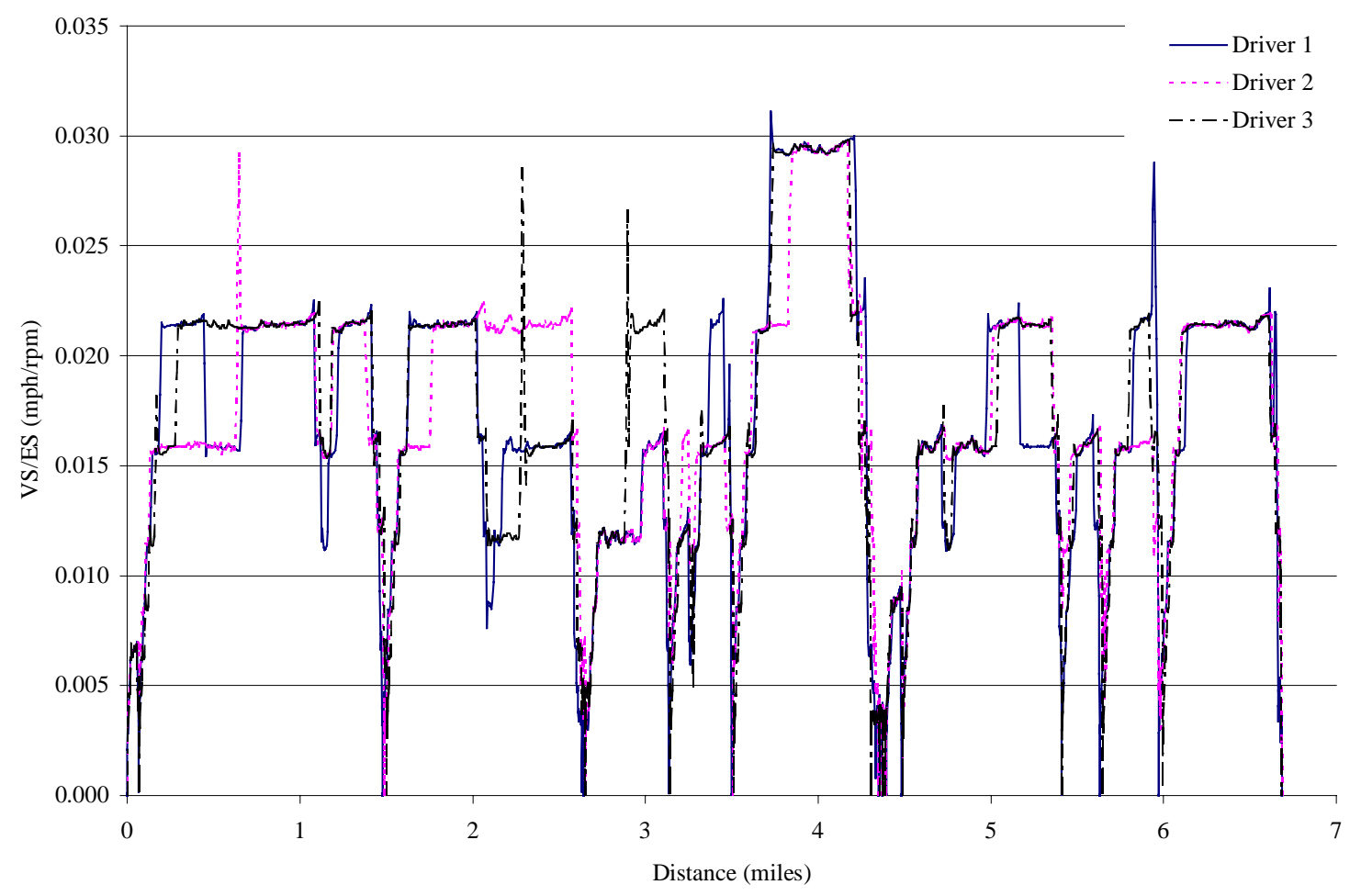

\subsection{Test Weight Variation:}

Three different test weights were used while testing a vehicle following the CSHVR. The three different weights were 26,000 lbs. 36,000 lbs. and 46,400 lbs. Emissions results are shown for each test weight in Tables 9.6.1-9.6.3.

Table 9.6.1 Emissions results from the CSHVR using a 26,000 lb. test weight with driver 1 operating an International road tractor.

\begin{tabular}{|l|c|c|c|}
\hline & $\mathbf{1 1 3 6 - 1}$ & $\mathbf{1 1 3 6 - 2}$ & Average \\
\hline $\mathbf{C O}$ (g/mile) & 4.89 & 5.44 & 5.17 \\
\hline $\mathbf{N O}_{\mathbf{X}}$ (g/mile) & 18.7 & 18.5 & 18.6 \\
\hline $\mathbf{H C}$ (g/mile) & 1.81 & 1.86 & 1.84 \\
\hline $\mathbf{P M ~ ( g / m i l e ) ~}$ & 0.53 & 0.63 & 0.58 \\
\hline $\mathbf{C O}_{\mathbf{2}}$ (g/mile) & 1790 & 1789 & 1789 \\
\hline Distance (miles) & 6.69 & 6.69 & 6.69 \\
\hline Time (sec.) & 1622 & 1617 & 1619.5 \\
\hline
\end{tabular}


Table 9.6.2 Emissions results from the CSHVR using a 36,000 lb. test weight with driver 1 operating an International road tractor.

\begin{tabular}{|l|c|c|c|}
\hline & $\mathbf{1 1 3 4 - 1}$ & $\mathbf{1 1 3 4 - 2}$ & Average \\
\hline $\mathbf{C O}$ (g/mile) & 5.61 & 5.62 & 5.62 \\
\hline $\mathbf{N O}_{\mathbf{X}}$ (g/mile) & 21.5 & 21.0 & 21.3 \\
\hline $\mathbf{H C}$ (g/mile) & 1.74 & 1.73 & 1.74 \\
\hline $\mathbf{P M ~ ( g / m i l e ) ~}$ & 0.65 & 0.63 & 0.64 \\
\hline $\mathbf{C O}_{\mathbf{2}}$ (g/mile) & 2114 & 2101 & 2107 \\
\hline Distance (miles) & 6.68 & 6.69 & 6.69 \\
\hline Time (sec.) & 1632 & 1638 & 1635 \\
\hline
\end{tabular}

Table 9.6.3 Emissions results from the CSHVR using a 46,400 lb. test weight with driver 1 operating an International road tractor.

\begin{tabular}{|c|c|c|c|}
\hline & 1126-1 & 1131-1 & Average \\
\hline CO (g/mile) & 5.52 & 5.20 & 5.36 \\
\hline $\mathrm{NO}_{\mathrm{X}}(\mathrm{g} / \mathrm{mile})$ & 24.4 & 22.5 & 23.45 \\
\hline HC (g/mile) & 1.89 & 1.82 & 1.86 \\
\hline PM (g/mile) & 0.602 & 0.6339 & 0.62 \\
\hline $\mathrm{CO}_{2}(\mathrm{~g} / \mathrm{mile})$ & 2511 & 2412 & 2461 \\
\hline Distance (miles) & 6.69 & 6.69 & 6.69 \\
\hline Time (sec.) & 1650 & 1653 & 1651.5 \\
\hline
\end{tabular}

Comparing results from all three test weights reveals a direct correlation between $\mathrm{NO}_{\mathrm{x}}, \mathrm{CO}_{2}$, time and simulated test weight. As the simulated weight of the vehicle increases the drive time and amounts of $\mathrm{NO}_{\mathrm{X}}$ and $\mathrm{CO}_{2}$ emissions also increase. From the data in Tables 9.6.1-9.6.3 no correlations can be made with CO, HC, and PM. The changes in $\mathrm{CO}, \mathrm{HC}$ and $\mathrm{PM}$ emissions are very small and unpredictable when compared to the change in simulated weight. The total distance traveled during the CSHVR is the same while the time is different for each run and simulated test weight. The average axle horsepower hour (ahp-hr) from all three simulated weights are shown in Table 9.6.4. Figure 9.6.1 shows a 46,400 lb. tractor and a 26,000 lb. tractor both traveling the CSHVR at the same scheduled distance. Since the two tractors are at the same section of the route at the same distance the traces are virtually identical. Figure 9.6.2 shows the same two test runs on a speed vs. time plot. From these two figures it is easily shown that a higher power-to-weight ratio tractor can bias emissions by not using a full power acceleration when using a speed vs. time cycle. 
Table 9.6.4 Average Axle horsepower hour for three different simulated test weights.

\begin{tabular}{|c|c|}
\hline Simulated Vehicle Weight & Axle horsepower-hour \\
\hline lb. & ahp-hr \\
\hline 26,000 & 11.94 \\
\hline 36,000 & 15.89 \\
\hline 46,400 & 19.66 \\
\hline
\end{tabular}

Figure 9.6.1 An International road tractor following the CSHVR at two different test weights. Results shown on a speed vs. distance plot, showing faster acceleration with lower GVW.

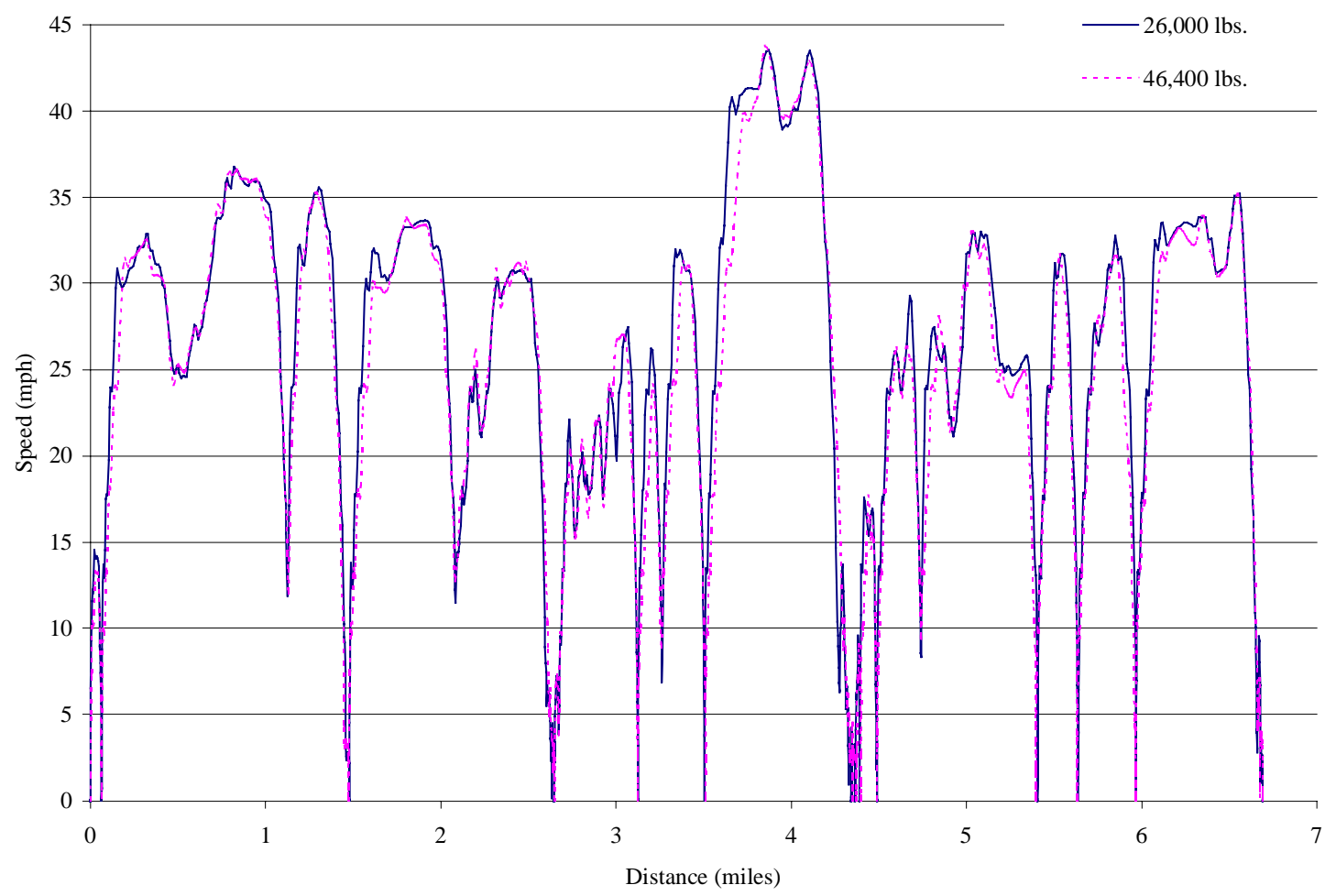


Figure 9.6.2 An International road tractor following the CSHVR at 2 different test weights. Results shown on a speed vs. time plot showing faster acceleration with lower GVW.

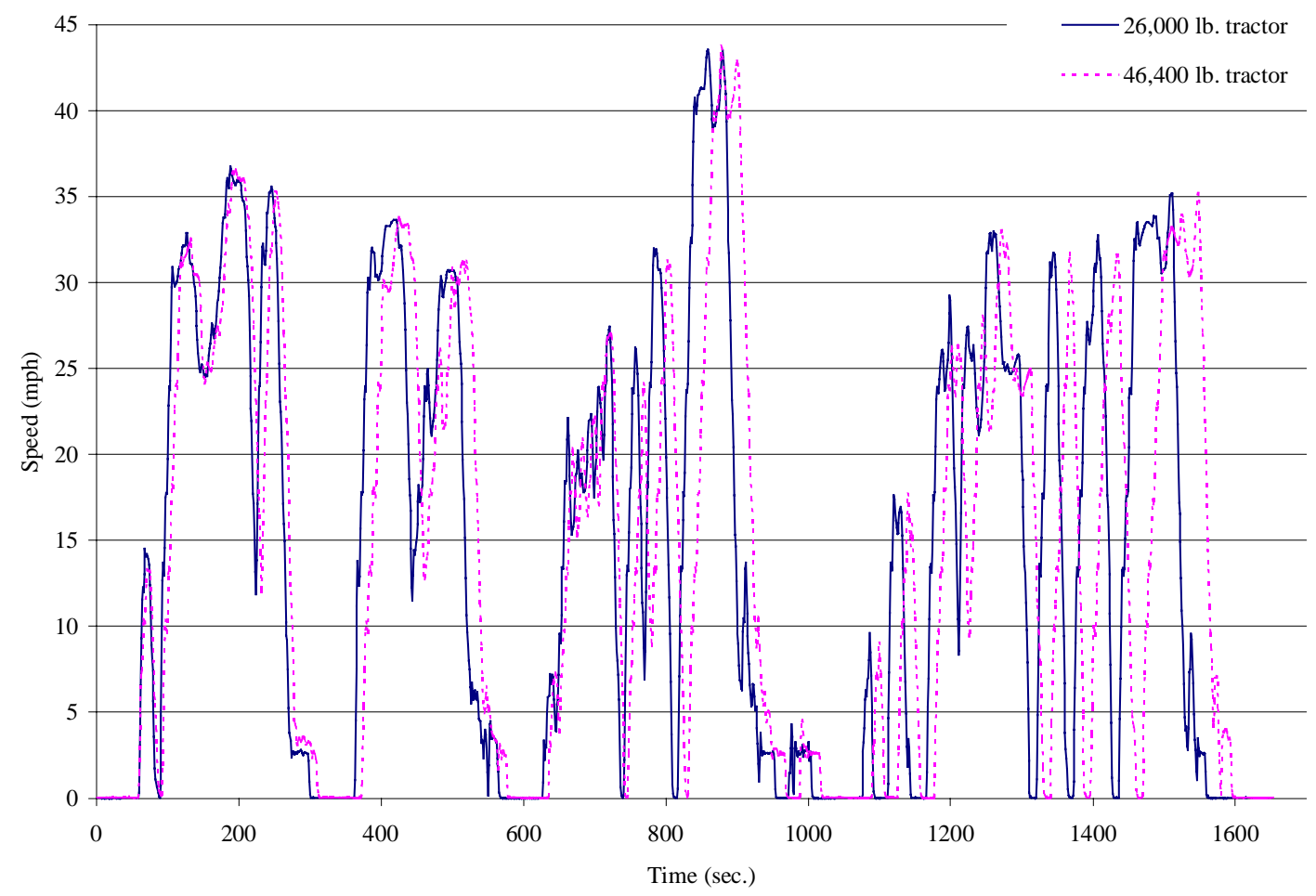

\subsection{CSHVR Compared to Existing Cycles:}

Various cycles and routes were tested to compare the emission results. Acquiring cycle variation results was accomplished using the WVU 5-Peak Cycle, WVU 5-Mile Route, and the CSHVR. All three tests were driven on the WVU Heavy Duty Transportable Laboratory \#1 by Driver 1 in a WVU heavy duty road tractor.

The WVU 5-Peak Cycle was chosen to use as a baseline for comparison with the WVU 5-Mile Route and CSHVR. In the past the WVU 5-Peak Cycle as been shown to be repeatable and its saw-tooth shape makes it easy for the driver to follow on the heavy duty chassis dynamometer. This particular set of data has a high COV for particulate matter. This high COV could be due to human error while weighing particulate filters with the microbalance. 
Table 9.7.1 Emissions results from the WVU 5-Peak Cycle using a Ford road tractor at a 46,400 lb. test weight.

\begin{tabular}{|l|c|c|c|c|c|c|c|}
\hline & $\mathbf{1 0 8 9 - 1}$ & $\mathbf{1 0 8 9 - 2}$ & $\mathbf{1 0 8 9 - 3}$ & $\mathbf{1 0 8 9 - 4}$ & Average & Stdev. & COV \\
\hline $\mathbf{C O}$ (g/mile) & 11.77 & 11.13 & 12.82 & 12.75 & 12.12 & 0.81 & $6.7 \%$ \\
\hline $\mathbf{N O}_{\mathbf{X}}$ (g/mile) & 20.2 & 19.3 & 19.9 & 20.0 & 19.85 & 0.38 & $1.9 \%$ \\
\hline $\mathbf{H C}$ (g/mile) & 2.12 & 2.02 & 2.23 & 2.03 & 2.10 & 0.09 & $4.5 \%$ \\
\hline $\mathbf{P M ~ ( g / m i l e ) ~}$ & 5.48 & 3.91 & 4.67 & 4.46 & 4.63 & 0.65 & $14.1 \%$ \\
\hline $\mathbf{C O}_{2}$ (g/mile) & 2236 & 2129 & 2212 & 2116 & 2173 & 59.58 & $2.7 \%$ \\
\hline Distance (miles) & 5.02 & 5.09 & 5.00 & 5.03 & 5.04 & 0.04 & $0.8 \%$ \\
\hline
\end{tabular}

The WVU 5-Mile Route was driven in order to compare cycle emissions with route emissions. As shown in Tables 9.7.1 and 9.7.2, all average emissions results were higher for the WVU 5-Mile Route. This is because full power operation is required for running the WVU 5-Mile Route and not required for running the WVU 5-Peak Cycle.

Table9.7.2 Emissions results from the WVU 5-Mile Route using a Ford road tractor at a 46,400 lb. test weight.

\begin{tabular}{|l|c|c|c|c|c|c|}
\hline & $\mathbf{1 0 9 2 - 1}$ & $\mathbf{1 0 9 2 - 2}$ & $\mathbf{1 0 9 2 - 3}$ & Average & Stdev. & $\mathbf{C O V}$ \\
\hline $\mathbf{C O}$ (g/mile) & 11.91 & 12.86 & 13.47 & 12.75 & 0.78 & $6.2 \%$ \\
\hline $\mathbf{N O}_{\mathbf{X}}$ (g/mile) & 22.7 & 21.6 & 21.7 & 21.96 & 0.60 & $2.8 \%$ \\
\hline $\mathbf{H C}$ (g/mile) & 2.12 & 2.14 & 2.22 & 2.16 & 0.05 & $2.4 \%$ \\
\hline $\mathbf{P M}$ (g/mile) & 4.84 & 4.47 & 4.69 & 4.67 & 0.19 & $4.1 \%$ \\
\hline $\mathbf{C O}_{\mathbf{2}}$ (g/mile) & 2292 & 2315 & 2356 & 2321 & 32.24 & $1.4 \%$ \\
\hline Distance (miles) & 5.00 & 5.01 & 5.01 & 5.01 & 0.01 & $0.1 \%$ \\
\hline
\end{tabular}

Emission results from the CSHVR were higher on average than both the WVU 5-Peak Cycle and WVU 5Mile Route. One of the reasons for this is average axle work required measured in axle horsepower hour (ahp/hr.). The average ahp/hr. for the CSHVR is 19.21 and average ahp/hr. values for the WVU 5-Peak Cycle and WVU 5Mile Route are 8.98 and 9.23 respectively.

Table 9.7.3 Emissions results from the CSHVR using a Ford road tractor at a 46,400 lb. test weight.

\begin{tabular}{|l|c|c|c|c|c|c|}
\hline & $\mathbf{1 0 9 1 - 1}$ & $\mathbf{1 0 9 1 - 2}$ & $\mathbf{1 0 9 1 - 3}$ & Average & Stdev. & COV \\
\hline $\mathbf{C O}$ (g/mile) & 34.76 & 29.55 & 30.75 & 31.69 & 2.73 & $8.6 \%$ \\
\hline NO $_{\mathbf{X}}$ (g/mile) & 32.2 & 34.1 & 32.1 & 32.80 & 1.15 & $3.5 \%$ \\
\hline $\mathbf{H C}$ (g/mile) & 4.43 & 3.91 & 4.01 & 4.12 & 0.28 & $6.7 \%$ \\
\hline $\mathbf{P M ~ ( g / m i l e ) ~}$ & 7.69 & 6.02 & 6.34 & 6.68 & 0.89 & $13.3 \%$ \\
\hline $\mathbf{C O}_{\mathbf{2}}$ (g/mile) & 2987 & 2843 & 2924 & 2918 & 72.40 & $2.5 \%$ \\
\hline Distance (miles) & 6.69 & 6.69 & 6.69 & 6.69 & 0.00 & $0.0 \%$ \\
\hline
\end{tabular}




\section{Conclusions}

A heavy duty vehicle route was developed. The CSHVR was developed to simulate real life driving in an urban environment and is to be used to compare the emissions levels between diesel fuel and alternative fuels. To include the power-to-weight ratios of heavy duty vehicles, 13 free acceleration ramps were added to the CitySuburban Heavy Vehicle Cycle and formed the CSHVR. The CSHVR is 6.69 miles long and takes approximately 30 minutes to drive on a chassis dynamometer, depending on the simulated power-to-weight ratio of the vehicle being tested.

Route-to-route repeatability was conserved while allowing free accelerations. The COV for emissions levels between 3 test runs was $6.9 \%(\mathrm{CO}), 1.3 \%\left(\mathrm{NO}_{\mathrm{X}}\right), 1.5 \%(\mathrm{HC}), 2.7 \%(\mathrm{PM})$ and $0.4 \%\left(\mathrm{CO}_{2}\right)$. Total distance traveled for the route was 6.69 miles with a COV of $0.1 \%$. These results show that a route can be repeatable while allowing the driver to freely accelerate under full power. Results from the CSHVR while varying the power-toweight ratio show that $\mathrm{CO}$ and $\mathrm{NO}_{\mathrm{x}}$ levels are directly correlated to simulated weight. Table 10.1.1 shows the average test weight difference and the corresponding average emissions level difference.

Table 10.1.1 Average emissions level difference corresponding to a $43.48 \%$ test weight difference.

\begin{tabular}{|c|c|}
\hline & average difference $\mathbf{( \% )}$ \\
\hline average test weight & 43.48 \\
\hline average $\mathbf{C O}$ & 3.64 \\
\hline average $\mathbf{N O}_{\mathbf{x}}$ & 20.68 \\
\hline average $\mathbf{H C}$ & 1.08 \\
\hline average $\mathbf{P M}$ & 6.81 \\
\hline average $\mathbf{C O}_{\mathbf{2}}$ & 27.30 \\
\hline average distance & 0.00 \\
\hline
\end{tabular}

In conclusion, the route created by WVU for heavy duty vehicles maintains 3 distinguished features. (1) It allows for a variable power-to-weight ratio which does not bias the emissions from a particular heavy duty vehicle. (2) Route repeatability is maintained while allowing the drive to freely accelerate under full power. (3) The CSHVR is a "real life" chassis dynamometer driving schedule because it was derived from real in-use heavy duty vehicle data. 


\title{
Appendix A Conversion used to convert gaseous emissions results
}

\section{from $\mathrm{ppm} / \mathrm{sec}$. to $\mathrm{g} / \mathrm{mile}$.}

\author{
Emissions Results Conversion \\ Dillution Tunnel flowrate $\quad$ V (scfm) \\ Emissions species level Esl (ppm) \\ Molecular weight $\quad \mathrm{mw}(\mathrm{g} / \mathrm{mol})$ \\ Test time $\quad \mathrm{T}$ (sec.) \\ Test length $\quad$ D (miles) \\ Emissions species result $\quad \mathrm{X}(\mathrm{g} / \mathrm{sec})$ \\ Total emissions level Et (g/mile)

$$
\begin{aligned}
& X=\left(\frac{\mathrm{Esl}}{1 \times 10^{6}}\right) \times(\mathrm{V}) \times\left[\frac{1(\mathrm{~min} .)}{60(\mathrm{sec} .)}\right] \times\left[\frac{28.3(\text { liters })}{1\left(\mathrm{ft}^{3}\right)}\right] \times\left[\frac{1(\mathrm{~mol})}{22.4(\text { liters })}\right] \times \mathrm{mw} \\
& \mathrm{Et}=(\mathrm{X}) \times\left[\frac{(\mathrm{T})}{(\mathrm{D})}\right]
\end{aligned}
$$




\section{References}

1) Clark, Nigel, personal communication, 1998

2) Clark, N. N., Lyons, D. W., "Class 8 Truck Emissions Testing: Effects of Test Cycles and Data on Biodiesel Operation” American Society of Agricultural Engineers Meeting, Orlando, Fl., 1998. ASAE paper 986082

3) Clark, N. N., Jarrett, R. P., Atkinson, C. M., "Field Measurements of Particulate Matter Emissions, Carbon Monoxide and Exhaust Opacity From Heavy Duty Diesel Vehicles", Air \& Waste Management Association, PM 2.5 Conference, Pittsburgh, Pa, 1998

4) Clark, N. N., McKain, D. L., Messer, J. T., Lyons, D. W., “Chassis Test Cycles for Assessing Emissions From Heavy Duty Trucks”, SAE Paper 941946, 1994

5) Clark, N. N., Messer, J. T., McKain, D. L., Wang, W.G., Bata, R. M., Gautam, M., Lyons, D. W., “Use of the West Virginia University Truck Test Cycle to Evaluate Emissions from Class 8 Trucks", SAE Paper 951016, 1995

6) Code of Federal Regulations, Title 40 Chapter 1 Parts 86 to 99, U.S. Government Printing Office, Washington D.C., 1996

7) FIGE Transient Cycle, www.dieselnet.com/standards/cycles/fige_trans.html, August 22, 1998

8) Graboski, M. S., McCormick, R. L., Yanowitz, J. Ryan L., "Heavy-Duty Diesel Vehicle Testing for the Northern Front Range Air Quality Study”, Colorado State University, Fort Collins, 1998

9) Hoppie, J. A., "Defining Drivetrain Losses in Developing A Cycle For Engine and Chassis Dynamometer Testing Compliance and Uncertainty Analysis of Emissions Test Facilities", MSME Thesis, West Virginia University, Morgantown, West Virginia, 1997

10) Nine, R. D., Clark, N. N., Daley, J. J., Atkinson, C. M., "Development of a Heavy Duty Chassis Dynamometer Driving Route”, Annual Automotive Technology Development Customers' Coordination Meeting, Vol. 3, Dearborn, MI, October, 1997

11) van de Weijer, C.J.T., van de Graaf, R., Hendriksen, P., Verbeek, R. P., "Urban Bus Driving Cycle”, $\underline{4}^{\text {th }}$ International EAEC Conference on "Vehicle and Traffic Systems Technology", Strasbourg, June 1993 
12) van de Weijer, C. J. T., "Heavy Duty Emission Factors, Development of Reprsentative Driving Cycles and Prediction of Emissions in Real-Life", Dissertation, Technischen Universitat Graz.,1997 


\title{
DEVELOPMENT OF A HEAVY DUTY VEHICLE CHASSIS \\ DYNAMOMETER TEST ROUTE
}

\author{
By \\ James Joseph Daley \\ A THESIS \\ Submitted to \\ West Virginia University \\ in partial fulfillment of the requirements \\ for the degree of \\ Master of Science
}

\section{APPROVAL OF EXAMINING COMMITTEE}

Ralph D. Nine, MSME

Mridul Gautam, Ph.D.

Christopher M. Atkinson, Sc.D.

Date

Nigel N. Clark, Ph.D., Chair 